\title{
The intersphincteric approach for rectal pathology : development of a concept
}

Citation for published version (APA):

Rutten, H. J. T. (1990). The intersphincteric approach for rectal pathology : development of a concept.

[Doctoral Thesis, Maastricht University]. Rijksuniversiteit Limburg. https://doi.org/10.26481/dis.19900202hr

Document status and date:

Published: 01/01/1990

DOI:

10.26481/dis. $19900202 \mathrm{hr}$

Document Version:

Publisher's PDF, also known as Version of record

\section{Please check the document version of this publication:}

- A submitted manuscript is the version of the article upon submission and before peer-review. There can be important differences between the submitted version and the official published version of record.

People interested in the research are advised to contact the author for the final version of the publication, or visit the DOI to the publisher's website.

- The final author version and the galley proof are versions of the publication after peer review.

- The final published version features the final layout of the paper including the volume, issue and page numbers.

Link to publication

\footnotetext{
General rights rights.

- You may freely distribute the URL identifying the publication in the public portal. please follow below link for the End User Agreement:

www.umlib.nl/taverne-license

Take down policy

If you believe that this document breaches copyright please contact us at:

repository@maastrichtuniversity.nl

providing details and we will investigate your claim.
}

Copyright and moral rights for the publications made accessible in the public portal are retained by the authors and/or other copyright owners and it is a condition of accessing publications that users recognise and abide by the legal requirements associated with these

- Users may download and print one copy of any publication from the public portal for the purpose of private study or research.

- You may not further distribute the material or use it for any profit-making activity or commercial gain

If the publication is distributed under the terms of Article $25 \mathrm{fa}$ of the Dutch Copyright Act, indicated by the "Taverne" license above, 
The intersphincteric approach for rectal pathology Development of a concept 
CIP-GEGEVENS KONINKLIJKE BIBLIOTHEEK, DEN HAAG

Rutten, H.J.T.

The intersphincteric approach for rectal pathology :

development of a concept / H.J.T. Rutten ; [photogr. Guy

van Dael ... et al. ; ill. by the author]. - [S.I. :

s.n.]. - Ill., foto's

Proefschrift Maastricht. - Met lit. opg.

ISBN 90-9003203-7

SISO 605.13 UDC 616.34/.35(043.3)

Trefw.: darmziekten.

ISBN 90-9003203-7 


\section{The intersphincteric approach for rectal pathology}

Development of a concept

\section{PROEFSCHRIFT}

ter verkrijging van de graad van doctor aan de Rijksuniversiteit Limburg te Maastricht, op gezag van de Rector Magnificus, Prof.Dr. F.I.M. Bonke, volgens het besluit van het College van Dekanen, in het openbaar te verdedigen op vrijdag, 2 februari 1990 om 14.00 uur

door

Herman Josef Theodorus Rutten geboren te Kerkrade in 1956 
Promotor

Co-Promotores

Beoordelingscommissie
Prof.Dr. G. Kootstra

Dr. J.J. Jakimowicz

Dr. C.G.M.I. Baeten

Prof.Dr. J.W. Arends (voorzitter)

Prof.Dr. W. Brummelkamp

Prof.Dr. J. Drukker

Prof.Dr. B.K. Janevski

Prof.Dr. A.H. Keijser 
To

my parents

my parents-in-law

Yvonne, Roxan \& Iris 



\section{Contents:}

\section{Chapter 1}

Concept for the study of the intersphincteric approach to low rectal pathology

1.1. Introduction ............................................................................. 9

1.2. New concepts for oncological problems in rectal cancer surgery. 9

1.3. Technical pecularities in low rectal cancer surgery..................... 10

1.4. New concept for surgical approach of low rectal cancer.............. 11

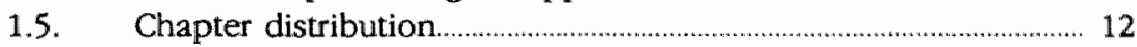

Chapter 2

History of dorsal approach to rectal pathology

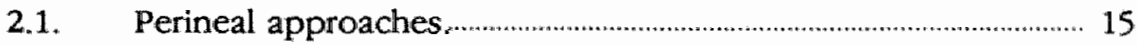

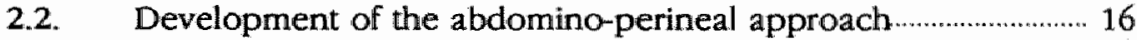

2.3. Development of modern pathological concept of dissemination. 17

2.4. Development of restorative procedures ........................................... 19

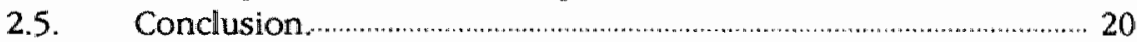

Chapter 3

Anatomy and physiology.

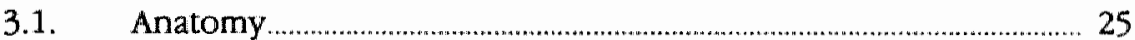

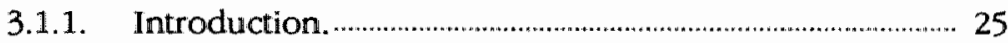

3.1.2. Topographical anatomy of the pelvic rectum ................. 29

3.1.3. The topographical anatomy of the perineal part of the rectum and the anus............................................................ 31

3.1.4. Blood supply and lymphatic drainage of the rectum and anal canal ...................................................................... 33

3.2. The physiology of the ano-rectum. .......................................... 35

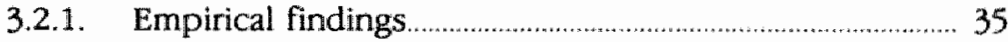

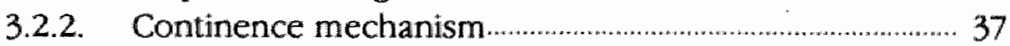

3.2.3. Conclusion …..................................................................... 38

Chapter 4.

The preoperative requirements for selection of patients with low rectal cancer.

4.1. Introduction 
4.2. Preoperative staging of rectal cancer …....................................... 45

4.2.1. Rectal digital examination.......................................... $\quad 46$

4.2.2. Rigid endoscopy and histologic grading ........................... 49

4.2.3. Imaging techniques ..................................................... 49

4.2.3.1. Computed tomography …...................................... 49

4.2.3.2. Endorectal ultrasonography ................................. 50

4.3. Preoperative preparation with reference to general risk factors and measures to prevent complications................................... 55

4.3.1. Introduction ................................................................... 55

4.3.2. Bowel preparation and antimicrobial prophylaxis......... 56

4.3.2.1. Introduction ..................................................... 56

4.3.2.2. Preoperative mechanical cleansing ..................... 57

4.3.2.3. Antibiotic prophylaxis .......................................... 57

4.3.3. Autologous blood transfusion............................................ 58

4.3.4. Information to the patient ................................................ 59

4.4. The role of adjuvant therapy in the surgical decision making 60

\section{Chapter 5}

The intersphinteric approach of the rectum.

A new surgical option for the treatment of low rectal pathology.

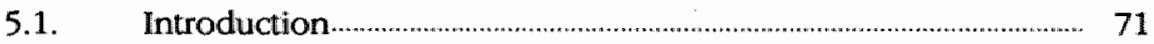

5.2. Radical restorative resections …........................................... 71

5.2.1. Transabdominal stapler techniques …............................ $\quad 72$

5.2.2. Abdomino-transsacral approach ......................................... 72

5.2.3. Abdomino-anal approach ................................................ 73

5.2.4. Abdomino-transsphincteric approach ……......................... 73

5.2.5. Abdomino-intersphincteric approach................................ 74

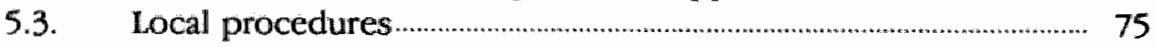

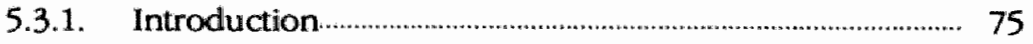

5.3.2. Electrocoagulation ……......................................................... 75

5.3.3. Endocavitary irradiation ……........................................... 76

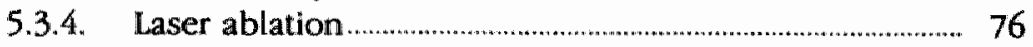

5.3.5. Peranal local excision of rectal cancer .............................. 77

5.3.6. The transsphincteric proctotomy........................................... 77

5.3.7. The intersphincteric approach of the rectum for

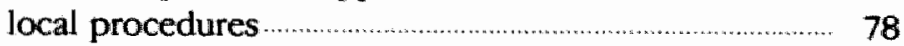

5.4. Technique of the intersphincteric approach …..................................... 79

5.4.1. Abdomino-intersphincteric rectum resection ................... 79

5.4.2. Local procedures through an intersphincteric approach 93 


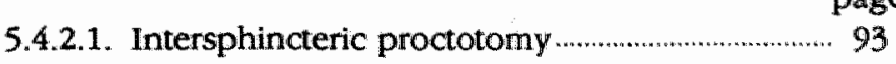

5.4.2.2. Intersphincteric segmental resection .................. 93

Chapter 6

Intersphincteric procedures.

- Clinical and Physiological results -

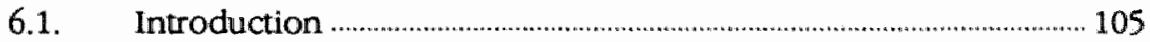

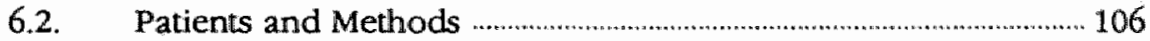

6.2.1. Abdomino-intersphincteric resections ............................... 108

6.2.2. Segmental resections...................................................... 109

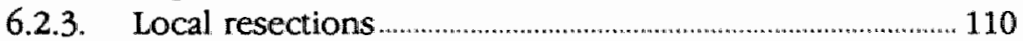

6.3. Complications after combined procedures and segmental

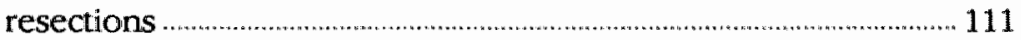

6.4. Oncological results .......................................................................... 113

6.4.1. Abdomino-intersphincteric resections ….......................... 113

6.4.2. Segmental resections ............................................................ 114

6.4.3. Intersphincteric local resections........................................ 115

6.5. Functional results .............................................................................. 11

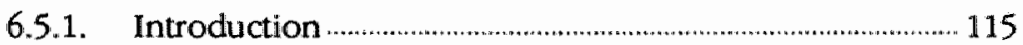

6.5.2. Subjective results …........................................................... 116

6.5.3. Physiological follow up evaluation ……............................... 117

6.5.3.1. Introduction ............................................................. 117

6.5.3.2. Manometric maximum resting pressure and maximum squeezing pressure and anal

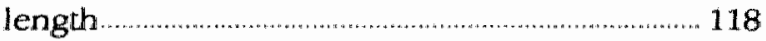

6.5.3.3. Measurement of rectal capacity .............................. 119

6.5.3.4. Recto-anal inhibitory reflex .................................... 120

\section{Chapter 7}

Intersphincteric procedures.

- Discussion and Conclusion -

7.1. Complications of colo-anal anastomoses, after intersphincteric procedures

7.2. Oncological principles applying to intersphincteric approaches

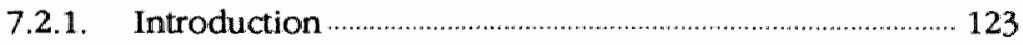

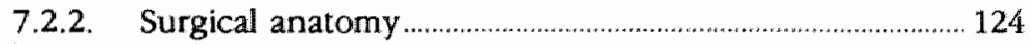

7.2.3. Oncological considerations in abdomino-intersphincteric procedures 
Contents

page

7.2.4. Oncological considerations in segmental resections ..... 130

7.2.5. Oncological considerations in local procedures ............ 132

7.3. Physiological follow up evaluation ....................................... 135

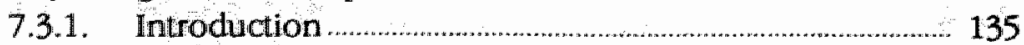

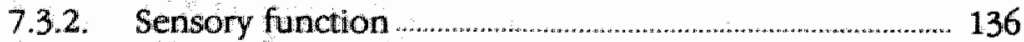

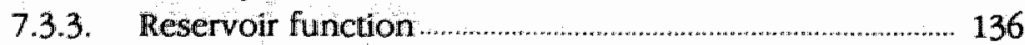

7.3.4. Sphincter function ............................................................. 137

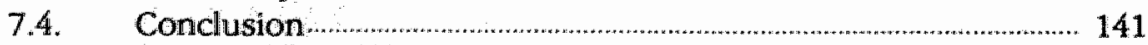

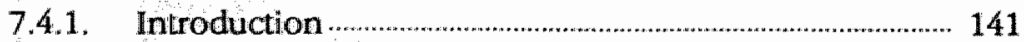

7.4.2. Place of the intersphincteric approach in rectal cancer surgery.................................................................. 142

Chapter 8

Recommendations for the selection of patients for intersphincteric procedures.

Chapter 9

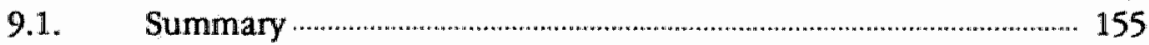

9.2. Samenvatting …................................................................................... 156

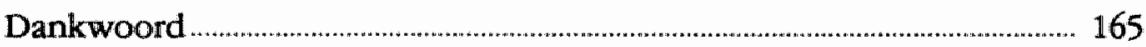

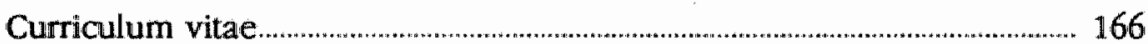




\section{Chapter 1.}

\section{Concept for the study of the intersphincteric approach to low rectal pathology.}

\subsection{Introduction.}

The basic idea behind this study was not the development of an alternative operative technique for low rectal pathology, but to evolve a new view, indeed a new concept for the approach of low seated rectal cancers. Recent insights in the anatomical and functional relationships of the pelvic floor and the anal canal form the foundation for this concept. The technique and the results in 35 patients will be the starting point for the discussion on whether there is room for still another alternative therapeutic modallity in the treatment of low rectal pathology.

In the recent decennia substantial advances have been made. Rectal cancer surgery has turned from destructive, amputative surgery into restorative surgery. The marked decline in the number of abdomino-perineal resections did not compromise recurrence and survival rates (Williams 1985). The mortality and morbidity figures have gradually declined; still, the natural history of the disease has remained unchanged (Kennedy 1985). Over the last half-century, longevity has not increased and overall results are poor. In specialized centres, corrected 5-year survival rates are about $50 \%$. Furthermore, no surgery with intent to cure shows such high local recurrence rates. The variability in the incidence of local recurrences between individual surgeons and institutes reflects the fact that experience and technical skill play an important role in the outcome of rectal cancer surgery (Phillips 1984).

\subsection{New concepts for oncological problems in rectal cancer surgery.}

Surgeons dealing with this pathology cannot feel comfortable as long as local control of the disease constitutes such a tremendous problem. The mesorectum and pararectal tissues frequently contain microscopic tumor deposits, resulting from radial spread of the tumor. Presence of this microscopic disease, which usually can only be detected after a thorough pathological examination, strongly correlates with local recurrence (Quirke 1986). The extent of local tissue removal, especially the mesorectum contained in its pararectal fascia, seems to be an explanation for the variability of reported local recurrence rates (Heald 1982). Theoretically two 
approaches for the eradication of residual microscopic disease may be contemplated.

The first, constitutes the search for appropriate adjuvant therapy to the standard surgical procedures, aiming at better local control. In the present state of knowledge; radiotherapy seems to be a logical choice. Promising results have been reported (Kodner 1989). However, controlled randomized trials are still few and often contradictory (Cummings 1986) Preliminary data from non randomized studies show that local recurrence may be prevented to some degree by preoperative or postoperative irradiation regimens (Gunderson 1988).

The second approach is, to search for a new surgical technique which enables a more radical resection of cancer. Whatever the type of operation, it should always aim at the removal of the whole mesorectum. This is especially true for tumors situated in the middle or distal third of the rectum. Technical difficulties and local recurrence rates increase the lower the tumor is situated. Several factors are responsible for the outcome of low rectal cancer surgery.

Accurate preoperative staging is a clue to the correct therapeutic strategy (Williams 1988). Chances for high risk patients will improve if these patients can be identified preoperatively to allow preoperative adjuvant therapy. Preoperative assessment of the intended surgical cleavage planes is also necessary. In some cases, curative surgery is possible even when the tumor has extended beyond its anatomical limitations and has crossed the surgical cleavage planes. I.e. the uterus or vaginal septum may be removed together with the primary tumor. The choice between a restorative or amputative approach is made easier after accurate preoperative mapping of the tumor. Decisions about the choice of adjuvant therapy are also dependent on the preoperative assessment.

\subsection{Technical pecularities in low rectal cancer surgery.}

Lack of accessibility is a major restriction to rectal cancer surgery. Mobilization and removal of the rectum within its covering perirectal fascia minimizes the chance of residual disease. Two factors contribute to the difficulties regarding adequate access to the lower pelvis. In the male or obese female, direct view of the operative field is difficult, especially if a voluminous tumor obstructs entrance to the lower pelvis. Identification of the correct cleavage planes will be equally difficult. Secondly, the anatomical relations on the anterior and caudal side of the distal rectum are complex and the partly blind and always deep dissection will not be easy. Anastomotic complications are very common at this site of the digestive 
tract. Partial dehiscence occurs in over $60 \%$ of all low anastomoses, leading to clinical signs in approximately $20 \%$. The operative mortality and morbidity is largely dependent on the integrity of the anastomosis (Goligher 1980).

Limits to restorative surgery have not yet been determined. Thus, it is possible from a technical point of view to remove the entire rectum and to suture the colon to the perianal skin. The functional results however will worsen the lower the anastomosis. At present, several of the important determinants of functional outcome are well understood. Still, it is not always predictable to what extent the functional result will be impaired. However, the associated inconvenience of a less perfect result is often preferable to the burden of a permanent colostomy. Following abdominoperineal resection, a large proportion of patients do have considerable problems regarding employment, housing, diet, social isolation and psychosexual behaviour. Patients who have had a restorative operation experience fewer problems, their quality of life being superior to those patients with a permanent colostomy (Devlin 1971, Williams 1983).

Summarizing. Low rectal cancer surgery is faced with several yet unresolved problems. Staging is still far from optimal, often confronting the surgeon with a tumor that is bigger or has infiltrated more into the surrounding area than could have been expected after the preoperative staging procedure. Exposure is limited and, furthermore anatomical complexities prevent from adequate transabdominal access. At present the oncological demands on restorative surgery are still under investigation. The role of adjuvant therapy is not yet completely understood. And, lastly, the functional results after restorative surgery are not quite predictable. The lowest level for an anastomosis strongly depends on the integrity of the remaining continence apparatus.

\subsection{A new concept for surgical approach of low rectal cancer:}

In this study the possibilities of the posterior, perineal, intersphincteric approach of the rectum have been explored. Anterior resection is the operation of choice for lesions in the upper third of the rectum and may still be feasible for midrectal cancers provided sufficient access is possible. To satisfy the requirements for radical resection in the obese female and for most male patients or patients with voluminous tumors, some other method will be necessary to preserve the sphincter. In the latter group of patients, low anterior resection may be technically possible at the cost of limited exposure with uncertain lateral and distal resection margins and subsequent 
incomplete removal of the mesorectum. Furthermore, the anastomosis will be difficult with an increased risk for complications.

Theoretically, a combination of a transabdominal approach and an approach from bellow offers some distinct advantages. Direct exposure by an interspincteric approach of the mesorectum and lateral ligaments distal to the tumor, covered with the perirectal fascia, permits complete radical resection even in a narrow pelvis. Contrary to the transsacral or transsphincteric approach, the anatomy of the pelvic floor is not disturbed as the approach is through the natural intersphincteric and interfascial cleavage planes ensuring as little damage as possible to the remaining continence mechanism. The anastomosis can be performed under direct vision at any level of the anal canal, if necessary at the dentate line. Transabdominally, the most distal possible level of the anastomosis is at the entrance into the surgical anal canal. After a combined abdomino-intersphincteric approach this level is two to three centimetres more distal, permitting a safe margin even if the tumor is five to six centimetres from the anal verge.

The indication for this approach is limited. In the spectrum of rectal cancer surgery it appears in the grey zone between a low anterior resection and abdomino-perineal resection. The justification for using this method cannot be supported by the results of a large randomized series, since the number of patients eligible for this procedure is too small. The results will resemble, perforce, a clinical pilot study.

\subsection{Chapter distribution.}

In chapter 2 , the historical roots of the perineal approach in rectal cancer surgery will be revealed.

In chapter 3 , the modern anatomical principles, which constitute the basis for the intersphincteric approach will be presented, as well as the physiological demands for successful restorative surgery.

In chapter 4, the preoperative requirements for the selection of patients with low rectal cancer will be discussed. Emphasis is put on the evaluation of tumor and patient factors in order to select a proper therapeutic strategy. The preoperative preparation of patients and the role of adjuvant therapy in the surgical decision making will be discussed as well.

In chapter 5, present techniques for restorative resection are presented. The technique of the combined abdomino-intersphincteric approach and its derived modalities are discussed in detail.

In chapter 6 , the clinical results are presented, with emphasis on complications, oncological and functional results.

In chapter 7, a synthesis is made of the theoretical basis for this new 
concept for approaching low rectal pathology and the clinical results which were attained.

In chapter 8 , practical recommendations are summarized and a flow chart is presented for the therapeutic strategies in rectal cancer patients.

In chapter 9 , an english and dutch summary of all chapters is present. 


\section{References chapter 1:}

Cummings BJ.: A critical review of adjuvant preoperative radiation therapy for adenocarcinoma of the rectum.

Br.J.Surg. $73,332-338,1986$.

Devlin HB, Plant JA, Griffen $\mathrm{M}_{\text {: }}$ Aftermath of surgery for ano-rectal cancer. Br.MedJ. 3;413-418, 1971.

Goligher JC.: Surgery of the anus rectum and colon.

Ed.4, Bailliere Tindall, London, 1980.

Gunderson LL.: Combined treatment approaches in the management of rectal cancer.In: Schllag P., Hohenberger P., Metzger U.: Combined modality therapy of gastrointestinal tract cancer. Springer-Verlag, 1988.

Heald RJ., Husband EM., Ryall RDH.: The mesorectum in rectal cancer surgery the clue to pelvic recurrence?

BrJ.Surg. 69;613-616, 1982 .

Kennedy HL, Langevin JM., Goldberg SM.: Recurrence following stapled coloproctostomy for carcinomas of the midportion of the rectum.

Surg.Gynecol.Obstet. 160;513-516, 1985.

Kodner IJ., Shemesh EI., Fry RD., Walz BJ., Myerson R., Fleshman JE., Schechtman KB.: Preoperative irradiation for rectal cancer. Improved local control and long-term survival.

Ann.Surg. 209; 194-199, 1989.

Phillips RKS., Hittinger R., Blesovsky L., Fry JS., Fielding LP.: Local recurrence following curative surgery for large bowel cancer: The overall picture.

Br.J.Surg. $71 ; 12-16,1984$.

Quirke P., Durdey P., Dixon MF, Williams NS.: Local recurrence of rectal adenocarcinoma due to inadequate surgical resection.

Lancet $1986 \pi, 996-999,1986$.

Williams NS, Johnston D.: The quality of life after rectal excision for low rectal cancer.

Br.J.Surg. 70;460-462. 1983.

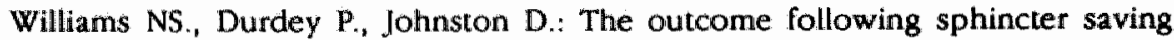
resection and abdomino-perineal resection for low rectal cancer.

Br.J.Surg. 72,595-598, 1985.

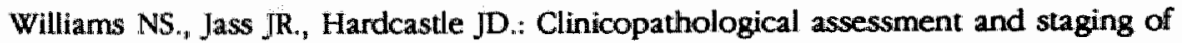
colorectal cancer.

Br.J.Surg. 75;649-652, 1988. 


\section{Chapter 2.}

\section{History of dorsal approach to rectal pathology.}

\subsection{Perineal approaches.}

Procedures which preserve the anal sphincter during intended curative surgery for rectal cancer were developed more than a century ago. Via a perineal approach Lisfranc was the first to remove a cancerous rectum in 1826. Verneuil preserved in 1873 the sphincter muscles. Kocher in 1875 attached the sigmoid to the external sphincter. Kraske gave a new impulse to rectal cancer surgery by creating an extended operative field by excision of the coccyx and a left segment of the sacrum. In suitable cases he performed a circular colo-anal anastomosis. Hochenegg (1889), also a proponent of the posterior transsacral approach, invaginated the upper rectal sigmoidal segment through the anus following excision. To this procedure the name "pull-through" was given. The protruding bowel was stitched to the anal verge and via the perineal wound to the upper margin of the anal stump (Hochenegg 1889). In later modifications he denuded the anal canal from its mucosa prior to the pull-through procedure to improve spontaneous fibrous fixation of the anal stump to the protruding bowel, thus creating a colo-anal anastomosis (Hochenegg 1900).

Cripps divided the posterior wall of the rectum along the middle-line of the anal margin to the tip of the coccyx. The external sphincter as well as the levator ani muscles were removed along with the rectum. The perineal wound was allowed to heal by granulation, resulting in a fistula-like artificial anus (quoted by Miles 1944).

Allingham (1882) made an incision from the tip of the coccyx to, but not including, the posterior wall of the rectum. Between the internal and external sphincter the rectum was isolated by dissection close to its wall. The wound was left to heal by granulation. An essential difference with Cripps' technique was that the external sphincter was left in situ, enabling some control over the artificial anus.

Up to 1900 various methods had been described for excising the cancerous rectum by local posterior procedures. The main differences consisted in the means employed for exposing the rectum and for facilitating its extirpation. Vogel (quoted by Miles 1944) reported the endresults of over 1500 perineal excision operations performed by twelve leading continental surgeons up to the year 1900: operative mortality $20.9 \%$ and recurrence rate $80 \%$. 


\subsection{Development of the abdomino-perineal approach.}

In the period between 1895 and 1908, Miles developed a new concept for treating rectal cancer. He learned about Allingham's technique in 1895-1896 at St.Mark's Hospital. Although operative mortality was as low as $3.7 \%$ he was struck by 25 recurrences in 27 patients. From 1899 to 1906 he gradually increased the amount of tissue he removed via the perineal and, at a later stage, transsacral approach. By doing so, the disease free interval was lengthened, but recurrent disease still occurred in over $90 \%$ of his patients. After postmortem observations he was able to explain this unsatisfactory result. It was due to insufficient removal of the diseased tissue along the so called upward zone of spread: Miles concluded (1944):

"If extension of cancer through continuity of tissue was the only or even the usual mode of spread from the rectum, the surgical treatment of the disease would be simple because, unless the growth has extended beyond the confines of the fascia a restricted operation, entailing nothing but the removal of the portion of the musculo-membranous tube containing the cancer in its interior, would be all that was necessary to rid the patient completely of his disease. Unfortunately, however, other and more important modes of spread take place simultaneously and with greater rapidity, leading to distant dissemination even when the primary growth is still in an early phase of development.".

He thought that venous dissemination was rarely encountered and the possibility of it happening could be disregarded. Infinitely more important was dissemination of cancer cells through the lymphatic system. He described three zones of spread: downward, lateral and upward:

"Since the majority of the efferent lymphatics, which form the intramural lymphatic system, either pass through or terminate in the structures contained in this zone (zone of upward spread), it follows that these structures constitute the principal paths by which cancer cells spread from primary growth in the rectum. In fact this is the most constant and, therefore, the most important of all the routes of spread."

Adding an abdominal phase to his perineal resection was a logical consequence of his observation. He was not the first to advocate abdomino-perineal approaches. In 1903, Mayo reviewed the current opinion on rectal cancer surgery. Many of the pioneers of rectal cancer surgery (Kocher, Kraske, Gaudier, Quenu, Weir) advocated the combined abdominal and perineal resection for high seated rectal cancer. British surgeons like Sir Charles Ball and Aldrich-Blake have also advocated the combined procedure (Aldrich-Blake 1903). However, Miles was the first to substantiate a theoretical concept for rectal cancer surgery. He planned the radical abdomino-perineal operation so as to embrace the tissues of the zone of 
upward spread as well as those of the lateral and downward ones. The protective colostomy, which was also performed in perineal resections to reduce morbidity, was turned into a permanent one. In most cases of perineal resection, the colostomy was also intended as a permanent one. In his early cases the mortality rate was as high as $42 \%$; this compared unfavourably with a mortality rate of less than $5 \%$ after perineal resections. However, Miles reported an increase in 5 year survival rate to above $60 \%$ for all cases operated (1944). During his lifetime, anaesthesia and postoperative care improved and the operative mortality rate dropped to $10 \%$. The concept of removing the tissues containing the three zones of spread was generally adopted and the abdomino-perineal resection became, and still is, the golden standard for rectal cancer treatment.

Essentially, the abdomino-perineal resection was developed from the perineal resection, which, in the hands of leading British surgeons was not a sphincter saving procedure. Lockhart-Mummery, a contemporary of Miles and consultant surgeon of St.Mark's Hospital, brought the perineal resection to perfection and obtained results which were equal to the results of today's radical resections (mortality rate $3 \%$, overall cure rate $54 \%$ and, in favourable cases, a cure rate $75 \%$ ). According to Lockhart Mummery, low seated rectal cancers could be removed more safely by perineal excision than by abdomino-perineal resection. He attributed the early unfavourable results of perineal excisions to a wrong indication. Surgeons were reluctant to open the abdomen therefore, they removed high seated growth by the perineal route and discredited the operation, which was never intended to deal with such cases. He stated that the actual difference between the amount of tissue removed by the perineal approach and the abdominoperineal route was very slight. It amounted to a few more of the secondary glands in the base of attachment of the mesorectum and the pelvic peritoneum, but, according to him, it was very doubtful if recurrence could have been avoided once the secondary glands had become involved. $\mathrm{He}$ took great care in removing the rectum, complete with its mesorectum enveloped in the fascia propria recti. Before 1900 this fascia was not recognized: the perirectal fat was opened and the rectum removed close to the bowel wall (Allingham 1882) or the rectum was even opened and removed as an open tube (Kocher 1879, Cripps). The careful anatomical dissection may be another explanation for his excellent results in the beginning of this century.

\subsection{Development of modern pathological concept of dissemination.}

Whereas Lockhart-Mummery casted doubt on the importance of the upward zone of spread, other surgeons did not agree wh Miles on the concept of 
lateral and inferior zones of spread. After a review of over 1000 sacral resections in Hochenegg's clinic Mandel concluded that, whenever possible in situations where the tumor is at a sufficient distance from the sphincters, these should be preserved (1926). He believed that a combined procedure was only necessary in high seated cancers. Babcock (1932) and Bacon (1945) developed an abdomino-anal pull-through sphincter preserving technique with equal good results. Miles concept of cancer spread was primarily based on patho-anatomical data of postmortem findings in patients who died from advanced inoperable cancer (1923). McVay (1922) found in only 1 out of 47 patients with nodal involvement a single node at $1 \mathrm{~cm}$ distal to the lesion. An accurate pathological study by Gabriel, Dukes and Bussey revealed that lateral or downward lymphatic spread was only found in a late stage of the disease when the haemorrhoidal lymphatics were blocked by metastases (1935). Coller (1940) failed to find metastases in the lateral zone of spread in lesions that were $3 \mathrm{~cm}$ or more above the ano-rectal junction. His statement beared much weight as he used a technique which identified a mean of 167 glands in a resected specimen. Best (1945) showed that $2.3 \%$ of 607 cases had nodal involvement 1 to $2 \mathrm{~cm}$ below the lower limit of the lesion and that less than $1 \%$ had nodal involvement more than $2 \mathrm{~cm}$ below the lesion.

Allthough contemporaries of Miles had produced sound evidence to support sphincter saving procedures, the abdomino-perineal resection gained worldwide popularity. Undoubtedly, complete resection secured optimal chance for survival and, technically, the abdomino-perineal resection was easier to perform than the sphincter preserving procedures which were fraught with additional complications: fistula formation, pelvic sepsis, necrosis of the efferent sigmoid and, last but not least, functional results were less than optimal in the majority of patients.

The ano-rectal anatomy with regard to its impact on continence was not clearly understood. Generally, the anal sphincters were thought to be responsible for closure of the rectum and these were preserved in sphincter saving procedures. Levator muscles were resected "as widely as possible" because extension of disease was often noticed in advanced cases in these pelvic floor muscles. The cardinal function of the puborectal muscle was not understood. Miles (1944) thought that the ischiorectal fat communicated freely with the perirectal fat. Even in 1989 Yeatman states that the middle and lower thirds of the rectum are considered extraperitoneal and are surrounded by ischiorectal fat, disregarding the important fact that the pelvic floor muscles are interposed between the perirectal fat and the ischiorectal fat. The basic anatomical understanding of the ano-rectal region had yet to be developed. Perhaps this is the most important explanation of why a sphincter preserving procedure which necessitated a very low colo- 
anal anastomosis was not further developed before the early seventies.

\subsection{Development of restorative procedures.}

A new kind of restorative procedure based on the knowledge of lymphatic spread was initiated by Dixon in 1930 (1939). He is credited with having performed the first anterior resection for high rectal cancer. Essential in this procedure is, that it is a complete abdominal procedure intended to resect low sigmoidal or rectal sigmoidal tumors and to anastomose the sigmoid to the rectum at or below the perineal reflection. In 1944 he was able to report results of 181 curatively intended cases which were completely comparable to results achieved nowadays (Dukes A $81.5 \%$ 3-year survival, Dukes B 54.3\% 3-year survival, Dukes C 44.8\% 3-year survival, overall $58.8 \%$ 3-year survival) (Dixon 1944). Clinical results of other authors with anterior resection proved the correctness of the former pathological studies with regard to lymphatic spread of rectal cancer.

The anterior resection was generally adopted for lesions in the upper third of the rectum and most surgeons performed an abdomino-perineal resection for lower seated lesions. Some surgeons (Turnbul 1961, Cutait 1961, Bacon 1971) performed pull-through spincter preserving operations, or (Best 1957) transabdominal dissection with posteriorly made anastomosis for midrectal cancers, but these techniques never gained wide acceptance.

It took till the early seventies when a more complete understanding of the anorectal anatomy and physiology was accompanied by a renewed interest in restorative procedures for rectal cancer. (Parks (1972) modified pullthrough procedures in colo-anal anastomosis, Mason (1972) and localio (1973) revived the abdomino-posterior approached with abdominal mobilisation and posteriorly performed anastomosis ).

It seems appropriate to end this historical review with the outstanding study of Dukes and Bussey in 1958. In a prospective study from 1929 to 1952 , 2447 rectal cancer patients were treated by surgical operation. In only 28 patients follow up could not be completed. The crude and corrected 5-year survival rates were correlated with many variables: malignancy grade (positive correlation) local spread (positive correlation) lymphnode involvement (positive correlation) extent of lymphnode involvement (positive correlation). More correlations between individual variables were demonstrated: i.e. a positive correlation was demonstrated between the extent of local spread and lymphnode involvement. This study identified the tumor factors which are the principal determinants for an estimate of the prognosis of a rectal cancer patient.

From this time onward, clinical results were correlated with a detailed 
pathological staging which enabled comparisons of different techniques and different patient groups.

\subsection{Conclusion.}

One of the most important drawbacks in the evaluation of formerly employed techniques, is the absence of clinico-pathological assessment and staging of rectal cancers in those days. A superficial study of the posterior approaches before 1900 may lead to the assumption that posterior approaches are unsuitable for rectal cancer surgery. Still, elements of posterior approaches have been modified and lead to very satisfying results nowadays (Parks, Localio, Mason). Understanding of the biology of rectal cancers has evolved very gradually. Allingham and Cripps were not aware of the importance of total resection of the mesorectum. One of their residents, Lockhart Mummery, realized the importance of the perirectal fascia in perineal removal of rectal cancer and had very gratifying results with dorsal approaches. Similarly, sphincter preservation or preservation of continence has always been an ambition of the first rectal surgeons. Anatomical understanding of what has to be preserved in sphincter preservation has only been evolved in recent decades.

Miles has received credit for a revolutionary concept in rectal cancer surgery. But with all due respect it may be better to relativate his axiomas in rectal cancer surgery. He was by no means the first to perform combined procedures and his concept about the biological behaviour of rectal cancer has been proved wrong by his contemporaries. The abdomino-perineal resection constitutes the most radical procedure in rectal cancer surgery, however it involves the removal of a lot of tissue of the human body which itself does not add to the cure of rectal cancer. 


\section{References chapter 2 :}

Aldrich-Blake LB: Abdomino-perineal excision of the rectum by a new method. Brit.Med.J. ;1586-1588, 1903.

Allingham W: Diagnosis and treatment of diseases of the rectum. Ed. Allingham HW 2nd edition, London, Churchill, 1882.

Babcock Wr: The operative treatment of carcinoma of the rectosigmoid with methods for elimination of colostomy.

Surg.Gynecol.Obstet. 55;627-632, 1932.

Bacon HE: Evolution of sphincter muscle preservation and re-establishment of continuity in the operative treatment of rectal and sigmoidal cancer.

Surg.Gynecol.Obstet. 81;113-127, 1945.

Bacon HE: Present status of the pull-through sphincter preserving procedure.

Cancer 28;196, 1971.

Best RR.,Blair JD.: Sphincter-preseving operation for resectable carcinoma as related to the anatomy of the lymphatics.

Am.Surg. 130;538, 1945.

Best RR., Rasmussen JA.: Results of sphincter-preserving operations for carcinoma of midrectum.

J.A.M.A. $164 ; 739-743,1957$.

Coller FA., Kay EB, MacIntyre RS.: Regional lymphatic metastasis of carcinoma of the rectum.

Surgery $8 ; 294-311,1940$.

Cutait DE. Figlioni FJ: A new method of colorectal anastomosis in abdominoperineal resection.

Dis.Colon Rectum 4;335-342, 1961.

Dixon CF.: Anterior resection for carcinoma low in the sigmoid and the rectosigmoid.

Surg. $15 ; 367-377,1944$.

Dukes CE., Bussey HJR. The spread of rectal cancer and its effect on prognosis. Br.].Cancer 12,309-320, 1958.

Gabriel WB., Dukes C., Bussey HJ.: Lymphatic spread in cancer of the rectum. Br.J.Surg. 23;395-413, 1935.

Hochenegg J.: Beitrage zur Chinurgie des Rectums und der Beckenorgane.

Wien.Klin.Wochenschr. 2;579-581, 1889.

Hochenegg J:: Meine Operationserfolge bei Rectumcarcinom.

Wien.Klin. Wochenschr. $13,399,1900$. 
Kocher T: Uber Radikalheilung des Krebses.

Deutsche Zeitschr.Chir. 13;155-166, 1880.

Kraske P.: Zur Extirpation hochsitzender Mastdarmkrebsen.

Verh.Dtsch.Ges.Chir. 14;464, 1885.

Localio SA., Baron B.: Abdomino-transsacral resection and anastomosis for midrectal cancer.

Ann.Surg. 178;540-545, 1973 .

Lockhart-Mummery JP.: Two hundred cases of cancer of the rectum treated by perineal excision.

Br.J.Surg. 14;110, 1926.

Mandl: Uber 1000 sakrale Mastdarmkrebsextirpationen (aus dem Hocheneggschem Material).

Dtsch.Z.Chir. 219;3, 1929.

Mayo CH.: Evolution of treatment of cancer of the rectum.

J.A.M.A. 1127, 1903.

McVay JR.: Involvement of lymphnodes in carcinoma of the rectum. Am.Surg. $76,755,1922$.

Miles WE.: Cancer of the rectum.

Trans.Med.Soc. 46;127, 1923.

Miles WE.: Rectal surgery. A practical guide to the modern surgical treatment of rectal diseases.

Cassell and co., Itd., London, 1944.

Parks AG: Transanal technique in low rectal anastomosis.

Proc.Roy.Soc.Med. 65;975-976, 1972.

Turnbull RP., Cuthbertson A.: Abdomino-rectal pull-through for cancer and Hirschsprung's disease, delayed posterior colorectal anastomosis.

Cleve.Clin.Q. 28;109, 1961.

York Mason A: Transsphincteric exposure for low rectal anastomosis.

Proc.Roy.Soc.Med. 65;974, 1972. 


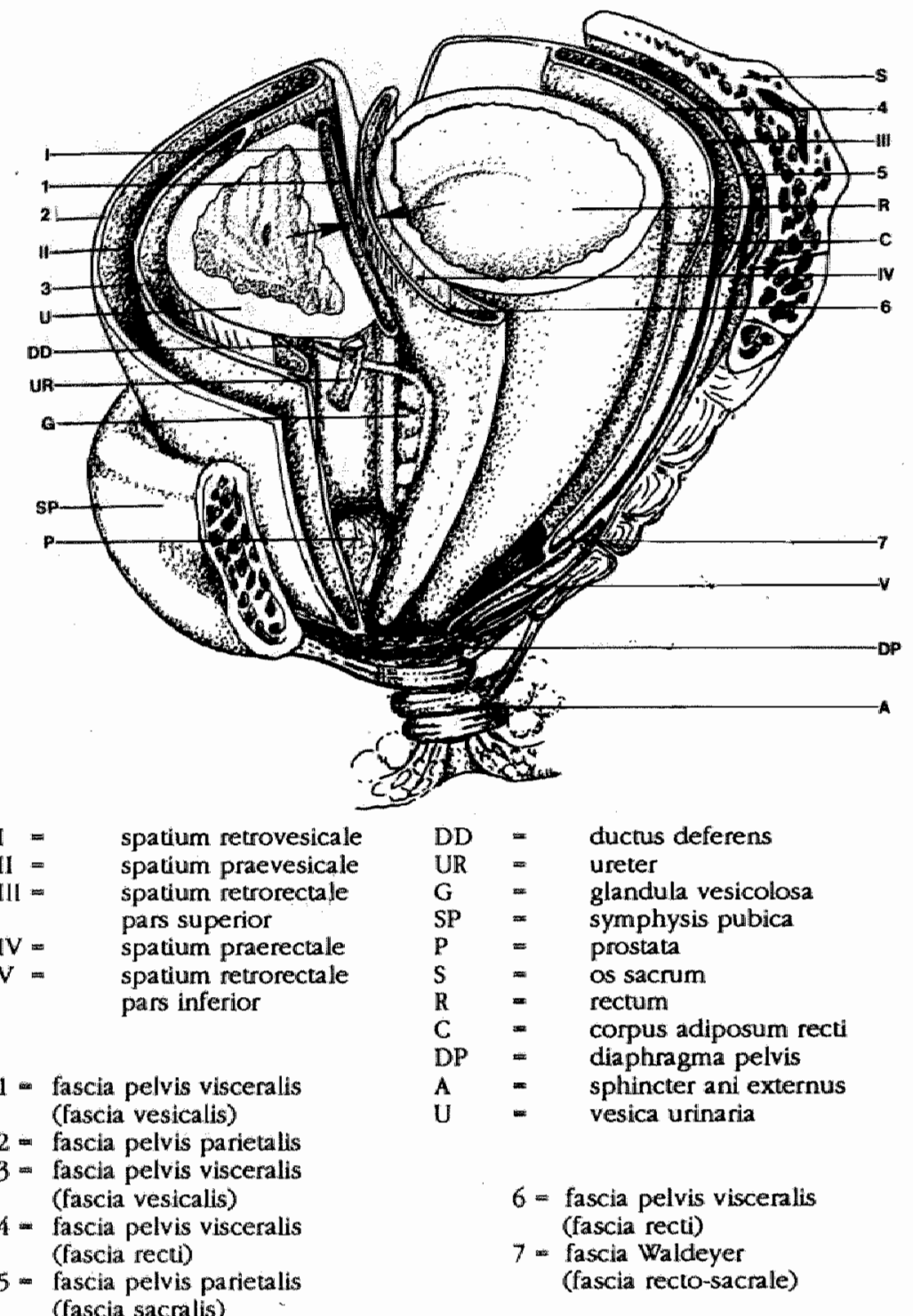

Bewween arrow heads: spatium fibnosum vesicorectale Denonvilliers

Fig. 3.1. Organization of pelvic fascias and interfascial spaces. An approach through the perivisceral interfascial spaces is the anatomical key to surgery. The spaces do not contain neurovascular structures, therefore, they constitute ideal cleavage planes.

The author refers to the spatium retrorectale as the spatium retrorectale pars superior and the spatium retrorectale pars inferior. 


\section{Chapter 3}

\section{Anatomy and physiology.}

\subsection{Anatomy.}

\subsubsection{Introduction.}

De Blok (1982) described extensively the musculo-fibrous tissue in the female pelvic region. He found that the the spatial architecture is bilateral symmetrical and possesses an interindividual constancy. Connective tissue sheats enclose several functional compartments, i.e. visceral, muscularbony, vessel and adipose tissue compartments. Furthermore, the musculus levator ani is not a separate structure but is an integrated part of the total connective tissue system of the pelvis. The visceral compartments and the musculus levator ani are linked up by the connective tissue septa with the side walls of the pelvis. The viscera with the perivisceral adipose tissue are located within sheats of connective tissue; from these sheaths radially oriented septa split up the corpus intrapelvinum and guide the neurovascular structures to the viscera (fig.3.2).

Understanding the basic pelvic architecture, which is necessary to suspend, open and close the pelvic organs, is helpful in surgery in the pelvis. From a functional or surgeon's point of view, the connective tissue is partly tightly organized as septa, usually called ligaments, which contain the neurovascular system and can also be rich of fatty tissue and smooth muscle fibres, and partly very loosely organized, devoid of passing vessels or nerves. It can then be described as "space". The borders between ligament and space are formed by fascia-like condensations of connective tissue, described by Stelzner as "Grenzlamellen" (Stelzner 1961, 1984) (fig.3.1.). Grenzlamellen may also be the border between a space and a pelvic visceral compartment. In that case, the organ is covered in an adventitia-like fashion. These bordering fascias differ from muscular fascia by the fact that no blood or lymphatic vessels are passing through them. The disease spreads primarily along the neurovascular structures in the ligaments and not through the bordering fascias. Cancer or inflammatory processes need bloodvessels. Fascias are natural barriers to the spread of disease. A tight fascia covers all pelvic organs and pelvic floor musculature. It is called fascia endopelvina or fascia pelvis interna and can be divided into a fascia pelvis visceralis (with local names as fascia rectalis, fascia vesicalis etc., these are designated by Stelzner as "Grenzlamellen" and they will be referred to as bordering fascias 


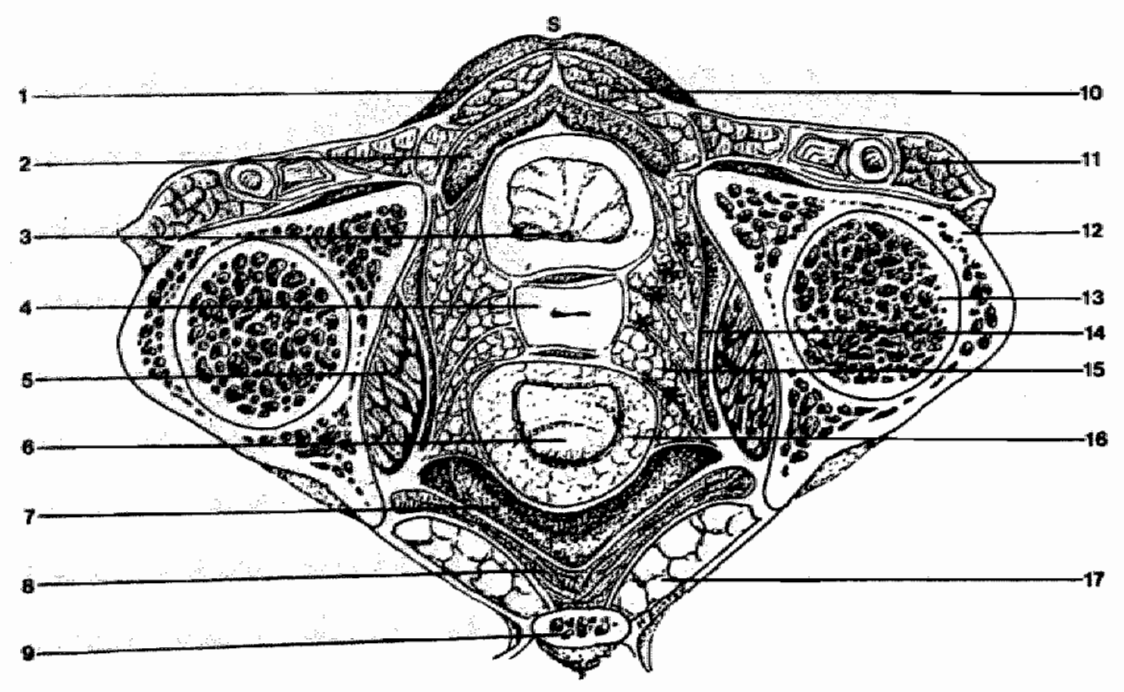

Legends to fig. 3.2. $\quad 1=$ os pubis

2 - spatium praevesticale

3 - compartment for the urinary bladder

4 - compartment for the uterus

5 musculus obturatorius internus

6. compartment for the rectum

7 spatium retrorectale

8 - musculus levatoris ani

9 os coccygis

10 - musculus abdominis recti

11 musculus il iopsoas

12 os coxae

13 - caput femoris

14 - compartment for the internal illac vessels

15 - corpus adiposum intrapelvinum

16 - corpus adiposum recti

17 - corpus adiposum fossale ischiorectal is

$\$$ - symphysis

* connective tissue septa in corpus adiposum

untrapelwinum

Fig. 3.2. Connective tissue septa in the supralevator retroperitoneal space of the female pelvils in a cranial to caudal view. The relation between the different visceral compartments, the connective tissue septa in the corpus adiposum intrapelvinum and the perivisceral spaces is shown.

in the rest of the text) and a fascia pelvis parietalis (fascia sacralis, fascia levatoris ani superior etc., called after the underlying somatic musculature). Pelvic viscera are characterized by several common denominators. They have to be suspended in the pelvis; an ingenious three dimensional system 
of ligaments/smooth/somatic muscles is present for this task. They also have to be able to adapt to changing volumes. The perivisceral spaces allow easy adaptation to quickly changing volumes. Furthermore, as pelvic viscera communicate with the outside, the orifices have to be regulated. As a whole, the pelvic floor must be able to prevent herniation of the abdominal viscera.

Suspension of the pelvic viscera is realized in three different planes. A vertical frontal, a horizontal transversal and a vertical sagittal plane.

In the frontal plane the lateral ligaments contain nerves, vessels and lymphatic vessels for the suspended organs. Each viscus has its own bilateral suspending ligament. Origin of the ligament is the postero-lateral sidewall. In the transversal plane, the ligament ischio-prostaticum with the ischio-prostatic muscle runs from the fascia pelvis parietalis at the level of the spina ischiadica to the prostate. It is comparable with the ligamentum cardinale uteri in women. It lies in close proximity to the somatic pelvic floor musculature which with its covering fascia.

In the sagittal plane, three ligaments subsequently run from anterior to posterior. The first ligament, the ligamentum pubo- prostaticum and the ligamentum pubo-vesicale with its muscles, attach the capsule of the prostate to the pubic bone. Hence, it runs as musculus recto-urethralis from the base of the prostate/urethra to the anterior aspect of the perineal part of the rectum. Next, the rectum is bilaterally passed by the musculus rectococcygeus, which attaches the lateral and posterior sides of the rectum to the os coccygis.

The junction of these planes is the centrum tendineum perinei, situated between urethra and rectum. It acts as an anchor for all suspending forces. The urogenital diaphragm is spread out ventrally and caudally to this point in the transversal plane.

Knowledge of these suspensory structures is essential to the surgeon as they must be avoided. The ligaments are pathways for nerves. Severance will cause neurological disfunction.

An approach through the perivisceral spaces is the anatomical key to surgery. All organs are enveloped by spaces allowing adaptation to changing volumes. These spaces are predestined for a surgical approach as they do not contain lymphatics, vessels or nerves. The spaces are bordered by visceral pelvic fascia. The spaces not only surround the organs, except on the side where the ligaments are invested, but also the lateral ligaments. The paracysteum (to the bladder), parapatrium (to the prostate), parametrium (to the uterus) and paraproctium (to the rectum) can be identified in the lateral ligaments. De Blok (1982) prefers to refer to these ligaments as connective tissue septa which can be identified rather then individual ligaments (fig.3.2.). 


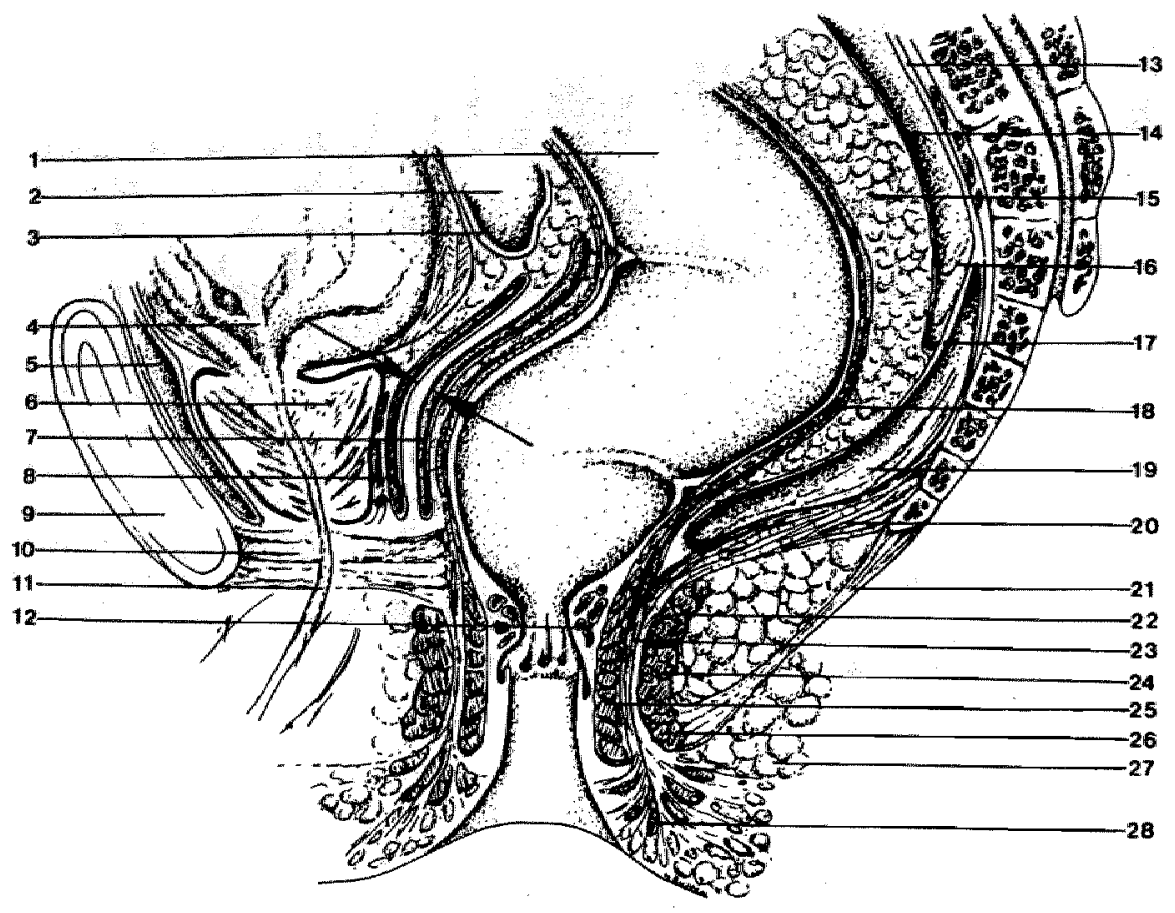

Legends to fig. 3.3 .

\begin{tabular}{|c|c|c|c|}
\hline $1=$ & rectum & $17=$ & fascia Waldeyer \\
\hline $2=$ & cavum Douglasi & $18=$ & tunica muscularis recti \\
\hline 3 & peritoneum & & stratum circulare \\
\hline 4 & vesica urinaria & & stratum longitudinale \\
\hline 6 & $\begin{array}{l}\text { spatium praevesicale } \\
\text { prostata }\end{array}$ & $19=$ & $\begin{array}{l}\text { spatium retrorectale } \\
\text { pars inferior }\end{array}$ \\
\hline 7 & spatium praerectale & $20=$ & m.levator ant \\
\hline 8 & spatium retrowesicalle & $21=$ & ligamentum anococcygeum \\
\hline 9 & symphysis pubica & $22=$ & m.puborectal is \\
\hline $10=$ & $\begin{array}{l}\text { diaphragma urogenitale } \\
\text { m.puboprostaticus }\end{array}$ & $23=$ & $\begin{array}{l}\text { m.corrugator ani } \\
\text { intersphincteric plane }\end{array}$ \\
\hline 11 . & $\begin{array}{l}\text { m. rectourethralis } \\
\text { urethra }\end{array}$ & $24=$ & $\begin{array}{l}\text { m.sphincter ani externus } \\
\text { pars profundla }\end{array}$ \\
\hline 12 & corpus cavernosum recti & $25=$ & m.sphincter ani internus \\
\hline 13 & $\begin{array}{l}\text { fascia pelvis parietalis } \\
\text { fascia sacralis }\end{array}$ & $26=$ & $\begin{array}{l}\text { m.sphincter ani externus } \\
\text { pars superficial is }\end{array}$ \\
\hline 14 & $\begin{array}{l}\text { fascia pelvis visceralis } \\
\text { corpus adiposum recti }\end{array}$ & $27=$ & $\begin{array}{l}\text { corpus adiposum fossae } \\
\text { ischilorectalis }\end{array}$ \\
\hline 16 & $\begin{array}{l}\text { mesorectum } \\
\text { Spatium retrorectale pars superior } \\
\text { arrowheads: spatium fibrosum vesio }\end{array}$ & $28=$ & $\begin{array}{l}\text { m.sphincter ant externus } \\
\text { pars subcutanea }\end{array}$ \\
\hline
\end{tabular}


Fig. 3.3. Topographical anatomy of the rectum and anal canal. The rectum is embedded in a posterior retrorectal space and an anterior prerectall space. The retrorectal space is divided in a superior and an inferior part by the fasicia of Waldeyer. The inferior part can be reached through the intersphincteric plane. This: avascular intersphincteric plane is the fusion site of the internal sphincter and the external sphincter.

The anterior prerectal space is lined by Denonvilliers' fascia, which is situated between the rectum and the urogenital system. At the apex of the prerectal fascia Douglas' pouch is encountered.

Theoretically, the rectum with its complete mesorectum, enveloped in the fascia visceralis recti, can be removed through an intersphincteric, dorsal and ventral interfascial approach with minimal disturbance of the anatomy.

\subsubsection{Topographical anatomy of the pelvic rectum (fig.3.3.).}

The upper third of the rectum has a complete peritoneal investment, except for a thin strip posteriorly where the peritoneum is reflected off it as the two leaves of the short mesorectum. This renders some mobility to the upper rectum (rectum mobile). As the rectum descends into the pelvis the mesorectum becomes wider and shorter and the peritoneum sweeps off more at the lateral side of the rectum, so that the uncovered posterior portion becomes progressively wider, until only the anterior aspect has a peritoneal covering. Finally, this becomes reflected forward at the bottom of the recto-vesical or recto-uterine pouch on to the back of the seminal vesicles and bladder or of the vagina and uterus in the female, leaving the lower third of the rectum without peritoneal covering. The extent to which the prostate and the seminal vesicles are covered by peritoneum depends on the depth of the recto-vesical pouch. In about the fourth or the fifth intra-uterine month, the cull-de-sac, formed by this pouch, extends to the pelvic floor. In the new born it reaches to the base of the prostate. The usual theory about the embryology of this area was as follows: The peritoneum of the anterior and posterior walls of the embryonic pouch approximate and fuse from below upward, so that a frontly disposed fascia is formed, called recto-vesicle or prostato-perineal fascia of Denonvilliers. The fascia between rectum and vagina, the so called fascia peritoneovaginalis is similarly formed.

Nowadays Silver's (1956) theory is generally accepted; he casted considerable doubt on the fusion theory as the relative posterior position of the pouch remains constant at the level of Houston's main valve from the fourth intra-uterine month onward. In studying human embryos the discovered condensations of areolar tissue between the prostate and the rectum at the site where later on in the development the fascia of 
Denonvilliers would arise. He concluded that the septum is formed in a manner similar to other fascial septa in the body, i.e. by condensation of areolar tissue.

The upper part of the posterior vaginal wall lies in direct contact with the anterior leaf of the recto-uterine pouch. The deepest point of the cul-de-sac in men lies 8-9 cm from the perineal skin; in women $5-8 \mathrm{~cm}$. Denonvilliers' fascia or its female equivalent has, in the adult, the appearance of a proper fascia. The ventral rectal fascia of the anterior prerectal space and the dorsal vesical fascia of the posterior perivesical space also fuse with Denonvilliers" fascia. The fascia prostato-perinealis or peritoneo-vaginalis may be present as a single layer, or locally also as a double layer. It intervenes between the rectum posteriorly and the prostate and seminal vesicles or vagina anteriorly. In literature, two opinions exist: Stelzner describes it as more adherent to the urogenital system (Stelzner 1977) whereas Goligher (1980) believes it to be more closely adherent to the rectum. The first author emphasizes not to remove Denonvilliers' fascia as damage to sympathic fibres in the paracysteum and parapatrium will result in bladder dysfunction and impotence. Goligher thinks it is more convenient to separate Denonvilliers' fascia from the urogenital organs along with the rectum in the course of a rectal excision, than to divide it transversally on a lower level. In advanced cancer, the prerectal space may have been invaded and it may be necessary from an oncological point of view to remove the intermediate fascia, which is a potent barrier to cancer growth and to accept the chance of neurological dysfunction.

In 1945 Tobin already has described the surgical importance of Denonvilliers' fascia in perineal approaches of the prostate. He advocates to develop the cleavage plane between the perirectal fascia posteriorly and the 'vesico-rectal' fascia anteriorly in accordance with Stelzner.

The mesorectum with its afferent and efferent structures lies at the lateral and posterior aspect of the bowel wall. As a cushion it fills the sacral concavity. Between the mesorectum and sacral fascia the retrorectal space is present. The fascia lining the mesorectum is called fascia pelvis visceralis interna recti or fascia rectalis propria. The opposite fascia is the fascia pelvis parietalis or fascia sacralis. Traced inferiorly from the abdomen, this fascia extends downwards to fuse with the fascia pelvis visceralis interna recti at the ano-rectal junction. The margin of these fascia is met in approaches from below, i.e. in post anal repair or abdomino-perineal resection. In the midline, a tough layer of fascia has to be divided to gain accesss to the retrorectal space. This reflection from sacral to rectal fascia is also called Waldeyer's fascia. Crapp (1974) prefers to call it recto-sacral fascia, which does describe its anatomical feature better and would help to dissolve the confusion about which structure should carry Waldeyer's name. Crapp also 
points out, that the recto-sacral fascia usually lies at a higher level than the ano-rectal junction, and that it extends from the fourth sacral vertebra to the back of the rectum. In carrying out the dissection from below, it is important to sever the recto-sacral fascia to enter the retrorectal space and not to strip the fascia pelvis parietalis or sacral fascia off the sacrum, for the sacral venous plexus and the parasympathetic nerves are liable to be torn if this faulty plane is struck. The retrorectal space with its fascia extends laterally to cover the lateral ligaments of the rectum (fig.3.3.). The lateral ligaments have a triangular shape with their bases on the pelvic sidewalls and apexes joining the rectal sidewalls. These ligaments carry afferent and efferent structures to the rectum. Due to this division of the retrorectal space, the author will refer to a spatium retrorectale superior and a spatium retrorectale inferior.

Summarizing. The pelvic part of the rectum is embedded in loose perirectal tissue, called the retrorectal and prerectal space. A fascia visceralis interna borders this space at the rectal side and constitutes a natural barrier to cancer spread. The perirectal fascia and space are divided by the lateral ligaments into a posterior half (retrorectal space) and anterior half. The transversally running ligaments are the inferior borders of the perirectal spaces. Ventral to the prerectal space is the centrum tendineum perinei with the ligamentum recto-urethrale and its muscle; before the retrorectal space this is the recto-sacral ligament and the musculus rectococcygeus. The retrorectal space communicates with the retro-peritoneal space of the abdomen. The prerectal space is shut off cranially by the anterior investment of the peritoneum to the rectum.

\subsubsection{The topographical anatomy of the perineal part of the rectum and the anus.}

The pelvic rectum is suspended in the frontal plane by the lateral ligaments. Through a slit in the transversal suspensory system the rectum leaves the pelvic cavity. A funnel shaped extension of the transversally spread levator muscle accompanies the rectum to the anal orifice. This short passage from the opening in the pelvic floor to the anus is of greatest importance because of its role in the mechanism of rectal continence. It is called the anal canal and it measures $3-5 \mathrm{~cm}$. The anal canal is surrounded by two sphincters.

The internal sphincter is continuous with the circular layer of the muscularis propria of the rectum. It ends inferiorly with a well defined rounded edge $6-8 \mathrm{~mm}$ above the level of the anal orifice.

The external sphincter extends further downward than the internal sphincter and the lowermost portion curves medially to occupy a position 
below the lower rounded edge of the internal sphincter. The lowermost or subcutaneous portion does differ in some aspects from the rest of the external sphincter. The intersphincteric longitudinal muscle fibres are radially continuous with the superficial perineal fascia which divides the subcutaneous fat in an ischio-rectal space and a peri-anal space (Milligan 1943, Morgan 1956).

It also divides the external sphincter in that the subcutaneous part comes into close contact with the perianal fat and skin.

Between the internal and external sphincter, a layer of longitudinal muscle fibres is seen. This layer exists of non-striated muscle fibres mixed with elastic tissue. Traced upward it is continuous with the outer longitudinal muscle layer of the muscularis propria, traced downward it gives elastic septa to the medially placed internal sphincter, further downward it breaks fanwise through the subcutaneous part of the external sphincter. Some of these diverting fibres ultimately attach to the perianal skin, forming the musculus corrugator ani. The subcutaneous part of the external sphincter is inseparably fused with the longitudinal muscle. Longitudinal fibres of the levator ani merge with this intersphincteric longitudinal ligament-muscle structure at the apex of the sphincter apparatus. Histologically, the external sphincter can be divided into two parts: a subcutaneous and a deeper part. The deeper part is without any discernable border continuous with the levator ani. Macroscopically, the external sphincter can be divided into three parts according to their respective attachments. The lowermost part, corresponding to the subcutaneous part, consists of a loop of muscle with its origin to the skin of the perianal region in the midline. At a slightly higher level the so called superficial part of the external sphincter contains fibres which form an anococcygeal raphe that runs backward and is attached to the dorsal aspect of the coccyx. Above this raphe, the deep part of the external sphincter is without a posterior attachment, but forms a loop of muscle around the back of the anal canal. This free-lying part of the sphincter extends up to the level at which the median raphe of the levator muscle inserts in to the front of the coccyx. Between this upper raphe of the levators and the lower raphe (called ano-coccygeal ligament), lies a space filled with fatty tissue. Anteriorly, the subcutaneous part merges with the skin, the superficial part forms the perineal body and the deep part proceeds continuously with the musculus puborectalis to the pubic bone. In the architecture of the anal canal no spaces comparable to the pelvic peri-visceral spaces are present. Yet, it is possible for the surgeon to find a plane which is suitable for dissection. Comparable to the gliding surfaces which surround the pelvic organs to render them mobility to adapt to changing volumes, a gliding surface is present between the internal and external sphincter. This intersphincteric plane is not crossed by blood, 
lymphatic vessels or nerves. In the intersphincteric plane, which is bordered medially by the longitudinal intersphincteric muscle, the external and internal sphincter can be separated, while avoiding nerve or vascular damage to the adjacent structures. Entrance to this intersphincteric plane from below may be obtained by the central space, as postulated by Shaffik (1976). This space is not a space with a fascial lining; it is a virtual space between the inferior border of the superficial and subcutaneous part of the external sphincter, bordered medially by the longitudinal intersphincteric muscle. In the apex of the intersphincteric plane, longitudinally running fibres from the inner aspect of the levator ani merge with the intersphincteric muscle. After dissection of these fibres, the external sphincter-levator ani muscles may be retracted laterally and posteriorly, exposing the dorsal aspect of the pelvic rectum. Dissection can be carried higher up to reach the rectal space. Posterior suspensory ligaments are encountered, of which the most prominent one constitutes the recto-sacral ligament, also called the fascia of Waldeyer, which divides the retrorectal space in a superior and inferiur part (fig.3.3.). Anteriorly, the intersphincteric plane can be developed in order to be able to encircle the perineal part of the rectum. In the lower part of the anal canal, the inferior haemorrhoidal vessels and its branches pass into the external and internal sphincter. At a level higher up in the the anal canal, lateral attachments are very loose and permit easy dissection to the anterior plane. Upward dissection will reveal anterior suspensory ligaments, which attach the rectum to the centrum tendineum perinei. Division of these ligaments will expose the prerectal space.

\subsubsection{Blood supply and lymphatic drainage of the rectum and anal canal.}

Restorative surgery is only possible if the remaining ano-rectal stump is provided with an adequate blood supply. Similarly, the mobillized proximal colon is dependent on adequate blood supply. The rectum and anal canal are supplied by the superior haemorrhoidal artery, which can be considered a terminal branche of the inferior mesenteric artery, by a right and left middle haemorrhoidal artery, originating from the internal iliac artery and by the right and left inferior haemorrhoidal arteries, which originate from the internal pudendal branches of the internal illiac vessels. The superior haemorrhoidal artery supplies approximately $90 \%$ of the entire rectum. In the remaining $10 \%$, a combined supply is present with the middle haemorrhoidal vessels either bilaterally or on one side dominant. At the level three to six $\mathrm{cm}$ above the peritoneal reflection the superior haemorrhoildal divides into two branches, which give off short branches for the upper rectum and then extend downward and end into terminal branches for the haemorrhoidal plexus. The lower part of the sphincter appa- 
ratus is supplied by the inferior haemorrhoidal arteries, which run from Alcock's canal through the ischio-rectal space to the anal canal.

The main colic arteries for the colon and sigmoid are the ileocolic and right and middle colic artery which originate in the superior mesenteric artery and the left colic and sigmoidal arteries, originating in the inferior mesenteric and superior haemorrhoidal artery. On their way to the colon, the arteries bifurcate and the resulting branches unite with corresponding branches of neighbouring vessels to form arcades about two $\mathrm{cm}$ from the mesenteric border of the bowel. The so formed collection of arcades is called marginal artery and runs from the ileocolic artery to the last sigmoidal artery. This marginal artery is capable of replacing the entire blood supply via the inferior mesenteric artery. In bringing down the sigmoid for a colo-anal anastomosis, the sigmoidal main stems may be divided to gain length. Sometimes, the arcades project deep into the mesosigmoid. If bifurcation of the main stem occurs near its origin, then care must be taken not to sever the arcade in the process of mobilization. At the junction of sigmoid and rectum, the marginal artery ends: there is no marginal artery between superior haemorrhoidal and last sigmoidal artery. Sudeck considered this of importance in planning the site for rectal transsection. Necrosis of the colo-rectal stump was in his opinion due to critical circulation in this area. At the present time, Sudeck's thesis regarding a critical point in the circulation of the rectal sigmoid has ceased to be clinically and surgically relevant. Griffiths (1956) has demonstrated abundant small anastomoses between the last sigmoidal and the superior haemorrhoidal artery. The main artery of the rectum is the superior haemorrhoidal, but the contribution of the middle and inferior haemorrhoidal is such, that it is capable of sufficient blood supply to nourrish a distal rectal stump to a point at least eight to ten $\mathrm{cm}$ above the peritoneal reflection. Even after complete division of the lateral ligaments a rectal stump up to just below the peritoneal reflection usually has a good blood supply (Goligher 1980).

The lymphatic vessels and nodes accompany the blood vessels; main drainage occurs along the superior haemorrhoidal artery only in advanced disease. With blocking of this upward route, lateral spread along the middle haemorrhoidal artery is seen (Dukes 1940). Downward spread along the lymphatic plexuses in the anal and perianal skin to the inguinal lymphnodes is very rare and occurs only when the skin of the anal canal or perianal region is involved by growth (Gabriel 1948). Lymphatic plexuses in the pelvis communicate extensively and in case of a blockade of the main lymphatic chain, lymphatic metastases in the pelvis may arise anywhere. According to the TNM classification, local lymphnodes of the rectum and 
anal canal are the pararectal in the meso-rectum and along the superior haemorrhoidal artery. In radical resection this chain has to be considered.

\subsection{The physiology of the ano-rectum.}

\subsubsection{Empirical findings.}

Describing the physiology of the ano-rectum means describing the complex phenomenon of continence. Instead of summing up all physiologic studies which have tried to unravel the different parts of the continence construction, it is also possible to report on what the surgeon has learned empirically about the mechanis of continence.

Looking at the work of Peña (1982) en Devries (1982) is useful to illustrate the value of empirical findings. They developed a landmark technique with the reconstruction of imperforate anus. This congenital vitium is characterized by a rectum ending in a recto-urethral fistula just above the level of the pelvic diafragm. Striated pelvic floor musculature is present also a rudimentary external sphincter body, but an internal sphincter is completely absent. Through a sagittal posterior midline incision, fullest possible exposure of all structures is obtained, while keeping to the midline to avoid damaging the neuro-vascular structures. The incision extends through the sphincteric muscles to the terminal rectum and fistula. The ectopic ending rectum is separated from the urethra with closure of the urethral defect. After mobilisation of the rectum, it is tapered and pulled through up to the perianal skin. The in the midline divided muscle complex is fixed to the tapered rectal segment and reapproximated. Voluntary bowel movements and absence of soiling between defaecations were realized in several patients. Kiesewetter (1967) and Stephens (1971) who have used a pullthrough technique for this condition also proved that formation of an anorectal ring of striated pelvic floor muscles at the junction of the rectum and that the neo-anal canal is capable of providing continence.

Surgery for perianal fistulas has shown that the external and internal sphincter can be divided without jeopardizing continence, as long as the anal rectal ring, formed by the pubo-rectal muscle, is not divided (Hanley 1978, Kuypers 1985)

Another feature of continence is the reservoir function of the rectum. The rectum is capable of storing faecal material and adapts to its increasing volume. In several procedures this function is totally or partly sacrificed. Suzuki (1980) has investigated rectal compliance after low anterior resection. Within six months of operation, rectal compliance was low: imperative urge to defecate after filling of the rectum with $31.3 \mathrm{ml}$ compared with $192.0 \mathrm{ml}$ in controls. Rectal pressures at this filling volume were the same. This resulted in frequent bowel movements because of the urge to evacuate 
with less rectal distension. Compliance of the neo-rectum increases in due course, as was demonstrated by investigating patients more than 6 months postoperatively. Mean rectal distension that elicited an imperative urge to defecate was more than $2^{1 / 2}$ times larger; approximately in the lower range of normal controls.

In low anterior resection, a cuff of distal rectum is preserved. After resection with colo-anal anastomosis, similar findings are reported. Several authors have shown that decreased capacity and compliance of the proximal colon, used for the anastomosis, correlates directly with increased stool frequency (Keighley 1980, Beart 1985, Lazorthes 1986, Schiessel 1986). Keighley (1980) demonstrated a marked reduction in the neo-rectal capacity compared to pre-operative values. $(64 \pm 31 \mathrm{ml}$ versus $268 \pm 24 \mathrm{ml})$. After a period of up to two years frequency decreases to three or four bowel movements per day (Lane 1977, Rudd 1979, Parks 1982, Enker 1985, Schiessel 1986).

After ileo-anal anastomosis, continence mechanism is heavily challenged. The reservoir is lost and the contents are fluid, increasing the demands on the sphincter mechanism. Ravitch (1947) was the first to suture the terminal ileum to the anus after total colectomy in the treatment of ulcerative colitis or polyposis coli. Only in half of his cases satisfactory function with regard to frequency, urgency, continence and perianal soreness was noted. Two surgical advances have led to a satisfactory solution for most of these patients. The first was the construction of an ileal reservoir (Kock 1966), the second, the development of a technique for colo-anal (endo-anal) anastomosis (Parks 1972). This resulted in an operation which combines an ileal pouch that eliminates propulsive activity. and acts as a storage organ with an endo-anal anastomosis to restore intestinal continuity (Parks 1978). Parks (1980) reported acceptable functional results with half the patients capable of voluntary spontaneous evacuation. In a more recent evaluation of Parks patients Nicholls (1984) reported a decline in bowel movements to an average of 3.7. Keighley (1987) addressed himself to another important feature of anal continence: anal sensation after ileo-anal anastomosis. Duthie $(1960,1963)$ recognized an area of anal epithelium of variable length above the anal valves which is associated with organized nerveendings. "This area, known as the anal transition zone, is thought to play an important role in the discrimination of faecal contents. After restorative procto-colectomy in which the anal transition zone was removed, the ability to discriminate was not lost and the risk of impaired continence had not increased (Keighley 1987). This compares with patients in whom this zone was preserved. These findings support the idea of Scharli (1970) that the efferent sensory fibres may be located in the external and the pubo-rectal muscle. 
Interpretation of sphincteric function in patients with neurological disorders has considerably contributed to the knowledge of the neurophysiology of the sphincter function. The anal sphincter shows a high degree of tone; it is normally in a state of permanent contraction, only relaxing in response to rectal distension. The intraluminal pressures recorded from the anal canal are the result of activity of both the internal and external sphincter (Taylor 1984). The greatest contribution is made by the internal sphincter, as evidenced by the high anal pressures recorded in paraplegics with external sphincter paralysis (Burleigh 1968) or in normal subjects with bilateral pudendal block (Frenckner 1976). Wheatley (1977) recorded only half the pressure found in normal subjects in patients with spinal cord lesions, suggesting after all a less prominent role for the internal sphincter in the continence mechanism. The rectal sphincteric relaxation reflex or recto-anal inhibitory reflex is independent of neurological centres higher than the spinal cord, as it can be obtained in patients with the spinal cord transsections (Porter 1962).

\subsubsection{Continence mecbanism.}

Normal continence, the capacity to discriminate between solid, liquid and gas, and to control the passage of this material depends on the interaction of many factors. Empirically, it is known that compensatory mechanisms are capable of replacing loss of function of any factor, except for the musculus pubo-rectalis. The internal and external sphincter maintain a zone of pressure within the anal canal. Division of the external sphincter in the treatment of fistula in ano or sphincterotomy of the internal sphincter for fissura ani causes only minimal functional disability. These observations suggest that internal and external sphincter contractions alone are not the major factors maintaining continence. In case of damage to the pubo-rectal muscle, incontinence is inevitable. The pubo-rectal muscle is responsible for the maintenance of the ano-rectal angle (Hardcastle 1970). Electromyography of the straight muscle of the pelvic floor and external sphincter displays the unusual property of continuous electrical activity, even during sleep (Floyd 1953). Ideopathic incontinence correlates with signs of denervation of the pubo-rectal muscle and hence an obtuse ano-rectal angle was noted (Parks 1977, Beersiek 1979, Neill 1980). Two theories have been advanced to account for the mechanisms whereby an anatomical angulation of the anal rectal junction seems to be so vital to the mechanism for the maintenance of continence. Phillips (1965) postulated that the pubo-rectal muscle creates a slit-like aperture in the pelvic floor for passage of the rectum. This slit-like aperture can be closed as a flutter valve by contraction of the pubo-rectal muscle. This mechanism of forcing the two walls together, is enhanced whenever intra-abdominal pressure is raised. 
Parks (1966) suggested that contractions of the pubo-rectalis create a flapvalve. Intra-abdominal rise in pressure would force the anterior wall of the rectum on to the upper anal canal, thus occluding its lumen. Whether these mechanical explanations are correct is uncertain, but no doubt exists about the necessity for integrity of the pubo-rectal muscle. Reflex contractions of the sphincters are an additional security measure for the maintenance of continence during intra-abdominal pressure rise (Parks 1962).

Reflex mechanisms are important in the regulation of continence and normal defaecation. Some of these reflexes may be autonomous and thus a part of the autonomic nerve system, whereas others may be augmented by voluntary control. Distension of the rectum leads to two measurable reflexes, the relaxation of the internal sphincter and the contraction of the external sphincter, permitting the rectal contents to descend to a level where precise perception of the nature of rectal contents is possible. According to Duthie (1963), sensory receptors are situated in the transitional zone of the rectum. Recent findings after removal of this transitional zone, cast doubt on the dominant role of these sensors, and sensors in the levator-puborectalis-external sphincter complex are postulated (Keighley 1987). The same discussion exists about the location of the stretch receptors that initiate the recto-anal inhibitory reflex. After complete rectal resection with colo-anal anastomosis this reflex is preserved (Lane 1976). Distension of the rectum leads to a decrease of pressure by the internal sphincter. In an autonomous reflex, but also voluntarily, the external sphincters can be made to contract to prevent leakage. The rectum will adapt to its increased volume and the inhibitory reflex is abolished, leading to an increase in pressure by the internal sphincter. If stimuli from the sensor mechanism are urgent, then voluntary contraction of the external sphincter and pubo-rectal muscles is imposed by the individual at regular intervals, until it is convenient to defecate. Controlled defaecation requires some form of reservoir that prevents continuous or repeated exposure of contents to the sensory area. This is an important function of the rectum or (neo-rectum) after restorative resection. The reservoir adapts to volume before eliciting reflexes through the stretch sensors. The importance of rectal compliance as a factor in reservoir continence has already been discussed.

\subsubsection{Conclusion.}

Continence is largely dependent on the integrity of the pubo-rectal muscle. A sensory deficit or damage to the internal or external sphincter results in only a minor degree of incontinence. The internal sphincter maintains the closed anal canal and probably prevents inadvertent passage of flatus, liquid stool and mucous and can be considered important to the fine tuning 
in continence. The external sphincter may preserve continence by vigorous contractions in situations when normal mechanisms are severely challenged.

Restorative surgery has led to a deeper insight in normal mechanisms of continence. Knowledge of the important structures for preserving continence may guide surgical strategies and may help to interpret the disturbances in continence postoperatively. 


\section{References chapter 3 :}

Beersiek $\mathrm{F}$, Parks $A G$. Swash $M$ : Pathogenesis of ano-rectal incontinence. J.Neurol.Sc. $42 ; 111-127,1979$.

Blok De S.: Spatial architecture of musculo-fibrous tissue in the female pelvic region.

Thesis, Amsterdam, 1982.

Burleigh DE. D'Mello A., Parks AG.: Responses of isolated human internal anal sphincter to drugs and electrical field stimulation.

Gastroenterology $77,484-490,1979$.

Courtney $\mathrm{H}_{\text {. }}$ : Anatomy of the pelvic diaphragm and anorectal musculature as related to sphincter preservation in anorectal surgery.

Am.J.Surg. 79;155, 1950.

Crapp AR., Cuthbertson AM.: William Waldeyer and the recto-sacral fascia.

Surgery Gynecol. Obstet. 138;252, 1974.

Devries PA., Peña A.: Posterior sagittal anorectoplasty.

J.Pediatr.Surg. 17;638-643, 1982.

Drake DB., Pemberton Jh., Beart RW., Dozois RR., Wolff BG.: Coloanal anastomosis in the management of benign and malignant rectal disease.

Ann.Surg. 206;600-605, 1987:

Duthie HL., Bennett RC.: The relation of sensation in the anal canal to the functional anal sphincter; a possible factor in anal incontinence.

Gut $4 ; 179-182,1963$.

Duthie HL. Watts JM: Contribution of the external anal sphincter to the pressure zone in the anal canal.

Gut $6,64-68,1965$.

Duthie HL: Progress report: anal incontinence.

Gut $12 ; 844-852,1971$.

Enker ME., Stearns MW., Janov AL.: Peranal coloanal anastomosis following low anterior resection for rectal carcinoma.

Dis. Colon Rectum 28;575-581, 1985.

Floyd WF, Walls EW.: Electromyography of the sphincter ani externus in man. J.Physiol. 122;599-609, 1953.

Frenckner B., Euler CV.: Infuence of pudendal block on the function of the anal sphincters.

Gut 16;482-489, 1975. 
Frenckner B.: Function of the anal sphincters in spinal man.

Gut $16,638-644,1975$.

Frenckner B., Ihre T.: Influence of autonomic nerves on the internal anal sphincter in man.

Gut 17;306-312, 1976

Goligher JC.: The adequacy of the marginal blood-supply to the left colon after high ligation of the inferior mesenteric artery during excision of the recum.

Br.J.Surg. 41;351, 1954.

Goligher JC.: Surgery of the anus rectum and colon.

Ed.4, Bailliere Tindall, London, 1980.

Griffiths JD.: Surgical anatomy of the blood supply of the distal collon.

Ann.R.Coll.Surg.Engl. 19;241, 1956.

Grinnell RS.: Lymphatic block with atypical and retrograde lymphatic metatasis and spread in carcinoma of the colon and rectum.

Ann.Surg. 163;272-280, 1966.

Hanley PH.: Rubber band seton in the management of abscess-anal fistula.

Ann.Surg. 187;453, 1978.

Hardcastle JD., Parks AG.: A study of anal incontinence and some principles of surgical treatment.

Proc.Roy.Soc.Med. 63;s116-118, 1970.

Keighley MRB., Winslet MC., Yoshioka K., Lightwood R.: Discrimination is not impaired by excision of the anal transition zone after restorative proctocolectomy.

Br.J Surg. 74;1118-1121, 1987.

Kiesewetter WB., Nixon HH.: Imperforate anus. Its surgical anatomy.

J.Pediatr.Surg. 2;60-68, 1967.

Kock NG.: Intra-abdominal 'resevoir'in patients with permanent ileostomy.

Arch.Surg. 99;223-231, 1966.

Kuijpers JHC., Schulpen T., Buyck B.: De seton-methode voor de behandeling van de buiten de sphincter gelegen perianale fistel.

Ned.Tijdschr.v.Geneesk. 129;945-947, 1985.

Lane RHS., Parks AG.: Function of the anal sphincters following colo-anal anastomosis.

Br.J.Surg. 64:596-599, 1976.

McVay CB:: In: Anson \& McVay Surgical Anatomy.

6 ed, W.B.Saunders Company, Philadelphia, 1984. 
Milligan ETC: The surgical anatomy and disorders of the perianal space.

Proc.R.Soc.Med. 36;365, 1943.

Morgan CN. Thompson HR. Surgical amatomy of the anal canal, with special reference to the surgical importance of the internal sphincter and conjoint longitudinall muscle.

Ann.R.Coll.Surg. Engl. 19;80, 1956.

Neill ME., Parks AG., Swash M.: Physiological studies of the anal sphincter musculature in faecal incontinence and rectal prolapse.

Br.J.Surg. 68;531-534, 1981 .

Nicholls J., Pescatori M., Motson RW.: Restorative proctocolectomy with a three-loop ileall reservoir for ulcerative colitis and familial adenomatous polyposis.

Ann.Surg. 199;383-388, 1984.

Nicholls RJ., Lubowski DZ, Donaldson DR. Comparison of colonic reservoir and straight colo-anal reconstruction after rectal excision.

Br.J.Surg. 75;318-320, 1988.

Oh C., Kark AE. Anatomy of the external anal sphincter.

Br.J.Surg. 59;717, 1972 .

Parks AG., Porter NH., Hardcastle JD.: The syndrome of the descending perineum.

Proc.Roy.Soc.Med. 59; $477-482,1966$.

Parks AG.: Transanal techniciue in low rectal anastomosis.

Proc.Roy.Soc.Med. 65;975-976. 1972.

Parks $\mathrm{AG}_{\text {. }}$ : Anorectal incontinence.

Proc.R.Soc.Med. 68;681-690, 1975.

Parks $\mathrm{AG}_{\text {. }}$ Stitz $\mathrm{RW}:$ Treatment of high fistula in ano.

Dis.Colon Rectum 19;487, 1976.

Parks AG., Gordon PH., Hardcastle JD.: A classification of fistula in ano. Br.J.Surg. $63 ; 1,1976$.

Parks AG., Swash M., Urich $\mathbb{H}$.: Spincter denervation in anorectal incontinence and rectal prolapse.

Gut $18 ; 656-665,1977$.

Parks AG., Nicholls RJ.: Proctocolectomy without ileostomy for ulcerative colitis.

Br.MedJ. 2;85-88, 1978.

Parks AG., Nicholls RJ., Belliveau P.: Proctocolectomy with ileal reservoir and anal anastomosis.

Br.J.Surg. $67,533-538,1980$. 
Parks AG., Percy JP.: Resection and sutured colo-anall amastomosis for rectal carcinoma.

Br.J.Surg. 69;301-304, 1982.

Peña A., Devries PA.: Posterior sagittal anorectoplasty; important technical consideration and new applications.

J.Pediatr.Surg. $17 ; 796-811,1982$.

Phillips SF, Edwards DAW: Some aspects of anal continence and defaecation. Gut 6;396-405, 1965.

Ravitch MM.: Anal ileostomy with sphincter presevation in patients requiring total colectomy for benign conditions.

Surgery $24 ; 170-187,1947$.

Rudd WWH.: The transanal anastomosis: A sphincter-saving operation with im= proved continence.

Dis. Colon Rectum 22;102-105, 1979.

Scharli AF, Kieswetter WD.: Defaecation and continence: some new concepts.

Dis.Colon Rectum 13;81-107, 1970.

Schiessel $R_{\text {, }}$ Wunderlich $M$., Waneck R.: Ergebnisse der coloanalen Anastomose bei tiefsitzenden Tumoren des Rectums.

Chirurg $57 ; 792-796,1986$.

Schuster MM.: The riddle of the sphincters.

Gastroenterology $69 ; 249-262,1975$.

Shafik A.: Anatomy of the perianal spaces.

Investigative Urology 13;414, 1976.

Silver PHS.: The role of the peritoneum in the formation of the septum rectovesicale.

J.Anat. $90,538,1956$.

Stelzner F.: Vermeidliche und unvermeidliche Folgen nach anorektaten Eingriffen.

Langenbecks Arch.Klin.Chir. 298;120, 1961

Stelzner F: Uber Potenzstoerungen nach Amputationen und Kontinenzresektion des Rektums.

Zbl.Chir. 102;212 1977.

Stelzner F.: In v.Lanz W/achsmuth: Praktische Anatomie -Becken-

Zweiter Band.Teil 8A, Springer Verlag, Heidelberg, 1984.

Stephens FD, Smith ED.: Anorectal malformations in children.

Chicago, Year Book Medical Publishers, 1971. 
Chapter 3

Suzuki H., Matsumoto $K_{\text {, Amano }}$, Honzumi M: Anorectal pressure and rectal compliance after low anterior resection.

Br.Jisurg. 67,655-657, 1980 .

Taylor BM., Beart RW, Phillips SF: Longitudinal and radial variations of pressure in the human anal sphincter.

Gastroenterology $86 ; 693-697,1984$.

Tobin $C_{\text {, }}$, Benjamin JA. Anatomical and surgical restudy of Denonvilliers ${ }^{1}$ fascia. Surg.Gynecol.Obstet: $80 ; 373,1945$.

Wheatley IC, Hardy KJ, Dent J.: Anal pressure studies in spinal patients.

Gut 18,488-490. 1977 . 


\section{Chapter 4}

\section{The preoperative requirements for selection of patients with low rectal cancer.}

\subsection{Introduction.}

Surgical preparation of patients with a rectal tumor begins with an accurate assessment of tumor related factors. After proper matching of these factors with the patient related factors: physical constitution, operative risk, expected postoperative functional results with regard to continence. A decision can be made on what constitutes the optimal surgical therapy. The risk factors that increase the incidence of postoperative complications are routinely identified and eliminated as far as possible.

Preoperatively, consideration should to be given to the possibilities of adjuvant therapy. Some views on the up to date state of adjuvant therapy will be given in the last paragraph of this chapter.

\subsection{Preoperative staging of rectal cancer.}

The choice of operation for rectal cancer and the decision to use adjuvant radiotherapy before or instead of surgery must be made on the basis of preoperative staging.

Many staging systems are widely used. The original Dukes' classification has been modified several times, but the eponym "Dukes' classification" has often been maintained regardless of the actual system used. Recently, Williams (1988) stressed the need for a detailed clinico-pathological assessment which describes all of the known prognostic determinants. Then, high risk patients, which may be eligible for adjuvant therapy, can be identified. Similarly, a surgeon may decide not to perform a restorative resection with colo-anal anastomosis because of an unacceptable risk of local recurrence. On the other hand, favourable tumors may have a local procedure without jeopardizing the chance of a cure.

Originally, the Dukes' classification and also the widely used Astler-Coller modification, emphasized the importance of depth of bowel wall penetration and the presence of lymphnode metastases (Dukes 1932, Astler 1954, Dukes 1958). Since then, several authors have stressed to beware of possible tumor spread beyond the bowel wall. Wood noted "that if extramural spread was absent, both patients with or without lymphnode metastasis survived. As a result of his findings, he proposed a staging 
system that is not based on the presence or absence of local tumor penetration and lymphnodes, but on the extent of local tumor penetration (Wood 1981). Habib (1984) and Wolmark (1986) confirmed these findings, but the latter added the prognostic significance of the number of positive lymphnodes to each tumor infiltration level.

Pathology studies have demonstrated the correlation of histological grade and prognosis. On one side of the scale are tumors with a favourable prognosis which are characterized by their being small, having an exophytic type of growth and being moderately well differentiated. On the other side are the tumors characterized by their being very big -more than 4 centimeters-showing an ulcerated type of growth and being poorly differentiated or being of a coloid type (Morson 1968, 1977, Cohen 1980). The important staging systems are based on the pathological findings in the resected specimen. Relation of the tumor to the bowell wall, tumor spread beyond the bowel wall, presence and number of pathological lymphnodes and histological grade, correlate well with survival and/or recurrence rate. The preoperative clinical staging should provide information which closely matches the postoperative pathology staging. An optimal choice of therapy can only be made after a thorough clinical staging. Rectal digital examination, endoscopy with the rigid rectoscope and imaging techniques such as, computed tomography and/or endorectal ultrasound are the tools for adequate clinical staging.

The whole organ should be examined, meaning coloscopy or at least double contrast barium enema, in order to rule out synchronous malignant lesions or polyps.

The choice of therapy may also be influenced by the presence of distant metastases. Routinely, sonography of the liver and screening of the lungs for metastases by X-ray should be performed.

\subsubsection{Rectal digital examination.}

Several features of the tumor can be assessed. Morphology, exophytic or ulcerated growth and the number of quadrants involved can be determined. Distance to the anal verge and longitudinal length of the growth can be explored. The degree of fixation to the bowel wall, the extent of extrarectal spread, the presence of involvement of extrarectal structures and the presence of palpable pararectall lymphnodes are estimated.

Inaccessibility of the upper border prevents optimal staging. The interpretation of the examination is subjective and the reliability of the assessment depends on the experience of the investigator. Despite these limitations York Mason, some years later, in collaboration with Nicholls, proposed a clinical staging system based on digital examination findings 
(York Mason 1976, Nicholls 1982). The original classification, based solely on bowel wall infiltration, was not of enough clinical relevance. Combination with other digital findings allowed staging in four clinical groups, which corresponded to different survival and local recurrence rates.

A stage 1 tumor may be recognized by complete mobility and absence of extrarectal growth, particularly when, in addition, ulceration is absent or shallow.

A stage 2 tumor is suggested by mobility with one or two quadrants involved and the absence of palpable extra rectal growth.

A stage 3 tumor is indicated by marked reduction of mobility with involvement of three or more quadrants and palpable extra rectal growth.

A stage 4 tumor is not mobile, possibly fixed to other pelvic organs.

This staging system may facilitate the decision between restorative resection and total rectal excision for low rectal tumors. In selected patients, stage 1 tumor could be treated locally. Nicholls found that fixation of rectal carcinoma was an important prognostic indicator. This is in support of the pathology studies of Wood (1981), Habib (1984), Wolmark (1986) as has been mentioned before. Nevertheless, fixation may be a result of an inflammatory reaction around a rectal tumor. Durdey (1984) reported an incidence of inflammatory fixation of $26 \%$ of all fixed tumors. Fixation by malignant infiltration was a most important prognostic indicator. In contrast, prognosis in patients with fixation due to the inflammatory reaction was comparable to those who had mobile tumors. Bonfanti (1982) also found a significant percentage of inflammatory fixation which did not influence prognosis.

As yet, no method can accurately differentiate between tumors fixed by inflammation or neoplastic infiltration.

Overstaging due to inflamation may occur, but a more serious error is understaging. Stage 1 tumors may be eligible for local excision. Morson pointed out in several publications $(1966,1977)$ that the chance of cancer cure is not prejudiced in patients with well of moderately well differentiated tumors. This in contrast to patients with anaplastic tumors, who are liable to lymphnode metastasis. Exact histological staging is only possible after complete full. thickness biopsy. Local excisions should be performed in such way, that adequate pathological examination of the specimen is possible. If the final examination reveals an anaplastic tumor further therapy should be contemplated (Morson 1977, Hager 1983, Stearns 1984).

Despite its limitations, digital examination is the first step in clinical staging for rectal cancer. 

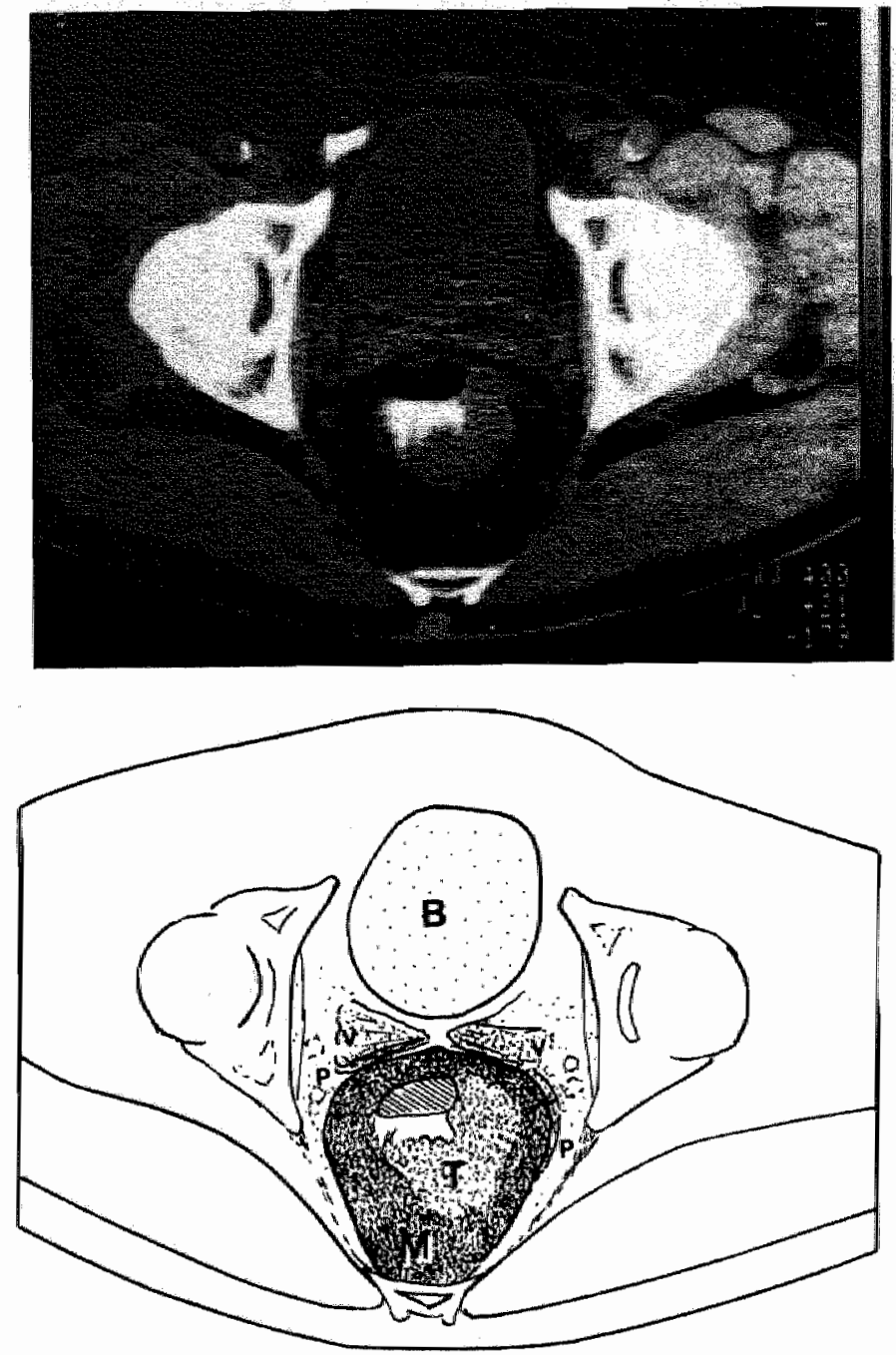

Fig. 4.1a-b. CT-scan of a rectal tumor. In cases of advanced tumor growth, CT provides objective information about both infiltration into the perirectal fat, staining dark on $\mathrm{CT}$, and the relation of tumor spread to the perirectal fascia, which borders the dark area and, normally, cannot be identified. In this patient the tumor is well confined within the perirectal fatty tissue. The border between the mesorectum and the pararectal connective tissue is sharp, suggesting good operability.

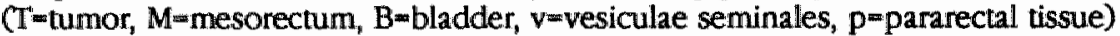




\subsubsection{Rigid endoscopy and bistologic grading.}

Rigid endoscopy enables verification of the exact distance of the rectal tumor to the anal verge and the extension over the different quadrants. Exophytic lesions can be differentiated from ulcerative ones. Representative biopsies can be taken. The value of preoperative histologic grading, versus final histological grading of the resected specimen, is very limited. Williams (1985) found a sensitivity of $38 \%$ in identifying poorly differentiated tumors. Even after multiple biopsies, including biopsies with a true cut needle, only three pathologists were able to reach overall agreement on $40 \%$ of the poorly differentiated tumors. Discrepancy between biopsy, resected specimen and intra-observer variation make preoperative histologic grading an unreliable determinant for therapy choice.

\subsubsection{Imaging techniques.}

For the staging of rectal cancer double contrast barium enema is of little value as it provides only an indirect image of the endoluminal tumor aspect, which also can be judged directly by endoscopy, while no information is provided about the invasiveness (Fork, 1983).

\subsubsection{Computed tomograpby.}

Using pelvic computed tomography, all rectal tumors can be visualized (Thoeni 1981,Dixon 1981, Williams 1985). It is tempting to regard the CTimage as a transverse anatomical slice through the tumor. However, CIscan is unable to differentiate between the separate layers of the bowel wall. The staging criteria for tumors not infiltrating the muscularis propria or for tumors infiltrating the muscularis propria but not beyond, are indirect ones: stage 1 tumor: confirmed to the bowel lumen and stage 2: only thickened bowel $>0.5 \mathrm{~cm}$ visible. Invasion beyond the rectal wall can be differentiated as stage $3 a$ : thickening of the bowel wall and invasion of the adjacent tissue, and stage 3b: extension to the pelvic wall. Stage 4 is reserved for tumors with distant metastases (Dixon 1981). Visualization of lymphnodes is possible even of small ones, but differentiation between malignant and reactive large lymphnodes is not possible.

Several authors have reported a high accuracy in predicting local malignant extension beyond the bowel wall (Grabbe 1981, Nicholls 1982, Williams 1985, Romano 1985, Beynon 1986). For the planning of a therapeutic strategy it is very important to have insight in the relation between perirectal infiltration and the perirectal fascia (fig.4.1.). The perirectal fascia constitutes an important obstacle to tumor invasion into the pararectal 
connective tissue. Grabbe (1981) demonstrated that, normally, the perirectal fascia cannot be detected because of limited spatial resolution. Pathological changes in the perirectal fat such as tumor infiltration, inflammation or postradiation effects, cause perirectal fascia thickening. The relation of the tumor to the fascia is important. A fixed tumor may become resectable after irradiation if the fascia is not penetrated. On the other hand, if a tumor has grown beyond the fascia, it will likely be incurable.

Cr-scanning is a valuable tool in mapping the spatial orientation of a rectal cancer. Accurate assessment of local spread is possible especially in advanced fixed growth, and this may be helpful in monitoring the effects of adjuvant therapy, like preoperative radiotherapy. Williams (1985) claims, that the $\mathrm{CT}$-scan can make a distinction between malignant or inflammatory fixation. The clinical relevance of computed tomography in the staging of mobile tumors is limited. In the latter group of tumors, the infiltration depth in relation to the separate layers of the bowel wall is more important in the decision making.

\subsubsection{Endorectal ultrasonography.}

Endorectal ultrasonography is a relatively new technique which enables visualization of all layers of the rectal wall. Many authors have reported that endosonographic infiltration depth staging correlates well with histologic staging of the resected specimen. This technique seems to be the first to provide the possibility of staging infiltration depths of rectal cancer, comparable to histological staging. Although endosonography is the imaging method to show layers inside the rectal wall, it is not agreed among different investigators how the exact anatomical interpretation of the sonogram should be. It seems strange that all authors claim a correct staging in over $90 \%$ of cases. The discussion over the interpretation is focused on the question wether the hyperechogenic bands represent acoustic interfaces between separate layers or wether they represent real anatomical structures, or even a combination of both. Rifkin (1985) describes two layers: one internal, which is hyperechogenic (condome and mucosa); and one external, which is hypo-echogenic (submucosa and muscularis propria). Hildebrandt and Pfeiffel (1985) and Boscaini (1986) describe five layers: a first hyperechogenic interface between the water inside the condome and the condome itself, a second hypogenic mucosa and submucosa, a third hyperechogenic interface between submucosa and muscularis propria, a fourth hyperechogenic layer representing the muscularis propria and, lastly, a hyperechogenic interface between muscularis propria and perirectal fat. According to Beynon (1986), the three hyperechogenic bands should be interpreted respectively: mucosa, submucosa and peri- 
rectal fat. Saitoh (1986) and Candio (1987) discern a fourth hyperechogenic interface between the inner and outer layer of the muscularis propria. Candio believes that the second hyperechogenic layer is determined both by interface and submucosal tissue. He observed that, in cases with marked thickening of the mucosa, i.e. postradiation or inflammatory effect, the second hyperechogenic layer is also thickened. All authors agree on identifying the muscularis propria as a hypoechogenic layer.

The author has conducted a comparative study to investigate the question on wether or not these different opinions influence the clinical interpretation of the sonographic image (Rutten 1989 in press).

Method:

Patients were prepared and positioned as for a rectoscopy. First, a digital palpation was carried out. A visual assessment of the tumor was obtained by a rigid rectoscopy. The endorectal ultrasound investigation was performed from the cranial to anal direction. If the tumor was seated in the middle or upper third of the rectum, the endoprobe was introduced through the rectoscope to obtain a good image of the healthy bowel proximal of the tumor, then the distal tumor was scanned. The endoprobe used, mounted a $7.0 \mathrm{MHZ}, 360^{\circ}$ rotating transversally scanning transducer (Type 1850 Brüel and Kjäer Kopenhagen). The transducer rotated in a waterfilled condome which, after filling, assured good acoustic contact with the bowel wall. Although a $360^{\circ}$ real time image is produced, the interpretation of the bowel wall can only be optimal if the acoustic wave hits the bowel at a right angle. The investigator has to manipulate the endoprobe to obtain an optimal sonogram of all the quadrants. After the surgical procedure, an in vitro sonogram was made of the specimen. The microscopic slice was then compared with the in vivo and in vitro sonogram.

Results.

30 Patients and their specimens were available for the comparative study. According to the following criteria it was possible to correlate sonographic staging with histologic staging:

Villous adenoma: apparently a sharp hypoechogenic band borders a villous adenoma (fig.4.2.).

T1 tumor: a T1 tumor seems to have a hypo-echogenic margin, representing the muscularis propria. The in vivo specimen of a T1 tumor is shown in figure 4.3 .

T2 tumor: differentiation between $\mathrm{T} 1$ and $\mathrm{T} 2$ tumors may be difficult. The hypo-echogenic border is present all around the tumor, perhaps maybe less conspicuous than in T1 tumors. Also, as a result of the disappearance of the interface between submucosa and muscularis propria, due to infiltration of 

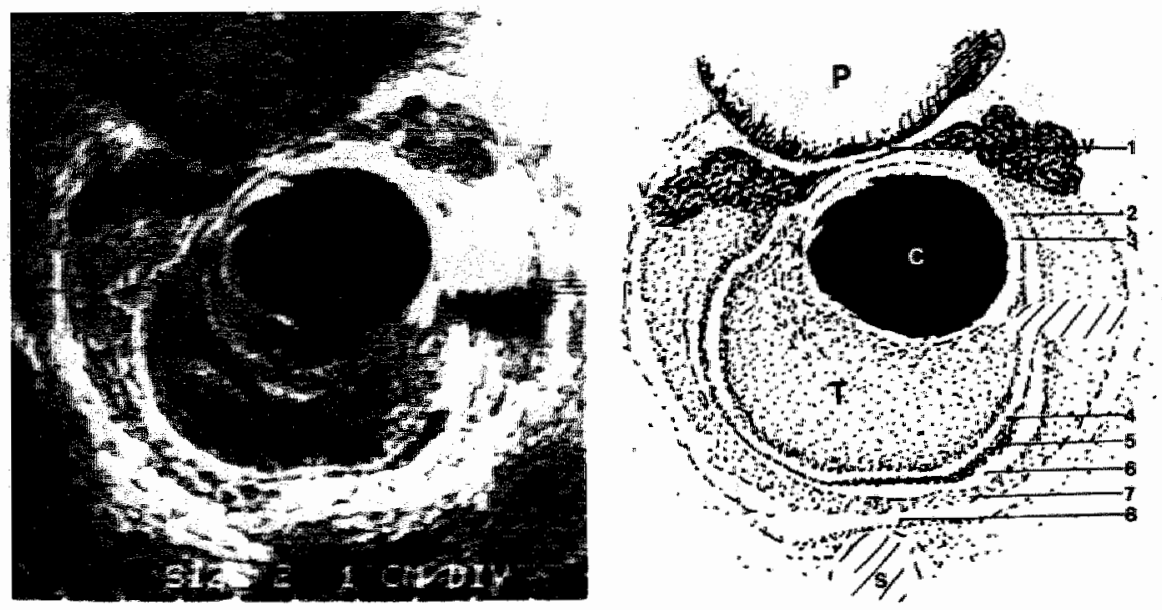

Flg. 4.2a-b. Endosonogram of villous adenoma. ( $T=T u m o r, ~ P=p r o s t a t e$, $c$-waterfilled condome, $v$-vesiculae seminales, $s=$ acoustic shadow caused by os coccygis, 1 -Denonvilliers' fascia, 2-muscularis mucosae, 3-interface watercondome, 4-interface submucosa-muscularis propria, 5 -muscularis proria, $6=$ interface muscularis propria-perirectal fat, 7 -mesorectum, 8 =interface mesorectum-fascia recti)
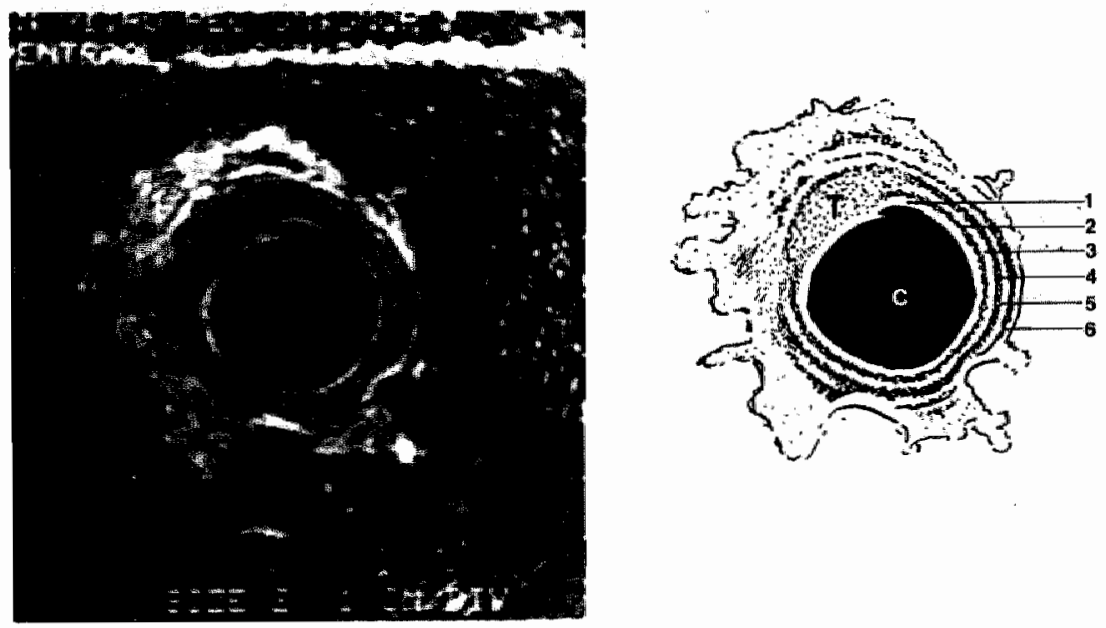

Fig. 4.3a-b. In vitro endosonogram of $\mathrm{T} 1$ tumor. (1-interface water-condome, 2-muscularis mucosae, 3-interface submucosa-muscularis propria, 4-circular layer muscularis propria, 5 -interface circular-longitudinal layer muscularis propria, 6-longitudinal layer muscularis propria) 

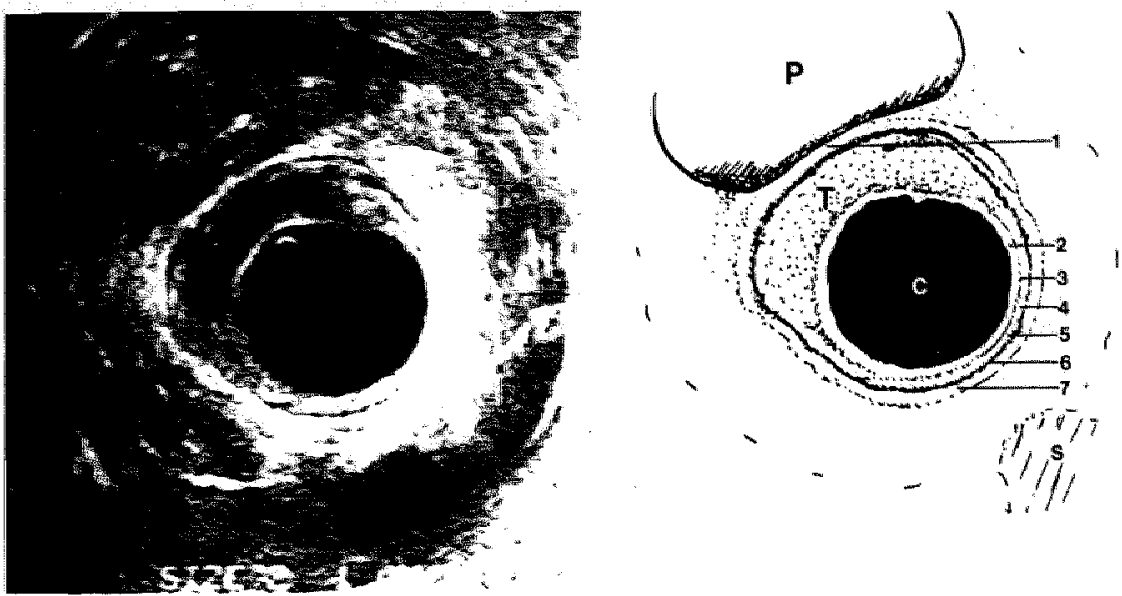

Fig. 4.4a-b Endosonogram of $T 2$ tumor ( $1=$ Denonvilliers' fascia, $2=$ interface water-condome, 3=muscularis mucosae, 4 minuerface submucosa-muscularis propria $6=$ muscularis propria, 7 =interface muscularis propria-perirectal fat)
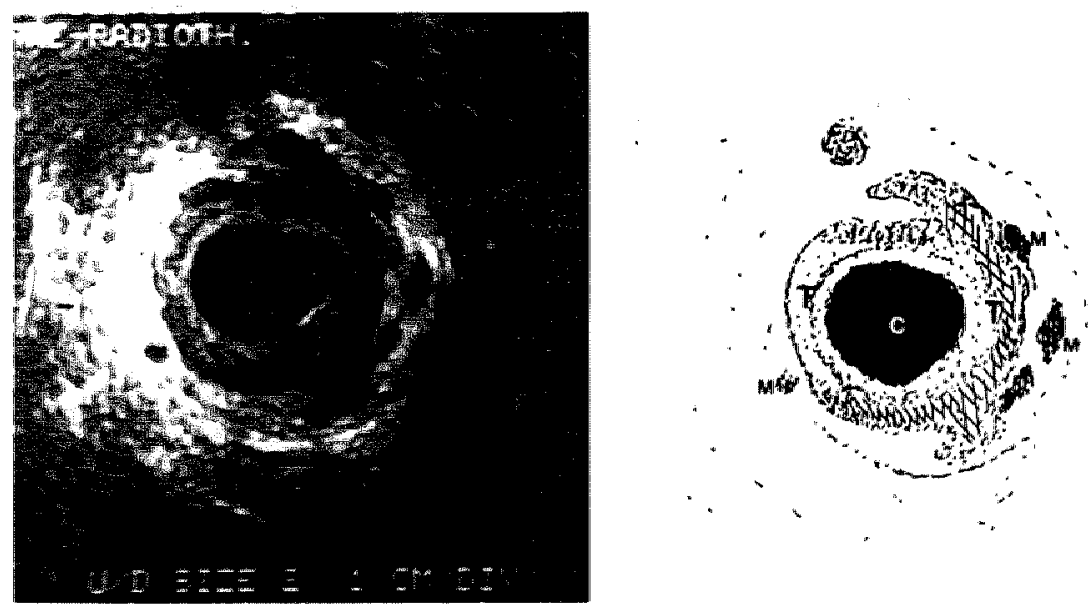

Fig. 4.5a-b Endosonogram of T3 tumor. (mmetastases)

the muscularis propria, the second hyper-echogenic ring is broken at the level of the tumor. In the hypoechogenic ring, which represents the muscularis propria, the interface between the inner circular and outer longitudinal muscle layer is disappeared. Figure 4.4. shows an in vivo sonogram of a T2 tumor. 
T3 tumor: T3 tumors are easy to identify, because of totall loss of the architecture of the echogenic rings. Digit-like irregular infiltration into the perirectal tissue can be observed. Satellite tumors or metastases in the perirectal fat can be distinguished in figure 4.5. Relation of the tumor to the male genital organs (prostate, seminal vescicles) and female genital organs (vaginal septum, uterus) can be studied. The fascia prostato-perinealis in men and the fascia peritoneo-vaginalis in women produce a conspicuous hyper-echogenic interface between the (peri)-recto and genital compartment. If these fascia are present as hyper-echogenic structures, tumor penetration is unlikely to have occurred beyond them.

Endorectal ultrasound is a reliable technique in the evaluation of local invasion of rectal cancer. Interpretation is optimal when combined with palpation and endoscopy. Even in tumors which are out of reach of the investigator's finger, reliable information can be obtained, provided the endoscope is used to introduce the endoprobe, to ascertain start of the scanning proximal to the tumor. Fixed and stenosed tumors are more difficult to evaluate, because of problems with passing the tumor or inflating the condome, which could prevent free movement of the transducer. Inflammatory reaction is also difficult to differentiate from tumor infiltration by endosonography.

Information about spacial orientation and local invasiveness of rectal tumors is considered to be of utmost importance in the planning of a therapeutic strategy. Many publications have tried to demonstrate superiority of one staging technique over the other. Nicholls (1985) has stressed that different staging techniques are complementary. From a surgeon's point of view, digital palpation provides information on the geographical characteristics of a tumor and helps to decide between an abdomino-perineal resection or a restorative resection. Local treatment of early rectal carcinoma is gaining interest. Unfortunately, many local therapies destroy the specimen (endocavitary irradiation, fulguration, laser therapy, cryotherapy). For comparative studies of selection criteria and of failure patterns, objective pre-therapeutical grading of invasion depth is necessary. Endorectal ultrasound can provide reliable information about small rectal cancers. CTscanning can determine the extent of extrarectal spread, and enables differentiation between incurable pararectal infiltration and limited penetration. In the latter case, adjuvant therapy (external beam irradiation) may turn an inoperable tumor into an operable one. In advanced growth $C T$ is able to monitor the effect of adjuvant therapy.

A differentiated therapeutic approach of rectal cancer is only possible after tumor specific grading. 


\subsection{Preoperative preparation with reference to general risk factors and measures to prevent complications.}

\subsubsection{Introduction.}

The risks associated with major surgical procedures should be in proportion to the aim of the proposed procedure. The careful preoperative evaluation of the risk factors may lead to modification, or even to cancellation, of the surgical procedure.

Cardiopulmonary problems are closely related to the development of postoperative life threatening or fatall complications. Goldman (1977) identified the most important cardiac risk factors which can easily be checked preoperatively: congestive heartfailure, recent myocardial infarction, rhythm disturbances, aortic stenosis and a poor general condition, as assessed by metabolic parameters such as, arterial blood gas, electrolytes and kidney parameters. Age over 70 is related to a 10-fold increased risk of perioperative cardiac death. Patients with class four or accelerating angina, carry a risk similar to that of a recent myocardial infarction (Goldman 1983). Bartlett (1980) studied the pulmonary risk factors that lead to postoperative pulmonary dysfunction: congestive heartdisease, extreme obesity, heavy smoking, advanced age and, last but not least, chronic pulmonary disease. Patients with these risk factors must have their respiratory deficits quantified and optimized preoperatively. Perioperatively, pulmonary physiotherapy should focus on regular maximal lung inflation to prevent atelectasis. Postoperative pulmonary risk factors include, ventricular failure with or without gross fluid overload, or decreased oncotic pressure as a result of an unbalanced nutritional status or excessive peroperative protein loss, which may cause pulmonary edema.

Following severe surgical trauma, patients usually lack the physiological mechanisms to adjust to a lowered calory intake. Considerable nitrogen loss results in a further disturbance of the patient's homeostasis. This condition may persist for weeks after the surgical intervention and should be regarded as a metabolic reaction to the inflicted trauma, rather then an expression of the preoperative nutritional status. Preoperatively, an abnormal nutritional condition may exist as a result of the underlying disease, and increase the patient's incapability to react adequately to intrusions postoperatively (Soeters 1987).

Most patients presenting with rectal carcinoma are in a good nutritional state and will not require specialized preoperative nutritional support. Incidently, patients with rectal carcinoma are malnourished. The complication rate in such patients may be 20 -fold. Correction of the concommitant disease, or of the nutritional deficit itself, should be the first step in the surgical treatment (Starker 1986). 
Another general risk factor is the chance of thrombo-embolic events. Prophylactic measures against pulmonary thrombo-embolism firstly consist of the identification of high ristk patients, i.e. patients who have a positive history of thrombo-embolic events, and the treatment of these patients with coumarine, and secondly, routine measures such as heparin 5000 IU s.c. twice daily, early mobilisation, and elastic stockings in patients with venous stasis.

Risk factors and prophylactic measures related to postoperative infectious complications will be discussed in more detail in the following paragraphs.

\subsubsection{Bowel preparation and antimicrabial propbylaxis.}

\subsubsection{Introduction.}

Infection counts for the majority of all complications and a great number of deaths after rectal resection (Whittaker 1976, Lockhart Mummery 1976, Hughes 1980, Williams 1987). Anastomotic dehiscence causes most infectious sequelae: intra-abdominal absces, peritonitis and/or sepsis (Irvin 1973, Fielding 1980). Wound infections are relatively common and have great economic concequences as hospitalization and healing process are prolonged. Wound infections are relatively easy to manage and rarely cause a serious clinical problem. Anastomotic dehiscence after colo-anal anastomosis occurs in 25 to $50 \%$ of all operated patients and constitutes a formidable clinical problem (Hautefeuille 1987). Several factors contribute to the risk of infectious complications. Weidema and v.d.Bogaart reviewed the literature on these factors (Weidema 1984). Old age, malnutrition, deficient immune status (i.e.use of steroids), malignant disease, obesity and diabetes mellitus are associated with an increased susceptibility to infection. Chance of colonisation with established hospital flora correlates with duration of preoperative hospitalization. Length of operation, blood loss, faecal spilling and the use of open drains instead of active suction drains are related to an increase in postoperative infectious complications. Anastomotic dehiscence is also dependent on technical factors: the intestine should be healthy, well vascularized, there should be no tension at the site of the suture. Clots of necrotic tissue and fluid collections are a a readily available nutrient for a bacterial inoculum. Inadequate preoperative mechanical cleansing of the bowel is a very significant factor in the etiology of anastomotic disruption (Irvin 1973).

With respect to the prevention of septic complications after elective surgery, three aspects are important: the operative technique (see above), adequate preoperative mechanical cleansing of the bowel and the use of prophylactic antibiotics. 


\subsubsection{Preoperative mechanical cleansing.}

Conventional mechanical cleansing of the large bowel consists of a three to five day regimen on a low or non-residue diet, purgatives and enemas. With this regimen, the faecal content can be reduced. It is a timeconsuming procedure. Furthermore, the patient will be malnourished and may even reach a catabolic state at the time of operation. A superior method was reported by Hewitt (Hewitt 1973): whole gut irrigation. Whole gut irrigation is carried out on the day prior to the operation and no dietary restrictions are placed upon the patient. Via a nasogastric tube, an irrigation fluid is introduced into the patient with a constant rate of 30 to $75 \mathrm{ml} / \mathrm{min}$. The irrigation is continued till the rectal effluent is completely clear. Usually, twelve to fifteen litres are needed. Prophylactically, ten milligram of metoclopramide intramusculary is administered to prevent nausea. Absolute contraindications are: obstruction, perforation and toxic megacolon. Relative contraindications are: congestive heartfailure or renal insufficiency. In such cases, 40 milligram of furosemide should be added. The irrigation fluid is isotonic and is composed of $\mathrm{NaCl} 6.14 \mathrm{~g} / 1, \mathrm{KCl} 0.75$ $\mathrm{g} / \mathrm{l}, \mathrm{NaHCO}_{3} 2.94 \mathrm{~g} / \mathrm{l}$ water. There may be some absorption of fluid and salt from the intestinal lumen into the circulation. Weidema and v.d.Boogaard recorded a mean bodyweight gain of $2.0 \mathrm{~kg}$, partly the result of an increase in plasma volume and partly the result of residual intestinal fluid. In most patients the bodyweight gain is lost within one day due to increased diuresis (Kujat 1981, Weidema 1984). Whole gut irrigation is superior to conventional bowel preparation in removing faeces from the colon and reducing resident colon flora. However, whole gut irrigation without concomitant administration of antimicrobial drugs is associated with an increased risk of septic complications when compared with patients who are treated with antibiotics (Weidema 1984, Gottrup 1985).

\subsubsection{Antibiotic propbylaxts.}

Faeces contain 200 to 400 species of bacteria. The defense systems of the peritoneal cavity eliminate the majority of these colon bacteria very rapidly. Only potentially pathogenic organisms survive either alone or in combination. Synergism between pathogenic aerobic and anaerobic flora plays an important role in the development of peritoneal infections (Tally 1979). Anaerobic bacteria are difficult to isolate and culture (Stone 1975). However, clinical studies have shown, that the postoperative septic complication rate does decrease when drugs against anaerobes are given (Keighly 1976, Eykyn 1979, Kusche 1981, Weidema 1984). Infections after colorectal surgery have a polymicrobial etiology, therefore, administration of anti- 
biotics should be directed against both anaerobes and aerobes (Feathers 1977, Bergman 1987).

In literature, considerable argument exists wether oral antimacrobial preparation or parenteral prophylaxis is more effective (Stone 1983, Menaker 1987). Oral antibiotics efficiently reduce bacterial concentrations in the intestine, but protection of the parenteral tissue against bacterial inocula is dependent on absorbtion of the administered antibiotic and subsequent tissue fluid concentration. Furthermore, postoperative infections are nearly always resistant to the antibiotics that have been used before. Resistant bacteria appeared to have been selected out by just a few hours of oral therapy (Keighley 1979). Experimental work of Weidema and v.d.Boogaard demonstrated the persistence of resistant strains of bacteria after oral antibiotic therapy (Weidema 1984). The symbiosis between normal aerobic and anaerobic microflora prevents the colonisation of the gastrointestinal tract by potentially pathogenic micro-organisms. This mechanism is, the so called, colonisation resistance (vd Waay 1979, Stoutenbeek 1987). Symbiosis is disturbed by oral antibiotics and subsequently, growth of more resistant and pathogenic organisms is favoured. In this manner, the gastrointestinal tract serves as a reservoir of pathogens that may enter the portal and systemic circulation and feed septic processes.

Parenteral prophylactic use of antibiotics is as effective or even more effective than oral preparations and lacks the afore mentioned disadvantages of oral therapy (Stone 1976, Bartlett 1978, Keighley 1979, Kaiser 1983, Lau 1988). Systemic antibiotics should achieve an adequate blood and tissue concentration at a time when dissemination of pathogens and subsequent bacterial innoculation occurs. For this reason, the prophylactic agent should be administered at the time of induction of anaesthesia. During operations lasting longer than 3 hours, the dose should be repeated intraoperatively (Kaiser 1983). The prophylaxis should not last longer than 24 hours, since this is ineffective and increases the risk of developing resistent strains of bacteria (Stone 1979).

Studies indicate that one dose of a long acting broad spectrum cephaiosporin, as ceftriaxon, in combination with one dose of metronidazol at the induction of anesthesia may be as efficient or even more efficient than former multiple doses schemes with short acting antibiotics (Brogden 1988).

\subsubsection{Autologous blood transfiuston.}

The patient's immuno-competency plays an important role in the prevention of infectious complications. Dissemination of cancer cells is probably facilitated by a deficient immune system. Some factors that compromise the immunological competence are inherent to the operative 
procedure such as, the choice of anaesthetic agent, duration of surgery and the extent of the procedure. These factors are relatively unavoidable (Jubert 1973, Vose 1975). Recently, allogeneic blood-transfusions have been linked to immune suppression. Tartter, demonstrated that the association of allogeneic transfusion with postoperative infections after colorectal cancer surgery was highly significant, independent of age, sex, blood loss, procedure, tumor differentiation, stage, admission hematocrit, duration of surgery, length of the specimen and tumor size (Tartter 1988).

Independent of tumor stage, 5-years survival is better in patients who did not receive bloodtransfusions. The exact mechanisms that influence immuno-competency by allogeneic bloodtransfusions are not understood. It seems reasonable to believe that autologous bloodtransfusion does not suppress the immune system.

V.Aken (1988) reviewed literature on preoperative blood transfusion. Publications which indicate increased mortality following allogeneic blood transfusion have appeared more frequently than papers which do not register this negative effect. But they are retrospective studies and definitive conclusions cannot be made until prospective randomized studies have been completed.

\subsubsection{Information to the patient.}

The need for a temporary colostomy after colo-anal anastomosis must be explained to the patient. The presence of a defunctioning colostomy does not prevent anastomotic dehiscence, but will certainly decrease the magnitude of the possible complications (Irvin 1973). After judgement of the local situation during the operation it may, from a technical or oncological point of view, be unwise to perform a colo-anal anastomosis. In such cases, an abdomino-perineal resection is indicated. The patient must be prepared for a permanent colostomy.

After rectal resection with colo-anal anastomsis, continence will be changed. The reservoir function of the rectum is lost and, although the sigmoid will adapt itself in time, defaecation will occur more frequently. Adaptation of the sigmoid to its reservoir function may take one to two years. After this, defaecation frequency may return to two to three times per day. The compliance function, meaning the ability to adapt to increasing volumes, is lost as well. This results in a feeling of urge when the neo-rectum, with its decreased capacity, is filled. The ability to retain is weakened and may be partly insufficient. Especially in the first months after the operation it may be necessary to wear pads. The pelvic floor musculature will regain part of its strength in the year following the operation. If the patient realizes that rectal resection with colomanal anastomosis is a good alternative to a 
permanent colostomy, he will more easily learn to cope with the inconveniences.

The discussion about the prognosis of the malignancy is a process that will be continued during the follow up after the operation. The psychological relation between surgeon and cancer patient is beyond the scope of this study.

\subsection{The role of adjuvant therapy in the surgical decision making.}

Results of surgery of rectal cancer have not changed in the last 50 years. Surgery is highly successful in curing tumors presenting at an early stage. However, for the more advanced tumors which have penetrated the rectal wall or have metastasized in the regional lymphnodes, local recurrence and distant metastases are a major problem. Morbidity from local recurrence is very distressing as it produces symptoms such as, pain, bladder dysfunction and sepsis.

Surgical adjuvant treatment is primarily aimed at improving local tumor control within the pelvis and, ideally, should also decrease distant metastases to gain prolonged survival. O'Connell (1988) and Gunderson (1988) have recently summarized the state-of-the-art of adjuvant therapy. At present, it is not possible to give answers to the following questions: 1 . Is there an effective adjuvant therapy? 2. Is there a high risk group of patients who should have adjuvant therapy? (Cummings 1986).

Many trials have been started to investigate the effectiveness of adjuvant therapy. One of the most important drawbacks is the difficulty to provide irrefutable statistical evidence.

To monitor a $10 \%$ improvement of a specific regimen with a $5 \%$ confidence interval, hundreds of patients are needed in each trial. On the other hand, if a hundred of such trials were performed, $5 \%$ would yield a false positive result. The chance of false positive result is multiplied if subsets of variables are analysed. Flemming warns against deriving conclusions from subsets or, likewise, interim analysis: in two out of five trials in which treatment is completely ineffective, subset analysis of four dichotomous patient characteristics will produce false positive resuits. Even if a significance of $<0.01$ is maintained, a $13 \%$ chance of producing a false positive result in subset analysis occurs ( $\mathrm{O}^{\prime \prime}$ Connell 1988). If, in a subset of patients, significant results of a therapeutic regimen are obtained, it is permissable to formulate hypotheses. These hypotheses however need definite verification in confirmatory trials. In a controlled trial of 500 rad preoperative irradiation, overall survival was not influenced, but in a subset of 38 patients with 
Dukes' $\mathrm{C}$ cancer, a beneficial effect was measured. The authors concluded, in spite of the small sample size: "the study demonstrates that preoperative irradiation benefits the patient suffering from Dukes' $C$ rectal cancer .... There can be few arguments against its universal use" (Raider 1977, quoted by O'Connell). In an other example of a controlled preoperative irradiation trial (2000 $\mathrm{rad} / 10$ days), overall survival was not influenced. However, following extensive subset analysis the authors concluded: there appears to be a definite benefit to irradiated patients who undergo abdomino-perineal resection". Confirmative trials found no support for this hypothesis, derived from subset analysis (MRC 1984, Higgins 1987).

Several trials have shown a beneficial effect of pre- or postoperative irradiation on local recurrence (Balslev 1986, Tepper 1987, Fisher 1987, Lise 1987, Gerard 1988). Overall survival was not influenced. A theoretical advantage of preoperative irradiation is the damaging of cells that might spread locally or distantly at the time of resection. Preoperative irradiation does not preclude enteric resection and primary anastomosis (Stevens 1978, Robertson 1985). The major advantage of postoperative treatment is the ability to exclude patients with advanced but undiagnosed metastatic disease, or patients who have a low risk for local recurrence. High risk patients are those who have macroscopic extrarectal extension or nodal involvement (Gunderson 1988).

The prognosis for patients with unresectable rectal cancer due to fixation is poor. Preoperative irradation for initially unresectable lesions may result in a resectability rate of approximately 50\% (Stevens 1976, Dosoretz 1983, Mendenhall 1987). Even after complete resection, a large number of patients will develop local recurrence and distant metastases. A long term survival rate of $30 \%$ is to be expected, versus a $0 \%$ three year survival rate for non. resected patients.

Finally, Taylor (1987) demonstrated the palliative value of radiotherapy in the relieve of distressing symptoms related to the presence of a pelvic tumor.

In vitro studies have shown, that exposure of cancer cells to 5 FU during irradiation enhances cell kill. The Gastro Intestinal Tumor Study Group has reported a survival advantage in patients treated with combined postoperative irradiation $(4000 \mathrm{rad}+$ concomitant $5 \mathrm{FU}$ followed by systemic chemotherapy GITSG, 1986). The Mayo Clinic confirmed these findings in an independent trial (Krook 1986). Patients were entered in both studies for randomization if they had transmural tumor penetration and/or lymphnode metastases. It is possible to identify a subset of patients after staging for rectal cancer, who are at moderate to high risk of local or systemic failure 
following surgical resection. Evidence is accumulating from several clinical trials, that local recurrence rate may be influenced by irradiation therapy in high risk patients. Irradiation therapy alone or chemotherapy alone does not influence overall survival. Aggressive combined therapy may influence overall survival, but, at present it is only justified to expose patients to this kind of therapy in the setting of a clinical trial.

The role of intraoperative irradiation has yet to be determined. Combined external beam and intraoperative irradiation may offer some future perspectives. The biologic effectiveness of single dose irradiation is considered equivalent to 2-3 times that quantity of fractioned external beam treatment (Suit 1973). The effective dosis in the operative boost field when added to 4500-5000 cGy delivered in fractions with the external beam technique is 6500-8000 cGy with a $1500 \mathrm{cGy}$ boost, and 8500-11000 cGy with a 2000 cGy intraoperative irradiation dose (Gunderson 1988). Thus a combination of external irradiation and intraoperative irradiation allows to deliver a significant higher dose. The incidence of complications has not appeared to increase as the result of this aggressive combination (Tepper 1984).

Gunderson (1988), from the Mayo Clinics, has shown that in patients with advanced rectal cancer or recurrent disease 4-year survival is above $30 \%$ after adjuvant intraoperative irradiation therapy, which compared well to an expected survival of 5 to $10 \%$ when treated with standard techniques.

Prospective randomized trials seem indicated to investigate whether local recurrence and survival may be improved in patients with rectal cancer. 


\section{References chapter 4:}

Aken v. WG.: Hebben perioperatieve bloedtransfusies een ongunstig effect op de prognose van patienten met maligniteiten?

CLB bulletin 7 no4; 1988.

Balslev IB., Pedersen M., Tegelbvjerg PS.: Postoperative radiotherapy in the carcinoma of the rectum and rectosigmoid Dukes' $B$ and $C$. A randomized multicentre study.

Cancer $58 ; 22-28,1986$

Bartlett RH.: Pulmonary pathofysiology in surgical patients.

Surg.Clin.North Am. 60;1323 1338, 1980.

Bergman, Solhaug $J H$.: Single-dose chemoprophylaxis in elective colorectal surgery. Annisurg. 205; $77-81,1987$.

Beynon J, Foy DMA, Roe AM, Temple LN, McMortensen NJ: Endoluminal ultrasound in the assessment of local invasionin rectal cancer.

Br.J.Surg. 73;474-477, 1986.

Beynon J, McMortensen NJ, Foy DMA, Channer IL Virjee J, Goldard P: Preoperative assessment of local invasion in rectal cancer: digital examination sonography or computed tomography.

Br.J.Surg. 73;1015-1017, 1986.

Bonfanti G.,Bozetti F, Doci R., Baticci F., Marolda R., Bignami P., Gennari L.: Results of extended surgery for cancer of the rectum and sigmoid.

Br.J.Surg. 69;305-307, 1982.

Boscaini $\mathbf{M}_{\text {, }}$, Montori A.: Transrectal ultrasonography: interpretation of normal intestinal wall structure for the preoperative staging of rectal cancer.

Scand.J.Gastroenterol. 21suppl;87-98, 1986.

Brogden $\mathrm{RN}$, Ward A.: Ceftriaxone. A reappraisal of its antibacterial activity and pharmacokinetic properties, and an update on its therapeutic use with particular reference to once-daily administration.

Drugs 35;604-645, 1988 .

Cohen AM., Wood WC. Gunderson LL., Shinnar M.: Pathological studies in rectal cancer.

Cancer $45 ; 2965-2968,1980$.

Cummings BI.: A critical review of adjuvant preoperative radiation therapy for adenocarcinoma of the recrum.

Br.J.Surg. $73,332-338,1986$.

DeVita VT., Hellman S., Rosenberg SA.: In: Cancer. Principles and practice of oncology. 2nd ed.

J.B. Lippincou Company, Philadelphia, 1985. 
Di Candio G., Mosca $F_{*}$, Campatelli $A_{*}$ Ferrari M., Basolo F.. Endosonographic staging of rectal carcinoma.

Gastrointest Radiol. $12 ; 289-295,1987$.

Dixon AK., Fry IK., Morson BC., Nicholls Ry., York Mason A.: Preoperative computed tomography of carcinoma of the rectum.

Bir.J.Radiol. 54,655, 1981.

Dosoretz DE., Gunderson LL $_{\text {, }}$ Hoskins B.: Preoperative imadiation for localized carcinoma of the rectum and rectosigmoid: patterns of failure, survivall, and future treatment strategies.

Cancer $52 ; 814-818,1983$.

Dukes CE., Bussey HJR. The spread of rectal cancer and its effect on prognosis.

Br.J.Cancer 12;309-320, 1958.

Dukes CE: The classification of cancer of the rectum.

J.Pathol.Bacteriol. 35;323-332, 1932.

Duncan W.: Pre-operative radiotherapy in rectal cancer.

World J Surg. 11;439-445, 1987.

Durdey P., Williams NS.: The effect of mallignant and inflammatory fixation of rectal carcinoma on prognosis after rectal excision.

Br.J.Surg 71;787-790, 1984.

Eýkyn S., Jackson BT, Lockhart-Mummery HE, Phillips 1.: Prophylactic peroperative intravenous metronidazole in elective colorectal surgery.

Lancet 1979 2;761-764, 1979.

Feathers RS., Lewis AAM., Sagor GR., Amirak ID., Noone P.: Prophylactic systemic antibiotics in colorectal surgery.

Lancet 1977 II, 1977.

Feifel G., Hildebrandt U., Dhom G.: Die endorectale Sonographie beim Rectumcarcinom.

Chinurg 56;398-402, 1985 .

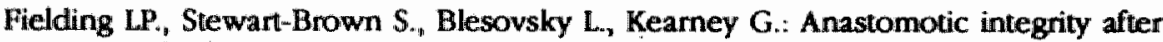
operations for large bowel cancer a multicenter study.

Br.Med.J. 9;411-414, 1980.

Finlay IG., Meek DR., Gray. HW., Duncan JG., Mcardle CS.: Incidence and detection of occult hepatic metastases in colonectal carcinoma.

Br.Med.J. 284;803-805, 1982.

Fisher B., Wolmark N., Rockette H.: Adjuvant chemotherapy or postoperative radiation for rectalcancer: 5-year result of NSABP R-01.

ASCO 6:92 (abstract) 1987. 
Fork FT, Lindstrom $C_{\text {, }}$, Ekelund G.: Double contrast examination in carcinoma of the colon and rectum.

Acta Radiologica $24 ; 177-188,1983$.

Gerard A.: Preoperative Radiotherapy and radical surgery as combined treatment in

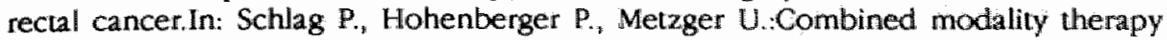
of gastrointestinal tract cancer.

Springer-Verlag Heidelberg, 1988.

Goldman L.,Caldera DL.,Nussbaum SR.: Multifactorial index of cardiac risk in noncardiac surgical procedures.

N.Engl.J. Med. $297 ; 845-850,1977$.

Goldman L.: Cardiac risks and complication of noncardiac surgery.

Ann.Surg.198;780-791, 1983.

Goligher JC, Graham NG, Dombal FT.: Anastomotic dehiscence after anterior resection of rectum and sigmoid.

Br.J.Surg. 57;9, 1970.

Goligher JC.: Surgery of the anus rectum and colon.

Ed. 4, Bailliere Tindall, London, 1980.

Gothlin JH, Lerner RM., Gadeholt $G_{\text {, }}$, Sischy B., Hinson J.: CT staging of early rectal carcinoma.

Gastrointest.Radiol. 12;253-256, 1987.

Gottrup F., Diederich P., Sorensen K., Nielsen SV., Ornsholt J., Brandsborg.: Prophylaxis with whole gut irrigation and antimicrobials incolorectal surgery. Am.J.Surg. 149;317-322, 1985.

Gunderson LL.: Colorectal cancer. In: Perez CA., Brady LW.: Principles and practice of radiation in oncology.

J.B. Lippincot Company, Philadelphia, 1987.

Gunderson $\mathbb{L L}$., Martin JK., Beart RW., Nagorney DM., fieck JM, Wieand HS., Martinez A., O'Connel MJ., Martenson JA., MCl Irath DC.: Intraoperative and external beam irradiation for locally advanced colorectal cancer.

Ann Surg. 207,52-60, 1988.

Gunderson LI.: Combined treatment approaches in the management of rectal cancer.In: Schlag P., Hohenberger P., Metzger U.: Combined modality therapy of gastrointestinal tract cancer. Springer-Verlag, Heidelberg, 1988.

Habib NA., Peck MA, Sawyer CN., Blaxland JW, Luck RJ.: Does fixity affect prognosis in colorectal tumours?

Br.J.Surg. 70;423-424, 1983.

Hager T., Gall FP., Hermanek P.: Local excision of cancer of the rectum.

Dis.Colon Rectum 26;149-151, 1983. 
Haukefeuille P., Valleur P., Perniceni T, Martin B., Galian A., Cherqui D., Hoang C.: functional and oncologic results after coloanal anastomosisfor low rectal carcinoma. Ann:Surg. 207;61-64, 1988.

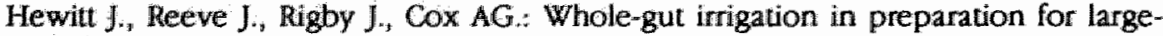
bowel surgery.

Lancet $18 ; 337-340,1973$.

Higgins GA., Humphrey EW., Dwight RW: Preoperative radiation and surgery for cancer of the rectum: Veterans Administration Surgical Oncology Group Trial II. Cancer 1987.

Hildebrandt U., Feifel G.; Preoperative staging of rectal cancer by inrarectal ultrasound.

Dis. Colon Rectum 28;42-46, 1985.

Holdsworth PJ,, Johnston D., Chalmers AG., Chennells P., Dixon MF., Finan PJ., Primrose JN., Quirke $P_{\text {.; }}$ Endoluminal ultrasound and computed tomography in the staging of rectal cancer.

Br.J.Surg. 75;1019-1022, 1988.

Hughes ESR., McDermott FT., Masterton JP., Cunningham IGE,, Polglase AL.; Operative mortality following excision of the rectum.

Br.J.Surg. 67,49-51, 1980.

Irvin TT., Goligher JC.: Aetiology of disnuption of intestinal anastomoses.

Brit.J.Surg. $60 ; 461-464,1973$.

Irvin GL, Horsley $\mathrm{JS}_{\text {" }}$ Caruana $\mathrm{JA}$.: The morbidity and mortality of emergent operations for colorectal disease.

Ann.Surg. 199;598-603, 1984.

Kaiser AB., Herrington JL., Jacobs JK., Mulherin JL., Roach AC., Sawyers JL.: Cefoxitin versus erythromycin, neomycin, and cefazolin in colorectal opera-tions. Importance of the duration of the surgical procedure.

Ann. Surg. $198,525.529,1983$.

Keighley MRB, Crapp AR., Burdon DW., Cooke WT., Alexander Williams J.: Prophylaxis against anaerobic sepsis in bowel surgery.

Br.J.Surg. 63;538-541, 1976.

Keighley MRB., Arabi $Y$., Alexander-Williams J., Youngs $D_{\text {., }} \mathrm{B}$ urdon $\mathrm{DW}$ : Comparison between systemic and oral antimicrobial prophylaxis in colorectal surgery.

Lancet $19791,894-897,1979$.

Kirwan WO., Drumm J., Hogan JM., Keohane C.: Determining safe margin of resection in low anterior resection for rectal cancer.

Br.J.Surg. 75;720, 1988. 
Krook J., Moertel C., Wieand $H$.: Radiation vs sequential chemotherapy-radiationchemotherapy. A study of the North Central Cancer Treatment Group and the Mayo Clinic.

ASCO $5 ; 32$ (abstract) 1986.

Kujat R., Grosse H., Gans E., Pichlmair R.: VerÑnderungen im Wasser und Elektrolythaushalt nach orthograder Darmspulung.

Chirurg 52;586, 1981.

Kusche J, Stahlknecht CE.: Antibioticaprophylaxe bei colorectalen Operationen: gibt es ein mittel der Wahl?

Chirurg 52;577, 1981.

Lau WY., Chu KW., Poon GP., Ho KK.: Prophylactic antibiotics in elective colorectal surgery.

Br.J Surg. 75;782-785, 1988.

Lise M., Gerard A., Nitti D.: Adjuvant therapy for colorectal cancer. The BORTIC, experience and a review of the literature.

Dis.Colon Rectum 30;847-854, 1987.

Localio SA., Baron B.: Abdomino-transsacral resection and anastomosis for mid. rectal cancer.

Ann.Surg. 178;540-545, 1973.

Lockhart-Mummery HE., Ritchie JK., Hawley PR.: The results of surgical treatment for carcinoma of the rectum at St Mark's Hospital from 1948 to 1972.

Br.J.Surg. 63;673-677, 1976.

MRC Working Party; The evaluation of low-dose preoperative $x$-ray therapy in the management of oprable rectal cancer: results of a randomly controlled trial.

Brit.J.Surg. $71 ; 21-25,1984$

Menaker GJ.: The use of antibiotics in surgical treatment of the colon.

Surg. Gynecol.Obstet. 164;582-586, 1987.

Mendenhall WM., Bland KI., Pfaff WW. Million RR., Copeland EM.: Initially unresectable rectal adenocarcinoma treated with preoperative irradiation and surgery.

Ann.Surg. 205, 41-44, 1987.

Morson BC., Bussey HJR., Samoorian S.: Policy of local excision for early cancer of the colorectum.

Gut $18 ; 1045-1050,1977$.

Nicholls RJ., York Mason A., Morson BC., Dixon AK., Fry IK. The clinical staging of rectal cancer.

Br.J.Surg, 69;401-409, 1982. 
Nicholls RJ., Galloway DJ., York Mason A., Boyle P.: Clinical staging of rectal cancer. Br.J,Surg. 72suppl;51-52, 1985.

O'Connell MJ., Gunderson LL., Fleming TR.: Surgical adjuvant therapy of rectal cancer.

Semin.Oncol. 15;138-145, 1988.

Rifkin MD., Marks GJ.: Transrectal US as an adjunct in the diagnosis of rectal and extrarectal tumors.

Radiology 157;499-502, 1985.

Robertson SH, Kerman HD., Heron HC., Bloom TS: Is anterior resection of the rectosigmoid safe after preoperative radiation?

Dis.Colon Rectum 28;254-259, 1985.

Romano G., de Rosa P., Vallone G., Rotondo A., Grassi R., Santangelo ML.: Intrarectal ultrasound and computed tomography in the pre and postoperative assessment of patients with rectal cancer.

Br.J.Surg. 72suppl;117-119, 1985.

Rutten H., Jakimowicz J.: Die Korrelation zwischen endorectaler Sonographie und histologischen Befunde. in: Brinkmann W., Strosche ed.: Stellenwert der Sonographie in der Chirurgie.

TM-Verlag (in press).

Saitoh N., Okui K., Sarashina H., Suzuki M., Arai T., Nunomura M.: Evaluation of echographic diagnosis of rectal cancer using intrarectal ulltrasonic examination.

Dis.Colon Rectum 29;234-242, 1986.

Soeters PB., De Jong PCM., Von Meyenfeldt MF.: De klinische diagnose ondervoeding.

Ned.Tijdschr.Geneeskd 131;765-768, 1987.

Starker PM., LaSala PA., Askanazi J., Todd G., Hensle TW., Kinney JM.: The influence of preoperative total parenteral nutrition upon morbidity and mortality.

Surg.Gynecol.Obstet. 162;569-574, 1986.

Stearns MW., Sternberg S., Decoss JJ.: Treatment alternatives. Localized rectal cancer. Cancer 54;2691-2694, 1984.

Stevens KR., Allen $\mathrm{CV}_{.}$, Fletcher WS.: Preoperative tadiothrapy for adenocarcinoma of the rectosigmoid.

Cancer 37;2866-2874, 1976.

Stevens KR., Fletcher W/S., Allen CV.: Anterior resection and primary anastomosis following high-dose preoperative irradiation for adenocarcinoma of the rectosigmoid.

Cancer 41:2065-2071, 1978. 
Stockholm Rectal Cancer Study Group: Short term pre-op radiotherapy for adenocarcinoma of the rectum.

Am.J.Clin.Oncol. 80;369-375, 1987.

Stouttenbeek CP.: Infection prevention in multiple trauma patients by selective decontamination of the digestive tract.

'Thesis 1987.

Stone $\mathrm{HH}$., Haney BB., Kolb I.D.: Prophylactic and preventive antibiotic therapy: timing, duration and economics.

Ann.Surg. 189,691, 1979.

Stone HH., Hooper CA., Kolb LD.: Antibiotic prophylaxis in gastric, biliary and colonic surgery.

Ann.Surg. 184;443, 1976.

Stone HH.: Antibiotics in colon surgery.

Surg.Clin.North Am. 63;3-9, 1983 .

Suit HD.: Radiation biology: a basis for radiotherapy. In: Fletcher GH.,ed. Textbook of radiotherapy,

and ed. Philadelphia: Lea and Febiger, 75-121, 1973.

Tartter PI.: Blood transfusion and infectious complications following colorectal cancer surgery.

Br.J.Surg. 75;789-792, 1988.

Taylor RE, Gillian RK, Arnot SJ: External beam radiotherapy for rectal adenocarcinoma.

Br.J.Surg. 74;455-459, 1987.

Tepper JE., Gunderson LL., Orlow E: Complications of intraoperative radiation therapy.

Int.J.Radiat.Oncol.Biol .Phys. 10; 1831-1839, 1984.

Tepper JE., Cohen AM., Wood WC., Orlow EL, Hedberg SE.: Postoperative radiation therapy of rectal cancer.

I.J. Radiation Oncology 13;5-10, 1987.

Thoeni RF., Moss AA., Schnyder P., Margulis AR: Detection and staging of primary rectal and rectosigmoid cancer by computed tomogaphy.

Radiology $141 ; 135-138,1981$.

Way vd: Colonization resistance of the digestive tract as a major lead in the selection of antibiotics for therapy.

Excerpta Medica p271, 1979.

Van De Water JM.: Preoperative and postoperative techniques in the prevention of pulmonary complications.

Surg.Clin. North Am. 60;1339-1348, 1980. 
Weidema WF, Bogaard vdAEJM: Whole gut irrigation and antimicrobial prophylaxis inelective colorectal surgery.

Neth.J.Surg: suppl 5; thesis, 1984 .

Williams NS., Durdey P., Quirke P., Robinson PJ., Dyson JED., Dixon MF., Bird CC.: Pre-operative staging of rectal neoplasm and its impact on clinical management. Br.J.Surg, $72,868-874,1985$.

Williams MP, Husband JE: CT scanning in carcinoma of the rectum: a review. J.Roy.Soc.Med. 80;701-703, 1987.

Wolmark N., Fisher B., Wieland SH. The prognostic value of the modifications of the Dulkes' C class of colorectal cancer.

Ann. Surg. 203; 115-121, 1986.

Wood CB., Gillis CR., Hole D., Malcolm AJH., Blumgart LH.: Local tumour invasion as a prognostic factor in colorectal cancer.

Br.] Surg. 68;326-328, 1981.

York Mason A: The spectrum of selective surgery.

Proc.Roy.Soc.Med. 69;237-244, 1976. 


\section{Chapter 5}

The intersphincteric approach of the rectum. A new surgical option for the treatment of low rectal pathology.

"No two patients with rectal cancer are ever exactly alike. It must follow, therefore, that no single orthodox standard operation can be the best treatment for every patient with carcinoma of the rectum". York Mason (1976).

\subsection{Introduction.}

The decision which surgical procedure is appropriate in the treatment of a patient with rectal cancer depends on several factors: tumor location, tumor grading, local and general patient factors and of course the surgeons experience and preference. Miles' radical abdomino-perineal resection is the gold standard for all rectal cancer surgery to which all sphincter saving procedures are compared. Sphincter saving surgery for rectal cancer has evolved along two lines. The first approach attempts to resect the tumor and its lymphatic field and to restore intestinal continuity, without sacrificing the sphincters. The second is, first to identify patients with early rectal cancer and then to ablate the tumor locally before lymphatic spread occurs. From the proximal to distal direction, the technical and oncological requirements of adequate cancer surgery increase. In the upper third of the rectum, the peritoneum constitutes a barrier to cancer spread. Cancers within the peritoneal covering may become very large but are still suitable for restorative resection. In the midrectum, the perirectal fascia are the natural barriers to cancer spread. Growth is limited by the pelvic bones, but. if the perirectal fascia has not been crossed, curative resection may be possible, even with restoration of the intestinal continuity, though adequate lateral clearance may be difficult to obtain. This is a prerequisite for successful surgery, as local recurrences are probably due to microscopic residual disease (Quirke 1986). Further downward in the distal third of the rectum, the outer tube of somatic musculature of the pelvis converges with the inner visceral musculature to a tight anal canal, where there is virtually no barrier between the two sphincter layers. So, at the lower end, only those primary growths which have not yet transgressed the inner muscle tube are suitable for restorative resection.

\subsection{Radical restorative resections.}

Anterior resection for growth in the upper third of the rectum has been 
proved to be adequate cancer surgery. (Waugh 1955, Deddish 1961, Palumbo 1968, Slanetz 1971, Lockhart Mummery 1976, Williams 1985). Better understanding of the growth and metastasizing patterns have led to reappraisal of the $5 \mathrm{~cm}$ rule of distal excision for rectal carcinoma. After realizing that distal intramural and lymphatic spread occurs only rarely, it became possible to resect favourable tumors in the midrectum without fear of jeopardizing the oncological result. (Williams 1983). Technical considerations restrict the range of tumors suitable for low anterior resection. If conditions are favourable, as in slender females with a wide pelvis, mobilization and resection of the rectum with subsequent restoration of bowel continuity can be done safely via an abdominal exposure. In the obese female and in most male patients, transabdominal clearance of lateral and distal margins is uncertain and anastomosis may be hazardous. Several techniques have been developed to overcome the problems of insufficient exposure in these patients. These techniques have in common, that the most difficult part of the operation, the anastomosis, is done from below.

\subsubsection{Transabdominal stapler techniques.}

The use of the stapler has enlarged the scope for low anterior resections. After removal of the rectum, the one stage stapler technique may be difficult as the ano-rectal stump may be partly concealed by the prostate or the vaginal septum. This may result in difficulties when placing the obligatory pursestring suture in the ano-rectal stump. A double stapler technique with stapling of the ano-rectal stump before transsection of the bowel makes the placement of a pursestring suture redundant. In this way, the stapler can also be of help in performing very low anastomoses. Mobilization and adequate clearance depend on the abdominal exposure.

\subsubsection{Abdomino-transsacral approach.}

Localio $(1973,1983)$ developed a one phase operation with the patient placed in the right lateral position. He opens the abdomen via an oblique incision and at the same time obtains lower access to the retrorectal space by removing the os coccygis via a transverse posterior incision. The rectum is mobilized completely as in other radical operations. After division of the superior haemorrhoidal lymphovascular pedicle, transsection of the lateral ligament is carried out as distal as possible. If mobilization allows sufficient length to perform an anterior resection, the operation is completed through the abdomen. However, with very low lesions, particularly in men or obese women, the tumor may be barely visible. Determination of adequate distal and lateral margins will be uncertain and the anastomosis very difficult. In 
such cases, transsacral incision provides the necessary exposure. The lower portions of the lateral ligaments, which often remain after the abdominal mobilization, are encircled and divided via the posterior incision. The entire pelvic mesorectum can be removed. The distal margin is easy to determine and after transsection of the bowel, an accurate end-to-end anastomosis is performed without disturbance of the sphincters and their innervation.

\subsubsection{Abdomino-anal approach.}

In Parks' approach (1972) mobilization and resection is completed via a conventional abdominal incision. A transanal anastomosis is performed through the dilated sphincters. Transanal anastomosis had been practised in pull through operations, but in the past, the lower rectal stump had usually been everted and the anastomosis performed external to the perineum. It would then either be returned, as in the Maunsell-Weir method, or left outside to be returned later, as in the Cutait-Turnbull technique. The disadvantage of the eversion type of anastomosis is, that the rectal stump has to be mobilized so extensively that damage to its nerve supply is likely to occur. The high immediate morbidity, bad functional results and disappointing survival figures have prevented the pull through type of anastomosis from being adopted at the St Mark's Hospital (Mann 1972).

In Parks' technique a specially devised retractor is used. The blades have a large groove to accomodate the sphincter, so that once opened up, the retractor can neither slide further in, nor fall out. The distal edge of the proximal colon is brought down by light tissue forcepses. Special needles with their curve parallel to the axis of the needleholder enable the performance of end-to-end anastomosis. Parks (1977, 1982) has reported good functional results, which were confirmed by Keighley (1980). Essentially this procedure enables performing a very low anastomosis.

\subsubsection{Abdomino-transspbincteric approach.}

The transsphincteric approach to low rectal pathology is probably the most widely used for local approaches to low rectal pathology. However, in combination with a laparotomy, the transsphincteric approach can also be used for radical resections. In an originally two stage procedure, York Mason mobilized and resected the rectum through a conventional full length paramedian incision. After repositioning of the patient from supine to prone position, the somatic sphincter complex is opened through a parasacral incision, assuring wide exposure of the distal anal rectal stump, ready for end-to-end anastomosis to the proximal colon. This technique also enables resecting growth in the distal third of the rectum. In such 
cases, the transabdlominal part is the same as for midthird growth, namely, dissection right down to the pelvic floor. However, it is not possible to transsect the bowel with an adequate margin of healthy tissue distally to the tumor. After repositioning the patient prone, the anal canal is opened by division of the somatic and visceral sphincter. Under direct vision of the distal edge of the rectal cancer, distal transsection is carried out in healthy tissue, well below this edge. Continuity is restored by a T-shaped colo-anal anastomosis. The somatic sphincter complex needs to be approximated very carefully. Functional results of this operation are acceptable. The pattern of defaecation deviates from the normal, but will improve progressively in the months following the operation.

\subsubsection{Abdomino-intersphincteric approacb.}

In most centres, abdomino-perineal resection is the complement of (very) low anterior resection in the choice of radical operation for rectal cancer. The abdomino-perineal resection is not the only alternative to not readily accessable midrectal tumors. Presently, techniques are available which fulfil the accepted criteria for cancer-curing surgery and preserve anal continence with normal defaecation. In theory, not all cancers sited at the lowest third of the rectum need to be treated by abdomino-perineal resection. Cancers which do not infiltrate beyond the muscularis propria may be treated by restorative resection, provided a technique is available which ensures carefull dissection of the perineal and lowermost pelvic part of the rectum along the anatomical cancer barriers.

The author prefers the combined abdomino-intersphincteric approach in these tumors as an alternative to abdomino-perineal resection. To his knowledge, this technique for radical restorative resection of low rectal cancer has not been described earlier. The approach is through the intersphincteric plane at the level of the perineal part of the rectum and through the dorsal and ventral interfascial spaces at the level of the pelvine part. The technique will be described in detail in one of the next paragraphes. With an abdomino-intersphincteric approach, maximal exposure is gained with a minimal disturbance of normal anatomy. The principal advantage of this procedure is not the ability to perform an easy colo-anal anastomosis, but to zuomplish a complete removal of the mesorectum with its covering fascia. Essentially, this operation is a radical resection, which also permits restoration of the continuity of the bowel with a colo-anal anastomosis. In the next chapter our results will be discussed. 


\subsection{Local procedures.}

\subsubsection{Introduction.}

Pathology studies have led to the following three assumptions for the effectiveness of local treatment:

1. Local treatment can effectively irradicate disease confined to the rectal wall.

2. When cancer has spread to the involved draining lymphnodes, surgical salvage is small and may not justify the significant operative mortality and morbidity after radical surgery.

3. Disseminated disease in liver, lungs or bone is beyond salvage by radical loco-regional surgery, but the intrarectal component of the problem may be palliated by effective local ablative measures. Essentially, two kinds of procedures are practised. The first is destruction of the growth; the second, dissection. Several techniques have been developed for the local treatment of rectal cancer.

\subsubsection{Electrocoagulation.}

Electrocoagulation was introduced in the Netherlands by Wassink in the Antoni van Leeuwenhoek huis (The Netherlands National Cancer Institute) in 1932 . In a period from 1932 to $1958 ; 195$ patients underwent electrocoagulation with curative intent, 96 died of cancer and 56 had a local failure. Local failure appeared at a median of 10.8 months after treatment (Klok 1963). The results compare less favourably with radical surgery than the results of Madden (1971, 1980), who treated all rectal cancers, independent of stage, with electrocoagulation. He found a 5-year survival of $62.8 \%$ in 105 patients treated with curative intent from 1954 to 1978 and concluded that electrocoagulation is at least equal to abdomino-perineal resection.

It is very difficult to assess the overall value of electrocoagulation in the treatment of rectal cancer. It is impossible to find a matched group of patients in a randomly controlled clinical trial treated with abdominoperineal resection or electrocoagulation. The national cancer institute preliminarly terminated a prospective randomized study because of insufficient patient accruel (Baker 1980).

Local failure is a frequent problem after electrocoagulation (Baker 1980, Stearns 1984, de Graaf 1985). De Graaf (1985) reviewed the results of electrofulguration on 49 patients, who, between $1959^{\circ}$ and 1982, were treated with curative intent for tumors within the bowel wall in the Antoni van Leeuwenhoek Huis. Fifteen patients had a local failure. Eleven patients 
had metastatic disease outside the pelvis. These results were compared with 34 patients, who, in the same period, had radical surgery (low anterior or abdomino-perineal resection) for tumors confirmed to the bowel wall. of these patients, three had a local failure, whereas 5 had metastatic disease outside the pelvis. Statistical analysis of this comparative non randomized study showed that; , after electrofulgeration, more local failures occurred but there was an equal chance of metastatic disease. Further analysis showed that the factor causing the local failures was the magnitude of the treated cancers. Tumors more than $1 / 3^{\text {rd }}$ of the circumference of the bowel were the cause of difference in local failure. The author concluded, that electrofulgeration is an alternative for small rectal cancers not infiltrating beyond the bowel wall. Cryle and Turnbull (1972) have reported favourable results with patients treated for mobile non encircling tumors. They concluded that, for this type of tumor, results are equal to abdomino-perineal resection.

Certainly, one of the most important drawbacks of electrofulguration is the lack of a resected specimen. Stage and prognosis can not be correlated. More important; information to arrive at a rational decision on the possible need for further radical surgery or adjuvant therapy is also missing.

\subsubsection{Endocavitary irradiation.}

Papillon pioneered a technique employing endocavitary contact irradiation, delivered per anum through a proctoscope. A total of 9000 to 15000 rads were delivered to the tumor in about three treatments. As a low voltage $\mathrm{X}$ ray machine was used, penetration depth did not exceed a few centimeters (Papillon 1975). Papillon reported a 5-year survival rate of $78 \%$ and a local failure rate of $7.5 \%$ in 186 cases treated with curative intent by endocavitary irradiation alone or in combination with implant. Equally good results were obtained by Sischy (1982). Moderate to well differentiated tumors within 12 centimeter from the anal verge and of moderate to small size were selected. Polypoid lesions were treated by endocavitary irradiation alone. With ulcerative invading tumors an implant was supplemented. Papillon (1987) recently reported good results with endocavitary irradiation after external beam irradiation. This therapeutic modality seems to offer some advantages which outweigh the disadvantage of lacking a specimen. In selected patients, this therapy may be performed on an outpatient basis. It carries a negligible morbidity, even in older or high risk patients. It appears to be a method that promises excellent local control.

\subsubsection{Laser ablation.}

Laser therapy is a powerful tool in the palliative treatment of rectal cancer. 
It had earlier been noted that palliative treatment resulted in complete resolution of tumor (Mathus-Vliegen 1988). These findings encouraged Mathus-Vliegen to attempt curative ablation of early colo-rectal carcinoma in high risk patients. The success rate in a small group of patients was $92 \%$ (11/12). She concluded that photocoagulation for the treatment of early' colo-rectal malignancies is equal to and, if strict criteria are maintained, even superior to, endocavitary irradiation, local excisional surgery and surgical electrocoagulation. Treatment is not restricted by the irradiation dose and any lesions that are accessible by the endoscope, can be treated.

\subsubsection{Peranal local excision of rectal cancer.}

The most important advantage of local resective techniques is that specimens are obtained. Cancer stage can be correlated with local recurrence and survival rate. As a result of these studies, high risk patients who need major radical surgery or adjuvant therapy after local excision may be identified. In selected patients with a small (less than $3 \mathrm{~cm}$ ), polypoid, well or moderately well differentiated tumor, not penetrating through the entire bowel wall, the reported results are good. (York Mason 1970, 1976, Morson 1977, Hager 1983, Stearns 1984, Killingback 1985, Whiteway 1985). Several techniques are employed to remove an early rectal cancer as a full thickness biopsy with adequate radial and peripheral margins.

By placing full thickness stitches around the tumor in healthy bowel wall, the tumor may be handled and placed under traction. Excision starts beyond this ring of sutures and is carried down till the perirectal fat is seen. Stay sutures, left behind in the rectal wall enable reapproximation and closure after removal of the tumor. To perform this procedure it is necessary to have a good exposure of the tumor site. Low seated tumors may be adequately visualized by a self retaining retractor placed in the anus $_{\|}$after dilation of the sphincters. However, the peranal route may be inadequate for tumors in the midrectum. For these cases, York Mason described the transsphincteric approach.

\subsubsection{The transspbincteric proctotomy.}

This technique will be described in more detail. The indications for the transsphincteric approach are the same as for the intersphincteric approach, which will be presented as an alternative.

Cancers which meet the clinico-pathological requirements for local resection may be sited at a level that can not be sufficiently exposed by the peranal approach. To obtain better access, a dorsal proctotomy must be performed. Exposure of the lower rectum can be done by a posterior 
transsacral approach with resection of the os coccygis, as introduced by Kraske (chapter 1) or by division of the anal sphincters, which was Cripps' choice more than 100 years ago. With the renewed interest in local rectal surgery, the transsphincteric approach has also been redeveloped by York Mason (York Mason 1970).

For the transsphincteric parasacral exposure, the patient is placed in prone position with elevated sacro coccygeal region and flexed hips. The oblique incision starts at a level just lateral to the sacro coccygeal joint, at the inferior border of the gluteus maximus muscle and parallels, on the left side, the os coccygis into the anus. The incision is carried down and the levator ani and the puborectalis-external sphincter complex is divided and marked by stay sutures. The perineal part of the rectum can now be seen: this represents the anal canal. To gain exposure to the pelvic part, the ampulla recti, the fascia pelvi parietalis and fascia pelvi visceralis interna have to be opened. This procedure exposes the perirectal fat. To obtain sufficient access by the proctotomy York Mason advocates splitting of the inner muscular tube, including the inner sphincter complex. By cutting the anus, the lower rectum opens as a book. Growth on the more ventral side of the rectum can now be easily observed and removed as a full thickness biopsy, as described earlier. Essentially, benign tumors may be resected as a mucosectomy. Borders of growth on the dorsal side of the rectum can be assessed by placing one finger in the rectum. A circle of full thickness stay sutures may be placed around the growth with guidance of the palpating finger. A full thickness diathermy excision is carried out at the periphery of the identifying stay sutures. As excision proceeds, stay sutures are placed into the rectal wall to enable easy reapproximation and closure of the gap in the rectum.

The divided sphincter complex should be closed meticulously. In order to achieve exact anatomical restoration, it is vital to have marked each muscle prior to division, so that they can be correctly identified when the repair is in process.

With this technique it is possible to remove tumors high up in the midrectum without the need of a laparotomy. Several authors have confirmed York Mason's good results with regard to preservation of continence. The transsphincteric approach is a method to gain accesss to the lower rectum. Oncological results after this procedure will be similar to the results of local excision for early rectal cancer.

\subsubsection{The intersphincteric approach of the rectum for local procedures.}

Technical details will be given in the next paragraph. The transsphincteric approach provides excellent access to the lower rectum. In our opinion, the 
disadvantage of the procedure is the need for division of the sphincter apparatus and the subsequent need for meticulous reapproximation of the individual muscle bundles. In the intersphincteric approach a similar exposure is obtained with minimal disturbance of the normal anatomy. The anatomical key to this approach is the intersphincteric plane. This plane is avascular and separates the smooth muscle of the internal sphincter and rectum from the outer circumferential somatic musculature of the external sphincter and pelvic floor. This approach is derived from Parks' approach for treating faecal incontinence: the postanal repair (1975).

In postanal repair reapproximation of the pelvic floor muscles at the dorsal side of the rectum can restore the ano-rectal angle and lengthen the anal canal. These two factors are thought to be reponsible for improving incontinence (Parks 1967, Keighley 1983).

After having separated the somatic and visceral muscle tube, the dorsal side of the rectum can be further mobilized by opening the interfascial space between fascia visceralis interna and fascia parietalis externa. The ampulla recti is now dissected off the sacrum, complete with its perirectal fat and covering fascia. A dorsal proctotomy for local excision of growth on the anterior side of the rectal wall or for mucosectomies, or a full thickness local excision for tumors at the posterior side of the rectum can be easily performed. The perirectal fat can be investigated for the presence of enlarged lymphnodes. Biopsies may be taken. The resilience of the external sphincter and pelvic floor muscles permits an exposure which is limited only by the pelvic bones.

Closure is a very simple procedure. After closing the proctotomy the pelvic and external sphincter muscles are allowed to fall into place again. Reconstruction of the pelvic floor or external sphincter is not necessary, as no anatomical structures have been divided. This technique combines maximal exposure with minimal anatomical disturbance.

\subsection{Technique of the intersphincteric approach.}

The intersphincteric approach may be helpful in restorative radical resection or in local procedures. The surgical technique and anatomical considerations for each procedure will be discussed separately.

\subsubsection{Abdomino-interspbincteric rectum resection.}

Position (fig.5.1):

The patient is placed in the right lateral position with the back and the buttocks at the edge of the table. An indwelling catheter is placed inside the bladder and taped to the thigh. In povidone iodine drenched gauzes 
are used to clean the anorectum, and in order to kill loose tumor cells, as a prophylactic measure against tumor cell impantation in the operation area. The skin is prepared and the patient is draped to provide simultaneous access to the abdominal and perineal wound. The left leg is draped cirumferentially, keeping it mobile. This enables turning the patient slightly on the back for the abdominal phase and to the right for the perineal phase. The surgeon has to reorientate his view of the anatomy from the horizontal to the vertical plane.

This position facilitates quick orientation of the anatomy when starting the dissection from below. A hand placed in the presacral interfascial space helps to identify and meet the corresponding plane from below, after the somatic and visceral sphincters have been separated. Similarly, blunt dissection in the anterior interfascial space is facilitated. It is possible to mobilize and deliver the recto-sigmoid stump and the proximal colon through the perineal wound, thus obviating the need for turning and redraping the patient. At any stage of the procedure, the proximal colon can be inspected. When performing the colo-anal anastomosis, it is possible to return to the abdomen to further mobilize the proximal colon in order to avoid tension on the anastomosis.

The abdominal incision (fig.5.2.):

The abdomen is opened by an oblique muscle splitting incision, starting between the left costal margin, and running parallel to the iliac crest, then slightly curving across the rectus muscles and ending at a point in the middle between the pubis and the umbilicus. The muscle layers of the abdominal wall are separated parallel to their fibre direction. The fascial sheath of the rectus is opened transversally. Usually, it is necessary to transsect the rectus abdominis muscle to gain further exposure. Exposure of the left hemicolon and sigmoid is excellent. After exploration of the abdomen for

further pathology, the small bowel is pushed away in the right abdomen and is separated from the operation field by laparotomy pads. Gravity helps to keep the small intestine out of the operation area.

The abdominal phase (fig. 5.3):

The adhesive peritoneal bands between the sigmoid and the left iliac fossa are transsected. The peritoneal reflection in the left lumbar gutter is incised and the embryonic fusion plane of the descending colon and the retroperitoneum is opened bluntly. The left gonadal vessels and ureter are identified and displaced laterally by blunt dissection. The peritoneal incision is carried into the pelvis. The sigmoid mesentery is swept off the bifurcation of the aorta. It is now possible to open the presacral interfascial 
space and to develop it bluntly as far as the retromrectal space allows, keeping the mesorectum anteriorly and the sacrall vessels and nerves posteriorly covered by their fascia. This manoeuvre is important in peroperative staging. If a tumor is fixed in the presacral hollow, because it transgresses the perirectal fascia, it may be considered inoperable with curative intent. The abdomen can be closed, and irradiation therapy may be employed to render the tumor operable.

After exploring the presacral space from the left, mobilisation continues from the right. At the base of the leaf of the sigmoild mesentery, the peritoneum is incised. The right ureter and gonadal vessels are identified and kept laterally. The inferior border of the sigmoid mesentery is lifted off the sacral space and aortic bifurcation. From the left and from the right, the peritoneal incision is continued anteriorly and joins in the deepest point of Douglas' pouch. Between the rectum posteriorly and the genitals anteriorly, a remnant of an embryonic fusion plane is present. In men, this is the the fascia prostato-peronealis (or Denonvilliers' fascia) and in women, the fascia peritoneo-vaginalis. It is also, in origin, a fascial double layer which can be developed. The anterior leaf of this double layer is very well developed and covers the internal genital organs. The posterior leaf of this double layer merges with the anterior Grenzlamelle of the prerectal space and thus borders this space directly. It is a definite barrier to cancer spread. In slender females, this anterior dissection may be carried down to the perineal part of the rectum. In men or in obese femalles, this dissection is much more difficult and presents one of the important limita- tions to the transabdominal approach.

At this point, the lower extent of the tumor is determined as accurately as possible and the decision as to whether an adequate distal margin is attainable, must be made. If mobilization provides sufficient length to permit anterior resection, the operation is completed through the abdomen. However, if the tumor is barely visible, and adequate distal or radial margins are uncertain, then further mobilization will be done from below.

Next, the superior haemorrhoidal lymphovascular pedicle in the inferior border of the sigmoid mesentery is doubly clamped, divided and suture ligated. The mesocolon is further divided until the site selected for the proximal margin is reached. Grinell (1965) and Pezim (1984) have shown, that ligation of the inferior mesenteric artery at the aorta does not correlate with prolonged survival if compared with ligation at a more distal level, which is much more convenient.

The lateral ligaments are broad bands of connective tissue on either side of the rectum which attach the rectum to the pelvic sidewalls and contain the middle haemorrhoidal vessels. These ligaments have a triangular form, with the base of the triangle at the lateral sidewall of the pelvis and the apex 
near the bowel. These ligaments may be difficult to visualize. Subsequently, much of the dissection will have to be carried out blind. This limitation is avoided by the intersphincteric approach. After the posterior and anterior planes have met the corresponding posterior and anterior planes from the intersphincteric approach, the lateral ligaments are much easier to clamp, divide and ligate.

In summary, the abdominal phase in a combined abdomino-intersphincteric procedure is limited to the mobilization of the descending colon and sigmoid, the opening of the dorsal interfascial space and the incision of the peritoneal reflection in Douglas' pouch. Furthermore, the superior haemorrhoidal vessels and meso-colon are divided. The difficult part of the mobilization of the rectum will be done from below.

The posterior perineal incision (fig.5.4.):

In the intersphincteric approach, the curved skin incision runs from the right to the left tuber ischiadicurn at the dorsal side of the anus with its convexity towards the os coccygis. Pelvic bones and ligaments constitute limitations to access from below. With this incision the pelvic ring is opened at its widest diameter, enabling maximal exposure. The posterior transsacral incision is made in the posterior angle of the pelvic ring and is limited by the bordering sacrum and sacro-tuberal ligaments. The oblique incision used in the transsphincteric approach provides a keyhole exposure in the angle between os coccygis, sacro-tuberal and sacro-spinal ligaments. Only by dividing the anus sufficient access can be obtained.

There are two possible routes to expose the intersphincteric plane. One: The incision is carried directly down, then the ano-coccygeal ligament, which runs from the os coccygis to the superficial part of the external sphincter, is transsected. By bluntly splitting the muscle fibres between the superficial and the subcutaneous part of the external sphincter, the intersphincteric plane is opened. Two: A more superficial skinflap is dissected after division of the superficially running subcutaneous muscle fibres between the subcutaneous part of the external sphincter and the skin. This exposes the anatomical inferior border of the external sphincter. From this point, access is gained to the intersphincteric plane between the visceral and somatic muscle tubes of the sphincter complex. We prefer the first route which leaves the subcutaneous superficial anatomy of the anus untouched.

The intersphincteric phase (Fig.5.5-6.):

At the fusion site of the internal and external sphincter, neither neural nor lymphovascular structures cross over from one to the other. After identification of the inferior border of the external sphincter, dissection in the 
intersphincteric plane can be initiated. If bleeding occurs, the correct course has been diverted from and re-adjustment is necessary. The separation of the somatic from the smooth musculature can often be facilitated by digital dissection. At the apex of the intersphincteric plane, the levator-puborectalis muscles usually adhere firmly to the rectum, anchoring the rectum to the pelvis. The space, developed by the intersphincteric approach between the rectum and the somatic pelvic musculature, is shut off from the retrorectal space, which has already been developed transabdominally, by a ligament. This fibrous ligament is usually called Waldeyer's ligament or recto-sacral ligament, as proposed by Crapp. After step by step transsection of this ligament, the intersphincteric plane meets the dorsal retrorectal interfascial space and, subsequently, the dissection from below joins the transabdominal dissection posteriorly. A transabdominally placed hand at the utmost lower border of the retrorectal space facilitates easy identification of the correct plane from below. Posteriorly, the rectum, with its mesorectum and covering perirectal fascia, is lying completely free (fig.5.7.). Next, the perineal part of the rectum must be encircled. Division of the loose tissue at the lateral side of the rectum, which contains the inferior haemorrhoidal vessels, is performed bluntly with pledges and scissors. The visceral fascial covering of the rectum is continuous with the visceral fascial covering of the sidewalls of the prostate in order to reach the correct anterior cleavage planes, the visceral fascial covering has to be opened in the groove between the prostate and the rectum. In women, the firm rectal vaginal septum is helpful in identifying the correct path. In men, the indwelling catheter may be an orientation point which, of course, should be avoided. A rubber band is placed to encircle the perineal part of the rectum (fig.5.8). Tension on this rubber band helps to identify the ventral interfascial space, which must be dissected upwards in order to meet the incised peritoneal reflection in Douglas' pouch. Again, a hand placed transabdominally is helpful in guiding the dissection. Anteriorlly, the rectum with its covering fascia, will also be lying completely free. The lateral ligaments are the only remaining attachments of the rectum to the pelvic sidewalls. Pushing the rectum to the opposite side will put tension on the lateral ligament which, under direct vision, can be clamped from below. Transabdominally, proper placement of the clamps can be felt. Division and ligation is done from below. The extent of the tumor is determined and the distal margin identified. Transsection of the rectum is done two centimetres distal to the inferior tumor border. In order to avoid tumor cell spill, a clamp is placed distally to the tumor. Before transsection, full thickness stay sutures are placed in the anal stump to facilitate handling this stump. Before delivering the recto-sigmoid through the perineal wound, the sigmoid is transsected in case this has not been done before. The recto-sigmoid stump is brought out through the perineal wound 
(fig.5.9.). A right angled clamp can be used to handle the proximal colon and to bring it down to the level of the anal stump. If necessary, further length may be obtained by ligation and division of the left colic artery near its source. Eventually, the splenic flexure must be mobilized.

Under direct vision, a colo-anal anastomosis can be made (fig.5.10). A series of interrupted monofilament absorbable 4.0 sutures are placed to approximate the ventral wall of the bowel to the ventral wall of the anal stump. The first and last ones are retained to mark the corners of the anastomosis. A second layer, either of running or interrupted full thickness sutures is started and run in both directions, creating an inverting anastomosis. After completion of the inner layer, the outer row is completed using a few interrupted approximation sutures.

In summary, the most difficult part of the dissection, namely, the anterior dissection and the division of the lateral ligaments, has been done from below under direct vision. A colo-anal anastomosis can be performed, if necessary, at the level of the dentate line, again under direct vision. This exposure allows optimal judgement on the radial and distal clearance of tumors in the lower pelvis.

Closure, and protective colostomy:

Closure of the perineal wound is not difficult. The levator-external muscles are allowed to fall into place (fig.5.11). Eventually, some approximation sutures may be placed to accentuate the (neo)-recto anal angle and to lengthen the (neo-)anal canal (fig.5.19). The anococcygeal ligament, which is a firm structure, is sutured again. The subcutis and skin are closed approximally to allow sufficient drainage between the stitches. Or the skin is just left open.

No attempt is made to close the defect in the pelvic peritoneum. Loops of small bowel or an omentumplasty on the right gastroepiploic artery will fill the pelvic dead space and fluid accumulating in the pelvis is allowed to drain into the peritoneal cavety. A silicone suction drain is left inside the pelvis. Before closure of the abdominal wall, a protective colostomy is constructed in the right upper abdomen. A double loop of transverse colon is brought out through a small aperture in the skin and through the rectus muscle. A large drain is placed between the loop and the skin to prevent sliding back into the abdomen. This drain will be left in situ for two weeks till adhesions have taken over its function. Care must be taken to bring out a loop proximal to the middle colic artery to prevent impaired blood flow in the marginal artery distal to the middle colic artery.

A protective colostomy will not prevent anastomotic problems which are very frequent after colo-anal anastomoses, but will certainly ameliorate its sequelae. 


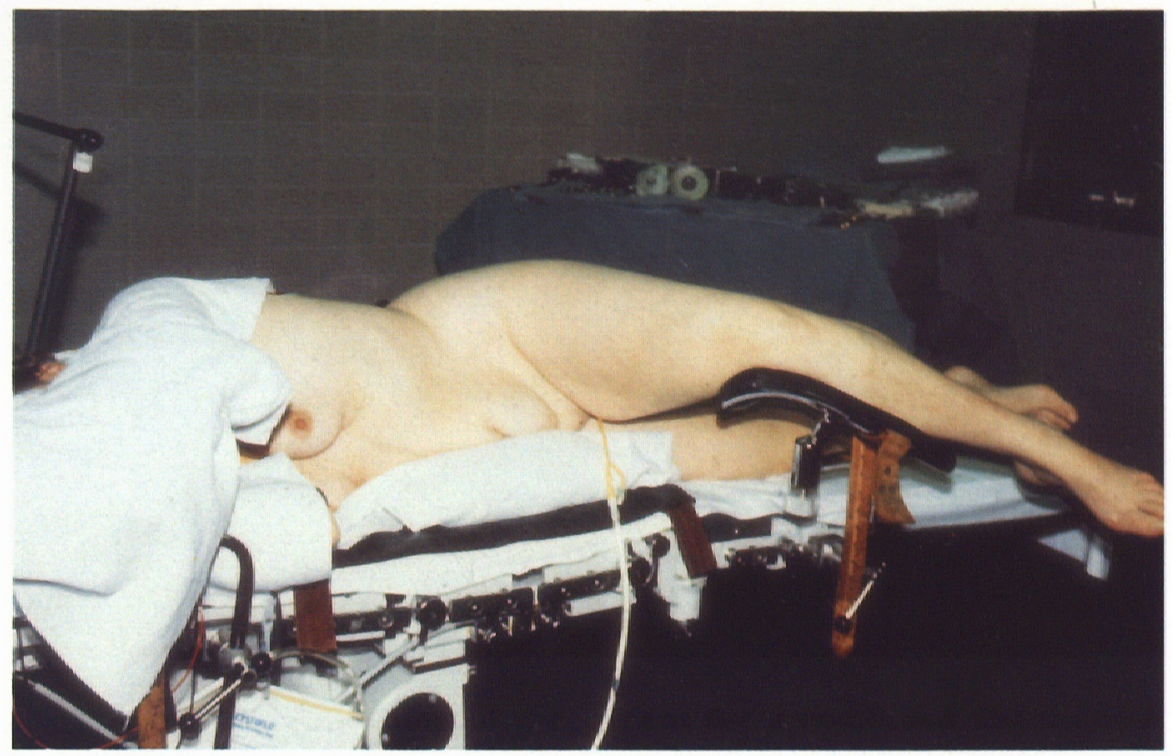

Fig. 5.1. Positioning of the patient for a combined abdomino-intersphincteric procedure. The patient is placed in the right lateral position. The left leg will be draped circumferentially, keeping it mobile. 


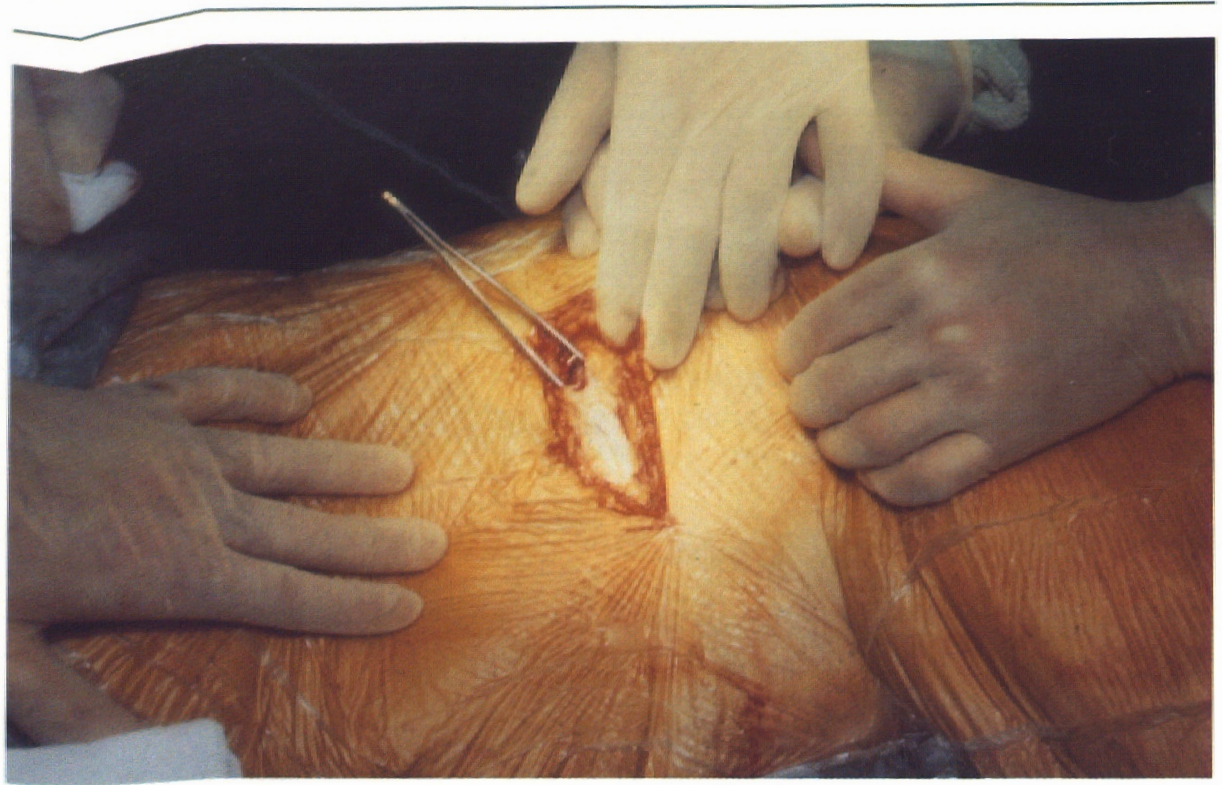

Filg. 5.2. The abdominal incision. The incision starts at the left costal margin, parallels the iliac crest and curves slightly across the rectus abdominis muscle ending at a point midway between the pubis and the umbilicus.

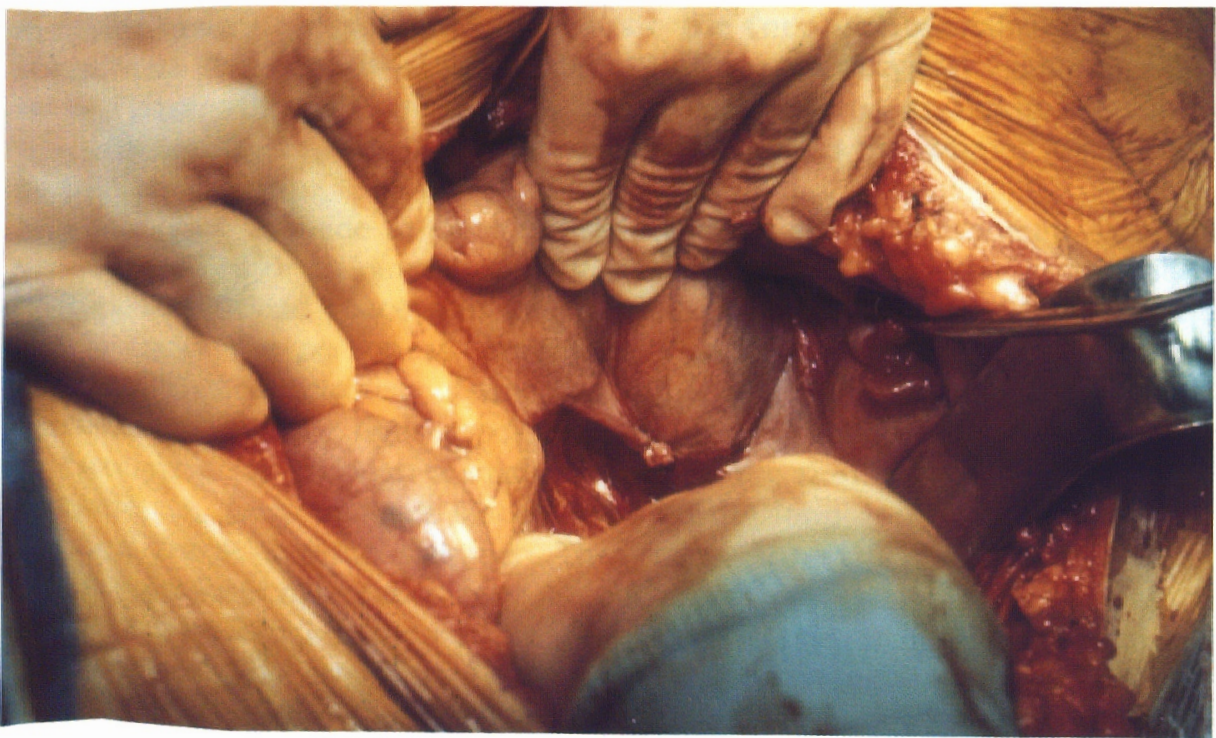

Fig. 5.3. The abdominal phase. In case of sufficient access, an anterior resection can be performed through this incision. Otherwise, the distal mobilization of the rectum and the restoration of the bowel continuity will be done from below. 


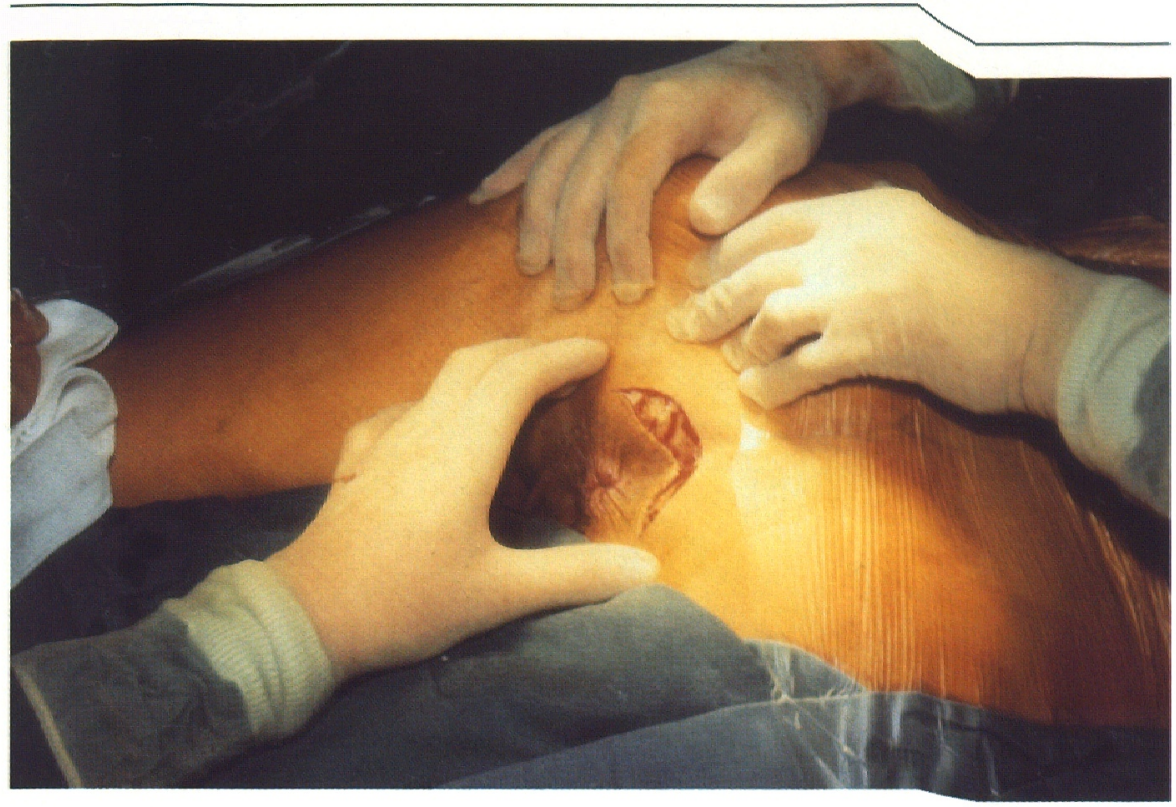

Fig. 5.4. The posterior perineal incision. The curved skin incision runs from the right to the left tuber ischiadicum at the dorsal side of the anus, with the convexity towards the tip of the os coccygis. 


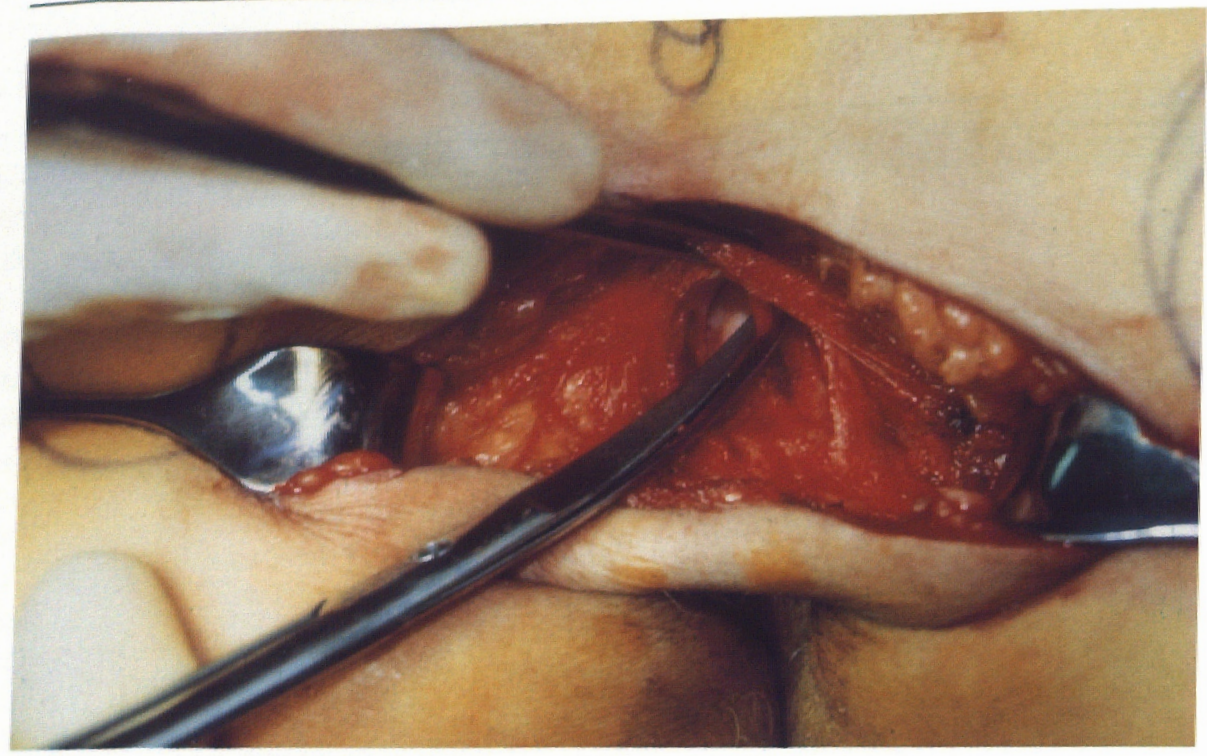

Fig. 5.5. Development of the intersphincteric plane. In the avascular intersphincteric plane, the striated muscle of the external sphincter is separated from the smooth muscle of the internal sphincter.

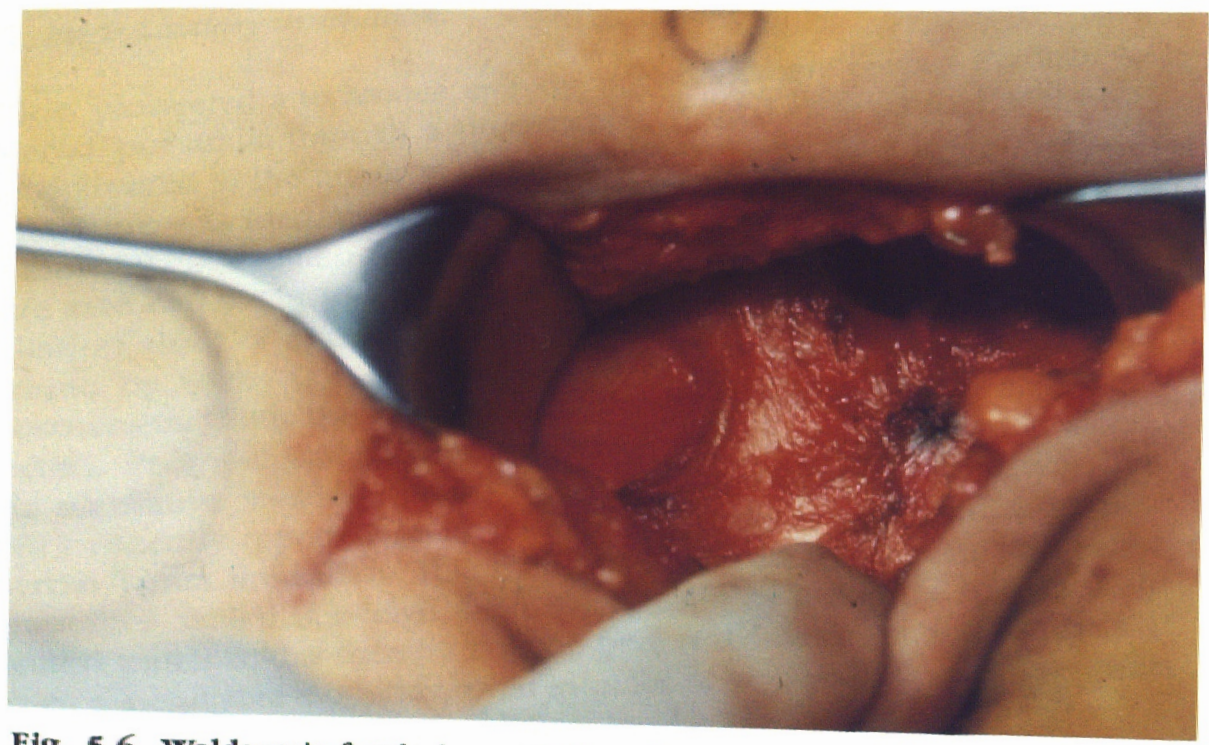

Fig. 5.6. Waldeyer's fascia is encountered at the apex of the dissection. This ligament-like fascia will be divided in order to free the rectum from its dorsal attachment to the fascia pelvis parietalis and to reach the superior retrorectal space. 


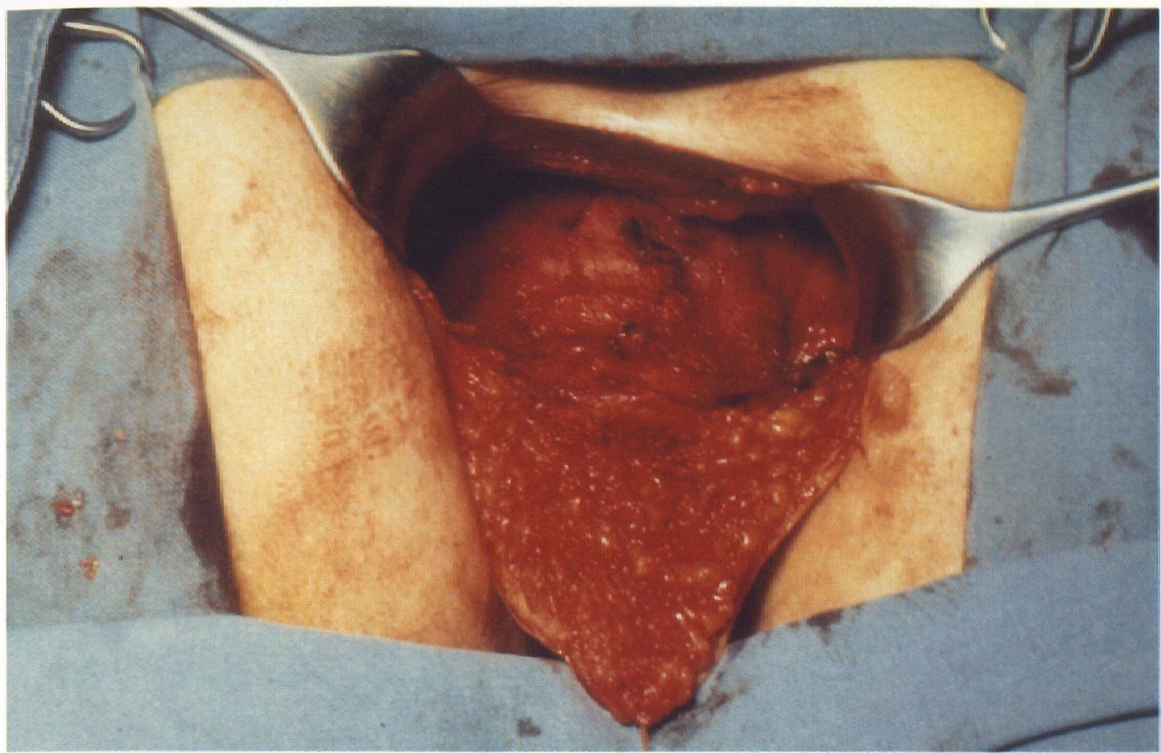

Fig. 5.7. Posteriorly, the rectum, with its mesorectum and covering perirectal fascia, is lying completely free.

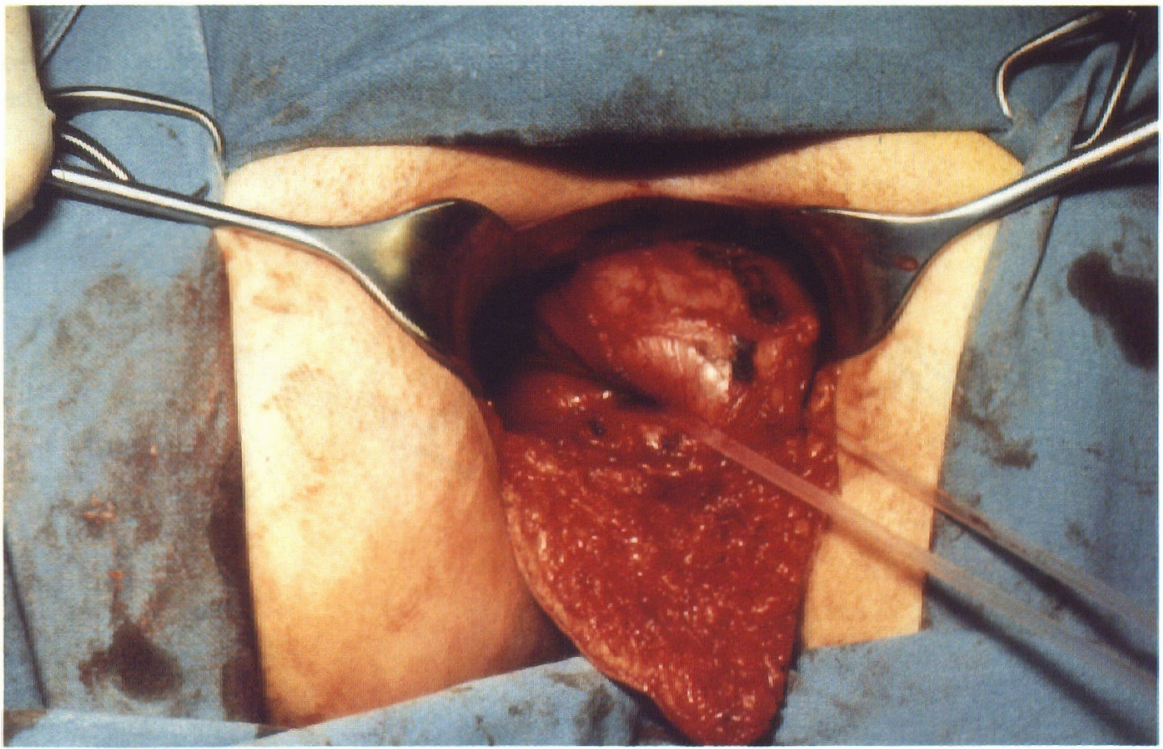

Fig. 5.8. The perineal part of the rectum is encircled by a rubber band. Tension on this rubber band helps in the upward dissection of the anterior interfascial space as well as in identifying the lateral attachments. 


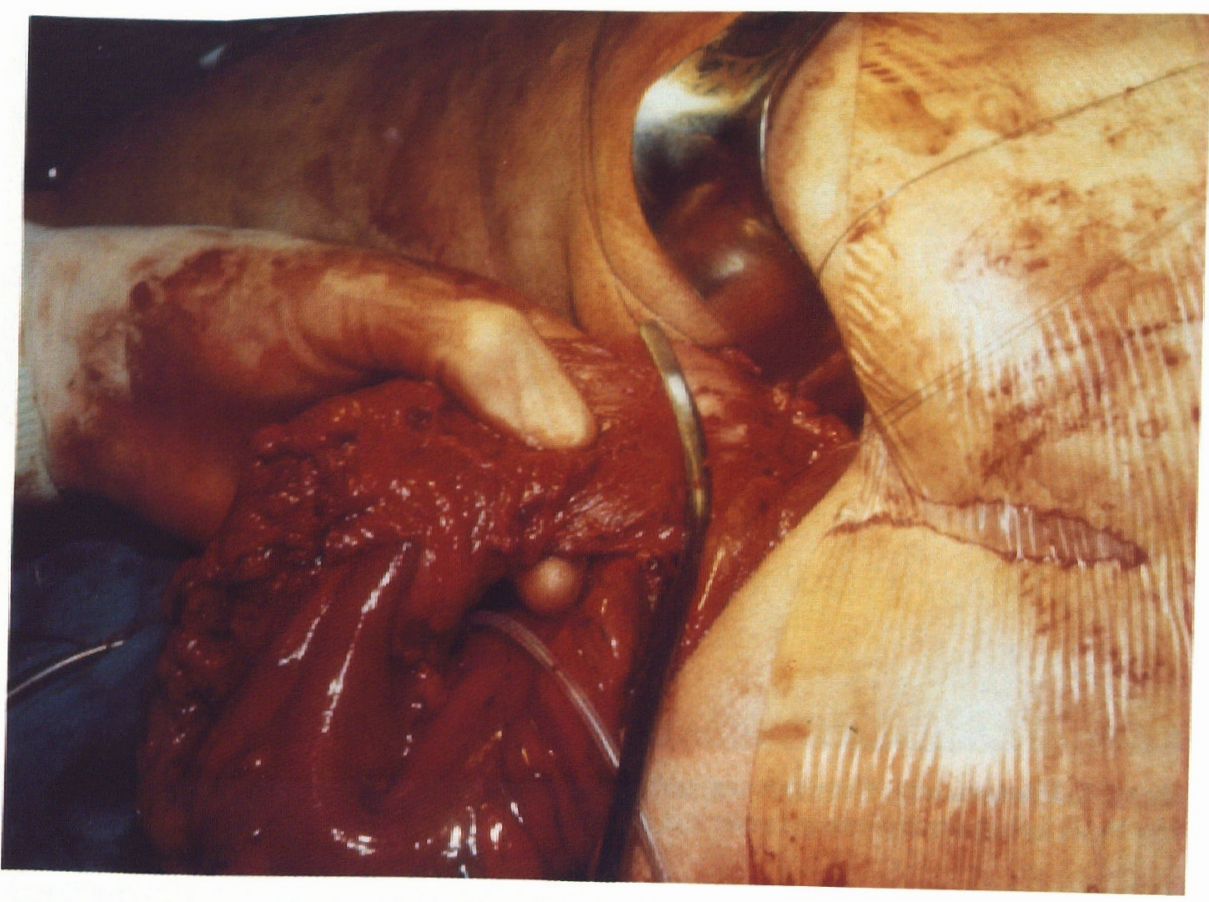

Fig. 5.9. The rectosigmoild delivered through the perineal wound. In order to avoid tumor cell spill, a clamp is placed well, or at least two centimetres, below the 
Fig.5.10a.
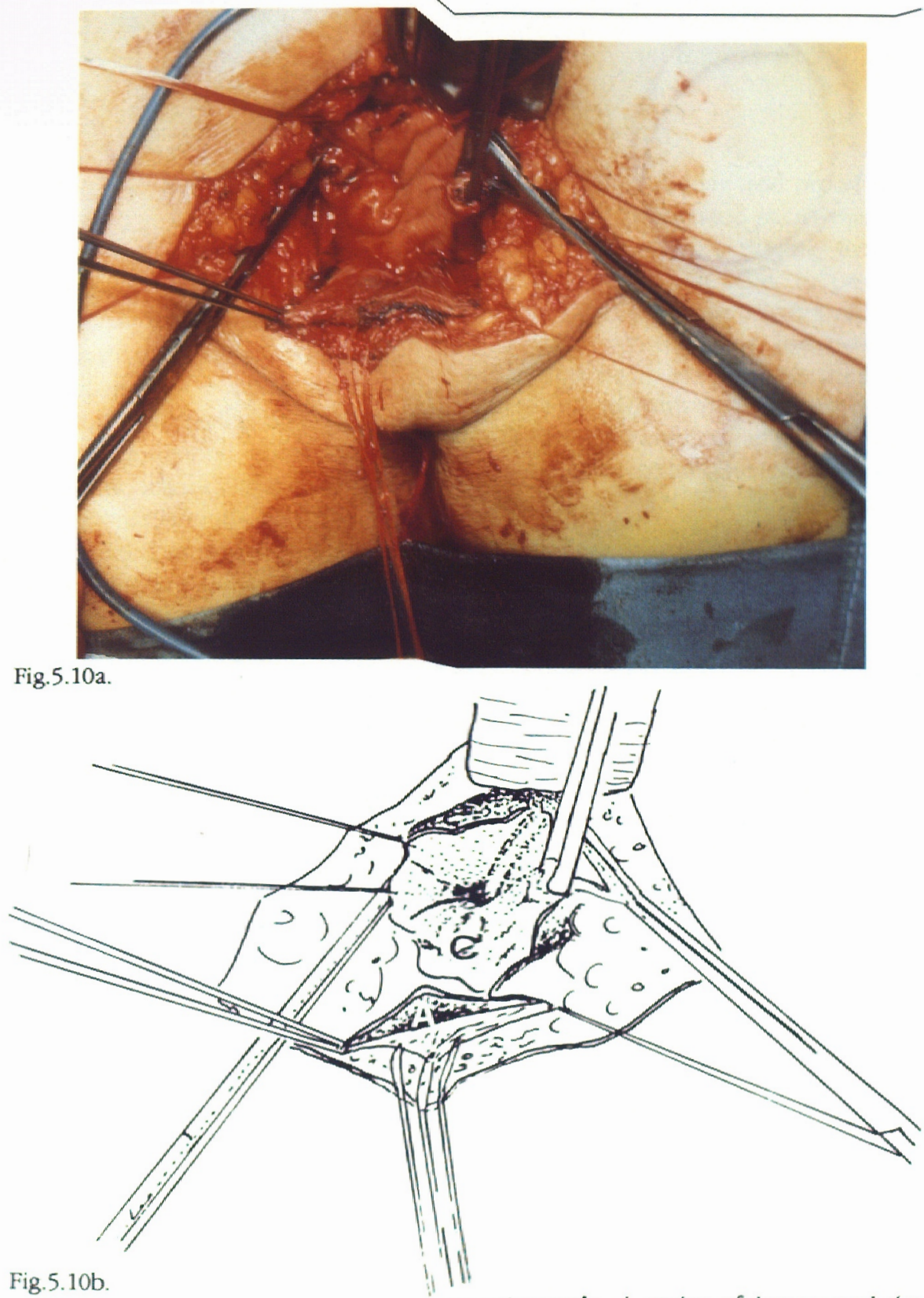

Fig. 5.10a-b. Start of the collo-anal

anastomosis. A series of interrupted 4.0 collon (C) the anal stump (A). Stay sutures sutures are placed to approximate the colon
are helpful in identifying the correct structures. 


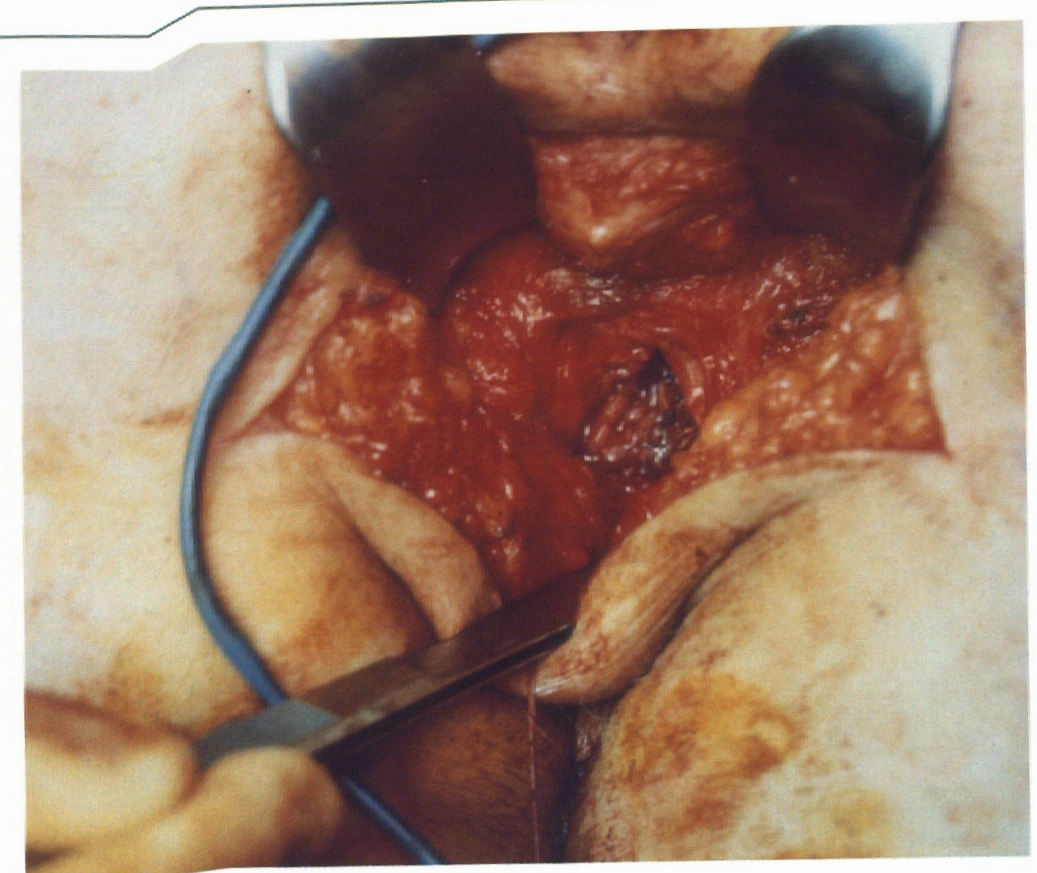

Fig. 5.11a.
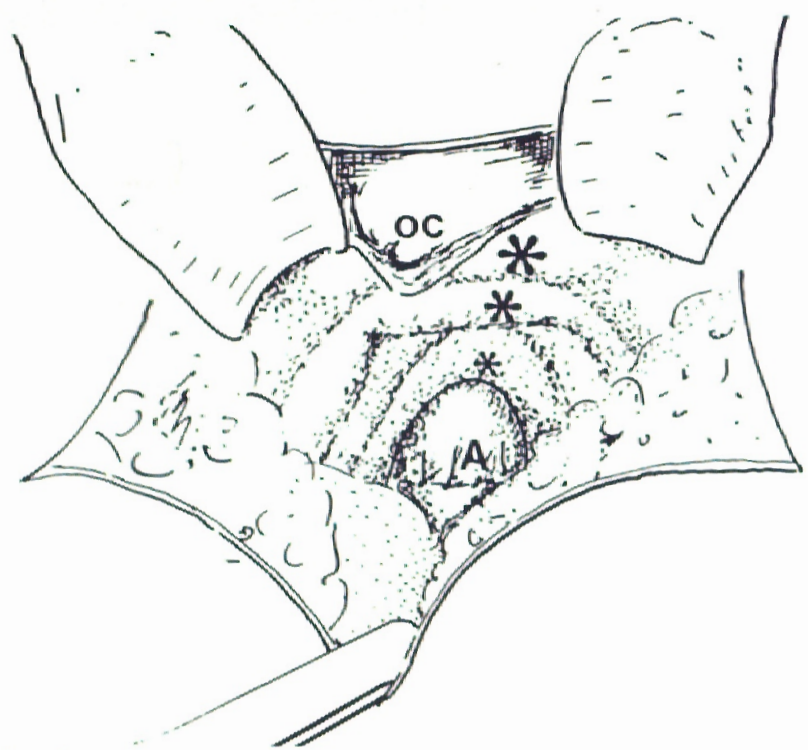

Fig. 5. 11b.

Fig. 5.11a-b. Completion of the anastomosis. The levator-puborectal-external sphincter muscle complex is allowed to fall into place. As this complex has not been divided, no suturing is necessary. (oc = os coccygis, $A=$ sutureline anastomosis, *** levator-puborectal external spincter complex). 


\subsubsection{Local procedures through an intersphincteric approach.}

\subsubsection{Interspbincteric proctotomy.}

An indwelling urine catheter is placed inside the bladder and taped to the thigh. The patient is placed in prone position with elevated sacro-coccygeal region. The legs are flexed and abducted in the hips and slightly flexed in the knees, enabling the surgeon to stand between the legs. In povidone iodine drenched gauzes are used to prepare the anorectum. After skin preparation the patient is draped, leaving a rectangle of the posterior perineum, including the anus, free for the incision. The perineal skin incision is the same as for the combined abdomino-intersphincteric approach. Carrying down the incision to the intersphincteric plane is easier in this horizontal position. Developing the intersphincteric plane is partly done by scissors and partly by digital dissection. In the midline, Waldeyer's fascia connects the rectum to the sacrum. Usually, the interfascial space can be opened at both lateral sides with pledges. In this manoeuvre the lateral ligaments are pushed down. After having done this, it is much easier to dissect the fibrous ligament in the midline and in the correct plane. Now, the anal canal and lower rectum may be retracted anteriorly and the external-puborectal-levator muscle posteriorly. Loose adhesions in the interfascial space are dissected. The dorsal aspect of the lower rectum, covered by its perirectal fascia, is now lying completely free from the pelvic floor and sacrum. The somatic musculature may be retracted as far as the pelvis bones and ligaments allow. A proctotomy, to reach growth on the anterior aspect or to perform a mucosectomy, may be done (fig.5.12.). This exposure provides an excellent opportunity to perform a full thickness local excision of the dorsal wall of the rectum (fig.5.13.). The mesorectum may be palpated and searched for lymphnode metastases. Biopsies may be taken. The pelvic rectum consists of a mucosa-muscular bowel wall, a mesorectum and a fascial covering. Closure of the tomy is done in two layers. The bowel wall is closed by either interrupted monofilament absorbable 4.0 sutures or a running suture of the same material. The fascial layer is closed with some interrupted approximation sutures. Closure in the intersphincteric approach is much the same as in the combined procedure, but differs in that a soft silicone suction drain is used to evacuate fluid accumulating in the sacral dead space. This drain remains in situ till it ceases to produce. A protective colostomy is not necessary.

\subsubsection{Interspbincteric segmental resection (fig.5.14-19).}

A more sophisticated extended local procedure is the segmental resection 
with colo-anal anastomosis. To do this, the anterior aspect of the perineal and pelvic rectum, the lateral ligaments and the superior haemorrhoidal artery have to be dissected. This technically very demanding procedure may have few indications. It can be considered as a limited kind of radical surgery. The pelvic rectum, covered by its perirectal fascia, is removed. All local lymphnodes are present for staging. The superior hemorhoidal artery is ligated just below the promontory which is three to five $\mathrm{cm}$ distal to the site of the transabdominal ligation. This was found in combined procedures, at the beginning of our series, when we started with the intersphincteric mobilization prior to the abdominal phase. By placing clips the difference in transsection site after an intersphincteric mobilization or after a transabdominal approach could be measured.

Rectal cancer does not spread intramurally; the dissemination routes are lymphogenic and blood born. Lymphogenic spread is stepwise. Local lymphnodes will not be left out. The chance of cure after dissemination has occurred in the regional lymphnodes along the superior haemorrhoidal artery, is very limited. From this follows, that the transsection site of the lymphovascular pedicle is of very relative importance (Pezim 1984). The length of proximal bowel needed for radical resection will not exceed a few centimeters (Black 1948), similar to the distal clearance, which has been investigated exhaustively. (Williams 1985). The advantage of a segmental resection is, that it permits doing a local radical resection without the need of a laparotomy. As the entire resection follows anatomical planes, bloodloss will rarely exceed a few hundred millilitres. Morbidity by obviating the need for a laparotomy is very low. This procedure may be considered in high risk patients or in patients with very large villous adenomas.

Mobilization of the ventral side of the rectum starts with encircling the perineal part of the rectum. Traction helps to identify the ventral interfascial space. This space is developed as high up as possible. In women, the peritoneal pouch of Douglas in easily reached. In men, this may be much more difficult, but it is not imperative to open the peritoneum. The lateral ligaments are bridges of tissue between the dorsal and ventral interfascial spaces. Stepwise these ligaments are transsected. After division of the lateral ligaments, the pelvic rectum is kept in place only by the superior haemorrhoidal lymphovascular pedicle. Traction on the distal rectum helps to identify this pedicle. Clamping, division and ligation of the superior haemorrhoidal vessels can be done from below, a few centimetres distal to the promontory. Ligation sutures must be secure as bleeding will be difficult to control from below and will after all necessitate a laparotomy. Mobilization of the pelvic rectum is not difficult. Theoretically, inflammatory processes may have caused firm adhesions in the pelvis and prevent suf- 

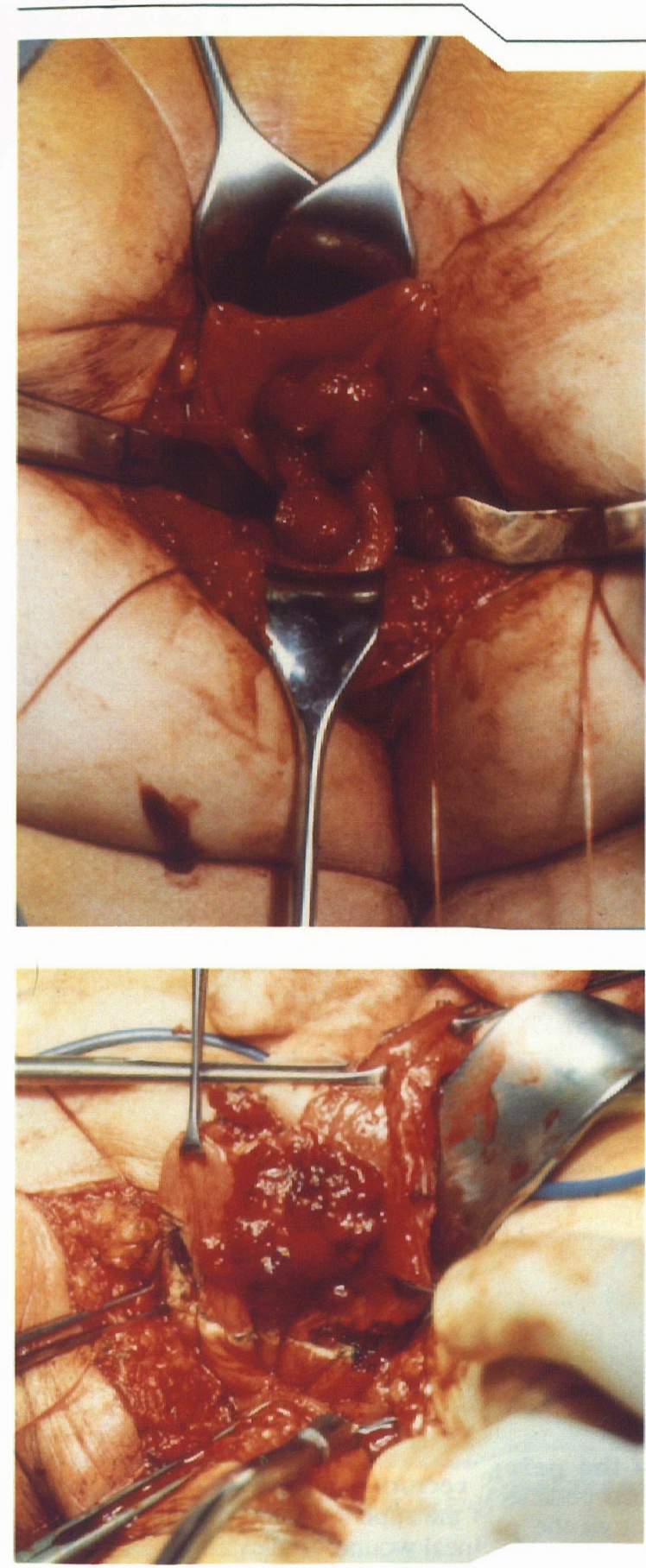

Fig.5.12. Intersphincteric proctotomy. Through the dorsal proctotomy a villous adenoma can be seen. It will be removed as a mucosectomy.

Fig. 5.13. Intersphincteric full thickness local excision. Stay sutures are placed in the resection margins in order to facilitate closure of the defect in the bowel wall. 


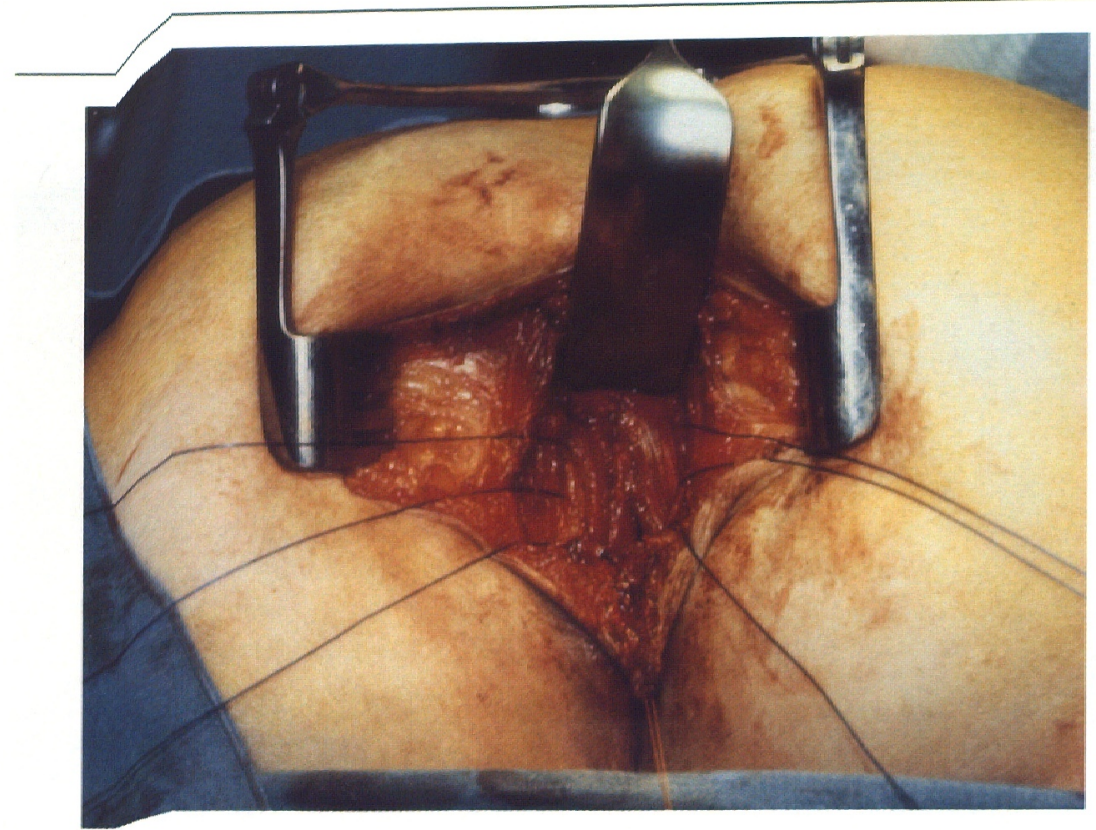

Fig. 5.19. Approximation of the external sphincter is optional. Some approximation sutures in the opposite limbs of the external sphincter may accentuate the (neo-)recto-anal angle and lengthen the anal canal. 
ficient mobilization. In this case a minimal laparotomy may help out. In our series, we never encountered serious problems in bringing down the rectosigmoid in segmental resection, after the rectum had been freed from its attachments. Placement of clamps proximally and distally from the tumor should secure a closed resection without chance of tumor cell spill. Under direct vision, a colo-anal anastomosis may be performed as in the combined procedure. After approximating closure and drainage of the perineal wound, the patient is turned and, via a small muscle splitting incision in the upper right abdomen, a diverting double loop colostomy is placed.

Conclusion: The intersphincteric approach provides excellent access to the lower rectum to easily perform local procedures. A technically very demanding procedure is the segmental resection, which provides the possibility for a local radical resection of the pelvic rectum without the need of a laparotomy. Since in this last procedure a colo-anal anastomosis is made, a protective diverting colostomy is recommended. 


\section{References chapter 5:}

Baker AR: Local procedures in the management of rectal cancer.

Semin. Oncol. $7,385-391,1980$.

Beart .RW. Kelly KA.: Randomized prospective evaluation of the EEA stapler for colorectal anastomoses.

Ann.Surg. 141;143-147, 1981 .

Black WA, Waugh JM.: The intramural extension of carcinoma of the descending colon sigmoid and rectosigmoid.

Surg. Gynecollobstet. 84;457-464, 1948 .

Crile $\mathrm{G}$., Turnbull RB.: The role of electrocoagulation in the treatment of carcinoma of the rectum.

Surg.Gynecol. Obstet. $135,391,1972$.

Cripps WH.: Cancer of the rectum; its surgical treatment.

Sth ed.London, J A. Churchill, 1907.

Cutail DE. Figlioni FJ: A new method of colorectal anastomosis in abdominoperineal resection.

Dis.Colon Recium 4;335-342, 1961.

De Graaf PW., Roussel JGJ., Hart GAM., Jongmans A., v.Slooten E.: Elektrofulguratie als sfinctersparende behandeling van rectumcarcinomen.

Ned.Tijdschr.Geneeskd. 129;1928-1931, 1985.

Deddish MR., Stearns MW: Anterior resection for carcinoma of the rectum and recto-sigmoid area.

Ann.Surg. 154;961-966, 1961.

Dixon CF: Anterior resection for carcinoma low in the sigmoid and the rectosigmoid.

Surg. $15 ; 367-377,1944$.

Drake DB., Pemberton Jh. Beart RW, Dozois RR., Wolf BG.: Coloanal anastomosis in the management of benign and malignant rectal disease.

Ann.Surg. 206;600-605, 1987 .

Dukes CE, Bussey HIR.: The spread of rectal cancer and its effect on prognosis.

Br.J.Cancer. 12;309-320, 1958.

Enker ME. Stearns MW, Janov AL. Peranal coloanal anastomosis following low anterior resection for rectal carcinoma.

Dis.Colon Rectum 28;575-581, 1985.

Gabriel WB., Dukes $C_{\text {. }}$ Bussey HJ.: Lymphatic spread in cancer of the rectum.

B.j.J.Surg. 23,395-413, 1935. 
Gemsenjäger E., Martina $B_{\text {. }}$ Anwendung verschiedener Operationsverfahren beim Rektum-Karzinom.

Chirurg 58;33-37, 1987.

Gillen P.x Peel ALG.: Comparison of the mortality, morbidity and incidence of local recurrence in patients with rectal cancer treated either by stapled anterior resection or abdominoperineall resection.

Br.J.Surg. 73,339-341, 1986.

Goligher JC., Lee PWR., McFie J., Simpkins KC., Lintoth DJ.: Experience with the russian suture gun for rectal anastomoses.

Surg.Gynecol.Obstet. 148;517, 1979 .

Greaney $\mathrm{MG}_{\text {, }}$ Irvin TT:: Criteria for the selection of rectal cancers for local treatment: A clinicopathologic study of low rectal tumors.

Dis.Colon Rectum 20;463-466, 1977.

Häring R., Karavias T., Konradt J.: Die posteriore Proktorectotomie.

Chirurg 49;265, 1978.

Henry MM., Swash M.: In: Coloproctology and the pelvic floor.

Buttersworths London, 1985.

Henry MM., Porter $\mathrm{NH}_{\text {: }}$ A colour atlas of faecal incontinence and complete rectal prolapse.

Wolfe Medical Publications Ltd., London, 1988.

Hill MJ., Morson BC., Bussey HJR.: Aetiology of adenoma-carcinoma sequence in large bowel.

Lancet $\mathrm{I} ; 245-247,1978$.

Holdsworth PJ., Johnston D.: Anal sensation after restorative proctocolectomy for ulcerative colitis

Br.J.Surg. 75;993-996, 1988 .

Huber A., Hochstetter v. AHC., Allgöwer M.: Transsphinktere Rektumchinurgie. Springer-Verlag Berlin, 1983.

Keighley MRB., Matheson D.: Functional results of rectal excision and endo-anal anastomosis.

Br.J.Surg. 67;757-761, 1980.

Keighley MRB., Fielding JWL.: Management of faecal incontinence and results of surgical treatment.

Br.J.Surg. 70;463-468, 1983 .

Kllok PAA: The treatment of some forms of rectal cancer by electrocoagulation.

Arch.Chir. Neerl. 14;173-183, 1964. 
Knight CD., Griffen HD.: An improved technique for low anterior resection of the rect um using the EEA stapler.

Surgery $88 ; 710,1980$.

Lazorthes F, Fages P, Chiotasso P., Bugat R. Synchronous abdominotranssphincteric resection of low rectal cancer: new technique for direct colo-anal anastomosis.

Br.J.Surg: $73,573-575,1986$.

Localio SA. Baron B. Abdomino-transsacral resection and anastomosis for mid rectal cancer.

Ann.Surg. 178;540-545, 1973.

Localio SA, Eng K., Coppa GF: Anorectal presacral and sacral tumors.

W.B.Saunders Company, Philadelphia, 1987.

Lockhart-Mummery HE, Ritchie JK., Hawley PR.: The results of surgical treatment for carcinoma of the rectum at St Mark's Hospital from 1948 to 1972.

Br.J.Surg. 63;673-677, 1976.

Madden JL.. Kandalaft S.: Electrocoagulation in the treatment of cancer of the rectum.

Ann.Surg. 174;530-538, 1971.

Mann $\mathrm{CV}$.: Techniques of local surgical excision for rectal carcinoma.

Br.J.Surg. 72suppl;57-58, 1985.

Mathus-Vliegen EMH.: The role of laser in gastroenterology.

Thesis, 1988.

Maunsell HW.: A new method of excising the two upper portions of the rectum and the lower segment of the sigmoid flecture of the colon.

Lancet $2 ; 4731892$.

Morson BC., Bussey HJR., Samoorian S.: Policy of local excision for early cancer of the colorectum

Gut $18 ; 10$ 15-1050, 1977 .

OH $\mathrm{C}_{\text {., Kark }} \mathrm{AE}$. :The transsphincteric approach to mid and low rectall villousadenoma: anatomic basis of surgical treatment.

Ann. Surg. 176,605, 1972.

Olsen WR: Transanal excision of sessile rectal polyps.

Surg.Gynecol.Obstet. $140 ; 766-768,1975$

Palumbo LT, Wendell SS.: Anterior versus abdominoperineal resection.
Am.J.Surg. $115 ; 657-660,1968$.

Papillon J, Intracavitary irradiation of early rectal cancer for cure. 
Papillon J: The future of external beam irradiation as initial treatment of rectal cancer.

Br.J.Surg. 74;449-454, 1987.

Parks AG.: Postanal perineorrhaphy for rectal prolapse.

Proc.Roy.Soc.Med. 60;920-921, 1967.

Parks AG.: Transanal technique in low rectal anastomosis.

Proc.Roy.Soc.Med. 65;975-976, 1972.

Parks AG.: Pre-anal anastomosis.

World.J.Surg. 6;531-538, 1982.

Parks AG., Percy JP.: Resection and sutured colo-anal anastomosis for rectal carcinoma.

BrJ.Surg. 69;301-304, 1982.

Penfold JCB.: A comparison of restorative resection of carcinoma of the middle thind of the rectum with abdominoperineal excision.

Aust.N.Z.J.Surg. 44;354-356, 1974.

Pezim ME., Nicholls RJ.: Survival after high or low ligation of the inferior mesenteric antery during curative surgery for rectal cancer.

Ann.Surg. 200;729-733, 1984.

Quer EA., Dahlin DC., Mayo CW.: Retrograde intramural spread of cancinoma of the rectum and rectosigmoid.

Surg.Gynecol.Obstet. 96;24-30, 1953.

Quirke P., Durdey P., Dixon MF, Williams NS.: Local recurrence of rectal adenocarcinoma due to inadequate surgical resection.

Lancet II;996-999, 1986.

Salvati EP., Rubin RJ., Eisenstat TE., Siemons GO.,Mangione JS.: Electrocoagulation of selected carcinoma of the rectum.

Surg.Gynecol.Obstet. 166;393-396, 1988.

Schiessel R., Wunderlich M., Waneck R.: Ergebnisse der coloanalen Anastomose bei tiefsitzenden Tumoren des Recrums.

Chirurg 57;792-796, 1986.

Sischy B.: The place of radiotherapy in the management of rectal carcinoma. Cancer 50;2631-2637, 1982.

Slanetz CA., Herter FP., Grinnell RS.: Anterior resection versus abdominoperineal resection for cancer of the rectum and rectosigmoid.

Am.J.Surg. 123;110-116, 1972.

Stearns MW., Sternberg S, Decoss JJ.: Treatment alternatives. Localized rectal cancer. Cancer 54;2691-2694, 1984 

Turnbull RB.: Carcinoma of the rectum: Nonresective treatment.
Dis. Colon Rectum 17;588, 1974 .

Vandertoll DJ., Beahirs OH.: Carcinoma of rectum and low sigmoid.
Arch.Surg. 90;793-798, 1965. Wassink WF.: The curative treatment of carcinoma recti by means of electro-
coagulation and radium.

Arch.Chir.Neerl. 8;313-329, 1955.

Waugh JM., Block MA., Gage RP.: Three and five-year survivals following combined abdomino-perineal resection, abdominoperineal resection with sphincter preservation and anterior resection for carcinoma of the rectum and lower part of
the sigmoid colon. Ann.Surg. 142;752-757, 1955. Whiteway J., Nicholls RJ., Morson $\mathrm{BC}$ : The role of surgical local excision in the
treatment of rectal cancer.

Br.J.Surg. 72;694-697, 1985.

Williams NS., Dixon MF. Johnston D.: Reappraisal of the 5 centimetre rule of distal excision for carcinoma of the rectum: a study of distal intramural spread and of patient's survival.

Br.J.Surg. 70;150-154, 1983.

Williams NS., Durdey P., Johnston D.: The outcome following sphincter saving resection and abdominoperineal resection for low rectal cancer.

Br.J.Surg. 72;595-598, 1985. 


\section{Chapter 6}

\section{Intersphincteric procedures. -Clinical and Physiological results-}

\subsection{Introduction.}

The intersphincteric approach was developed primarily to gain additional access to the lower pelvis, thereby facilitating rectal resection in low seated rectal cancer. The aim of the rectal resection is to remove the entire mesorectum covered by its fascia in order to eliminate remaining mesorectal adipose tissue, which, theoretically, may be a reservoir for residual microscopic disease.

However, the intersphincteric approach also provides an excellent operating field for procedures relating to the anorectum. It enables the performance of a colo-anal anastomosis in a simple way, thereby extending the scope of restorative rectal surgery. And lastly, it has enabled the development of new techniques for local procedures.

From an oncological point of view, a procedure may be classified as either radical, meaning en bloc resection of the rectum, including its regional lymphatic field, or locally ablative. Nevertheless, a small band in the spectrum of treatment is represented by segmental resections. In segmental resection, the pelvic rectum is removed along with its mesorectum containing all local lymphnodes and covered by its perirectal fascia. The regional lymphatic field along the superior haemorrhoidal artery is left in situ. The presence of local lymphnodes in the specimen permits accurate postoperative staging. If lymphnodes are negative and the tumor is confined to the bowel wall, the procedure may be considered radical. From a technical point of view, this procedure is a resection with a colo-anal anastomosis. For the patient the magnitude of the operation is comparable to a local procedure.

Complete full thickness biopsies or mucosectomies through intersphincteric proctotomies are, strictly speaking, local procedures.

Patient selection for any of the intersphincteric procedures depends on several factors: Preoperative staging should have indicated, that the tumor is limited to the rectum, i.e. that the perirectal fascia has not been invaded by tumor, to allow free lateral margins. Furthermore a free distal margin of at least two centimetres should be available. This means, that the distal margin of the tumor should be no less than two centimetres proximal to the dentate line, as this level is considered the lowest possible for a colo-anal anastomosis. After clinical staging it is generally possible to decide which procedure may be carried out. In fixed tumors, additional CT-scanning is 
needed to provide information regarding the operability and/or the desirability of preoperative irradiation. When segmental or even more limited local resections are contemplated, endorectal ultrasound may be helpful in determining the degree of infiltration into the bowel wall.

Ultimately, of course, the definite choice of procedure is made after the abdomen has been opened.

In figure 8.1. (chapter 8) a flow-chart is presented summarizing the selection criteria.

Table 6.1. provides general information about the patients treated in this study.

\begin{tabular}{|c|c|c|c|}
\hline & \multirow{2}{*}{$\begin{array}{l}\text { Abdomino-intersph. } \\
\text { procedures }\end{array}$} & \multicolumn{2}{|c|}{ Local procedures } \\
\hline & & $\begin{array}{l}\text { Segmental } \\
\text { Resections: }\end{array}$ & $\begin{array}{l}\text { Local } \\
\text { Excisions }\end{array}$ \\
\hline Number Patients & 14 & 9 & 12 \\
\hline Mean age & $56 \mathrm{yr}$ & $71 \mathrm{yr}$ & $66 \mathrm{yr}$ \\
\hline Range age & $46-73$ yrs & $40-88$ yrs & $46-80$ yrs \\
\hline $\operatorname{Sex}(M / F)$ & $8 / 6$ & $6 / 3$ & $3 / 9$ \\
\hline $\begin{array}{l}\text { Mean distance } \\
\text { twumor - anal verge }\end{array}$ & $6.2 \mathrm{~cm}$ & $5.8 \mathrm{~cm}$ & $6.8-10.3 \mathrm{~cm}^{*}$ \\
\hline $\begin{array}{l}\text { Number patients } \\
\text { with malignancy }\end{array}$ & 14 & 8 & 6 \\
\hline
\end{tabular}

Table 6.1.

- Mean lower and upper borders of the numor.

Three different kinds of procedures were performed using the intersphincteric approach. These techniques were applied in three quite different categories of patients. Thus, the clinical results of abdomino-intersphincteric, segmental and local resections will be discussed separately.

\subsection{Patients and Methods.}

\subsubsection{Abdomino-interspbincteric resections.}

Patients eligible for this procedure should have a mobile or only slightly tethered tumor on rectal palpation and the margin between the lower border of the tumor and the dentate line should be no less than two centimetres. Transabdominal removal should be regarded impractible or too and resection. 
Fourteen patients underwent a combined procedure: six women and eight men, with a mean age of 56.

Most patients $(10 / 14)$ presented with loss of blood or mucous, three had noted a change in bowel habits (a degree of incontinence or sensation of tenesmus). One patient underwent regular check-ups since the local peranal removal of a T1 tumor two years earlier. During one such checkups, a small nodule was felt in the mesorectum. Puncture, guided by endorectal ultrasound revealed a local recurrence.

Clinico-pathological staging primarily consisted of rectal palpation and rigid rectoscopy during which biopsies were taken. All but one of the patients had mobille or only slightly tethered tumors. One patient had a voluminous tumor which made evaluation of mobility difficult. An additional CT-scan confirmed the integrity of the perirectal fascia.

Prior to operation, biopsies confirmed the presence of adenocarcinoma in 13 patients. During operation, a frozen section from a mucosectomy specimen of a villous adenoma revealed invasive growth in patient fourteen. After this finding, the procedure was continued as an abdomino-intersphincteric resection.

The mean distance between the anal verge and the inferior border of the tumor was six centimetres. In two patients a rim of exophytic growth extended down to a level of only a few millimetres above the dentate line. This had only been detected during the operation, and meant that a segment of the dentate line had to be removed as well.

Led by curiosity rather than necessity, an ultrasound investigation was performed in seven out of fourteen patients. The sonograms confirmed the clinical impression that no gross infiltration of the perirectal tissue had taken place.

In staging patients with rectal cancer, fixation at rectal examination appeared to be a bad omen. Ct-scanning showed that only one patient out of the six who were examined for fixation had an intact fascia recti propria. This patient was the only one who could be selected for a combined procedure. All other patients received, during the time of this study, irradiation or were treated by abdomino-perineal resection for tumors which had infiltrated the surrounding structures.

Only patients with intact surgical cleavage planes, indicating tumor growth that had not affected the perirectal fascia, were considered candidates for very low restorative procedures.

Preoperatively, a full colon examination by colonscopy or barium enema had ruled out the possibility of a tumor elsewhere in the colon.

Method.

The operations on the first five patients were all started off with the inter- 
sphincteric part of the procedure. Later on, the operation was started with the laporotomy. By performing the laparotomy first, the abdomen can be explored for further pathology. Furthermore, the tumor itself can be accurately staged with regard to operability; if the tumor cannot be mobilized by simple manoeuvres like opening the sacral hollow and incising the peritoneal reflection in Douglas" pouch, operability may be doubtfull, and the therapeutic approach may have to be reconsidered. None of the patients scheduled for restorative resection appeared to be inoperable after abdominal staging.

In favourable cases, the operation could be completed as an anterior resection after mobilization had provided sufficient length of bowel for a safe resection and anastomosis. During the study, four patients had been prepared for a combined procedure, but the operations could be completed transabdominally.

Another advantage of commencing the operation with a laparotomy was, that it simplified the intersphincteric dissection. Identification of the interfascial spaces from below could be guided by placing a hand in the corresponding spaces above. Ligation of the lymphovascular pedicle was performed just distal to the left colic artery, leaving the remaining sigmoid solely dependent on the marginal artery for its bloodsupply. Ligation of the proximal sigmoidal vessels was enough to mobilize the climbing limb of the sigmoid and bring it down for a colo-anal anastomosis. Rarely, it was necessary to mobilize the splenic flexure.

After a number of serious complications, which shall be discussed in a later section, protective colostomies were performed routinely. A double loop colostomy was created in the right upper abdomen, proximal to the middle colic artery to avoid possible damage to the marginal artery. All fourteen patients had a colostomy, of which twelve now have been closed. One patient refused closure facing an impending operation for two solitary liver metastases and one patient is still convalescing.

Preoperatively already in the operating room, the rectum was washed out with povidone-iodine solution in an effort to destroy loose tumorcells, which may be the cause of local recurrence after implantation. Another measure to prevent tumor cell implantation was clamping the rectum distal to the tumor before the transsection. Apart from small resection margins, possible tumor cell spill may be a reason for postoperative irradiation. Two patients had an open transsection due to a very small distal margin. These patients received adjuwant irradiation therapy. 


\subsubsection{Segmental resections.}

Indications for this procedure are open to discussion:

1. Segmental resections may be performed for benign lesions, i.e. a circular growing giant villous adenoma.

2. They may be regarded as extended local resections. If there is a place for local treatment of rectal cancer, segmental resections provide an opportunity for the removal of all the local lymphnodes contained in the mesorectal fat.

3. At last, a rectal tumor confined to the bowel margins may be resected locally, thus obviating the need for a laparotomy. It is, strictly speaking, a palliative procedure for patients with too many general risk factors to undergo major surgery. The advantage of a segmental resection in comparison with other palliative treatments is, that the bowel, including its mesorectal tissue, is removed, thus reducing the chance of local recurrence. Locally, a segmental resection may offer the chance of becoming radical..

The variety of possible indications is reflected by the group of patients who underwent segmental resections.

A 71 year old male patient lost mucous due to a giant villous adenoma, which almost occluded the rectum and extended from 5 to $13 \mathrm{~cm}$ from the anal verge.

One 40 year old female patient was examined for bleeding haemorrhoilds. A $2.5 \mathrm{~cm}$ mobile, exophytic growing adenocarcinoma was detected $5 \mathrm{~cm}$ above the anal verge. A segmental resection was performed as a local procedure with curative intent. Microscopically, the tumor had infiltrated the inner muscular layer, but none of the local lymphnodes contained tumor metastases.

The remaining seven patients, two women and five men, with a mean age of 76 , had larger sized rectal cancers. Four had presented with anal bloodloss and three had noted a change in their bowel movement. All patients had one or more cardio-pulmonary risk factors, and some were older than 80 . One patient had, apart from his rectal carcinoma, a NonHodgkin lymphoma. Clinico-pathological staging revealed adenocarcinomas of the rectum at a mean distance of $5.9 \mathrm{~cm}$ from the anal verge. Four patients had tumors adjacent to the prostate, which revealed limited mobility during palpation. Endorectal ultrasound indicated that the tumors did not cross the full thickness of the bowel wall.

It was decided to offer these seven patients the possibility of a local radical resection to obviate the risk of morbidity related to a major abdominal procedure. 
Methods.

Segmental resections are technically difficult procedures. The most difficult part being the complete transsection of the lateral ligaments and the superior haemorrhoidal vessels. Mobilization of the rectosigmoidal junction for anastomosis with the anal stump did not present a problem. The sshaped position of the rectal ampulla in the frontal as well as the transverse planes considerably reduces the absolute distance between the rectosigmoidal junction and the anal canal.

In the first four patients no diverting colostomy was employed. Two patients developed anastomotic dehiscence which led to the development of a fistula in one a peritonitis in the other. This last patient had a very protracted and difficult period of convalescence. Since then, protective colostomies are performed routinely in this category of patients. All but two patients had their colostomy closed. One became incontinent and the other had an early local recurrence.

\subsubsection{Local resections.}

The intersphincteric approach provides excellent access for local procedures. Indications for this technique are, benign or suitable malignant tumors, which can not be dealt with by a peranal exposure.

Eight men and four women with a mean age of 66 were operated. Four had presented with loss of blood or mucous, four had noted a change in the defaecation pattern, two had a recurrence following the previous removal of rectal polyps, one patient had been examined haemorrhoids and another had suffered a prolaps of a tumor which had earlier been attended to by the referring physician.

Nine patients had biopsies of villous adenomas, which were either too remote too extensive for peranal resection. Three patients had a small, mobile and exophytic adenocarcinoma. One of these was 80 years old, and one could be described as a cardio-pulmonary cripple. She was 67 years old. One 56 year old woman had a villous adenoma with focal malignant degeneration; she refused any major operative intervention. One patient had a tumor located in the bowel wall, which had not penetrated the mucosa; after a full thickness excision was found to be a leiomyosarcoma of low malignancy grade.

\section{Method.}

In three out of the nine villous adenomas, focal malignant degeneration was present. All three had their tumor removed as a full thickness total biopsy and were judged to be completely resected by the pathologist. During the operation, direct palpation of the full thickness bowel wall did 
arouse suspicion of malignant degeneration. Six more local excisions were performed: one for a small T1 tumor, two for ' $\mathrm{T} 2$ tumors, one for a recurrent tubulo-villous polyp and one for a villous adenoma. One resection was performed for an intramural tumor. Four mucosectomies were performed via an intersphincteric posterior proctotomy. The technique for the actual mucosectomy has been described by Parks (1972). The submucasa is an easily distensible space. Fluid injected into it spreads rapidly in all directions and may distend the space to a thickness of 1 to $2 \mathrm{~cm}$. This greatly facilitates the dissection of a mucosal lesion from the underlying circular muscle. Apart from direct palpation of indurated sections, submucosal infiltration may also indicate malignant change, since invasion of the submucosa will produce tethering during injection and ta malignant area will fail to lift off the muscle. After infiltration, dissection is then carried out with scissors in the submucosal plane, close to the circular muscle. All bleeding points are dealt with using diathermy coagulation. In most cases no suturing of the rectal mucosa is required as even quite large bare areas on the rectal wall heal with little narrowing. In this series no tumors which involved the whole of the circumference of the rectum were removed. Parks advocates reducing the circumferencially denuded muscle wall by imbricating the rectal wall in a longitudinal plane and approximating the upper mucosal margin to the lower.

In none of these patients a diverting colostomy was employed.

Two complications occurred in twelve patients. Both patients developed a perineal woundinfection with subsequent fistulla. These fistulas healed spontaneously.

\subsection{Complications after combined procedures and segmental resect- ons.}

As mentioned in the previous paragraph, complications were rare after local procedures and if they occurred did not require intervention. In contrast, complications after combined or segmental resections are of much greater consequence. This paragraph will be dealing with these complications.

Combined abdomino-intersphincteric excision of the rectum and segmental resection differ in the extent of the procedure, but since complications are comparable they will be discussed together. Partial anastomotic dehiscence was the major complication after these procedures. Three out of twenty three patients developed peritonitis ( 2 patients after a combined procedure, 1 after a segmental resection). Laparatomies had to be performed to drain 
the abdominal cavity and diverting colostomies were installed to prevent further leakage at the site of the dehiscence. The perineal wounds were opened as well to provide better drainage.

Primary diverting colostomies were carried out in 17 out of 23 patients. None of these patients developed peritonitis, whereas three out of six patients without colostomy did. These were patients who were treated at the beginning of the series. Since then, a protective colostomy was routinely used. Subsequently, peritonitis did not recur.

Six patients developed a perineal woundinfection with a faecal fistula. Four of these fistulas healed spontaneously; in one patient the fistulous tract was layed open and one fistula healed after performing a diverting colostomy. Persistent incontinence was the major reason for employing a diverting colostomy in the last patient.

\begin{tabular}{llll}
\hline & $\begin{array}{l}\text { Primary diverting } \\
\text { colostomy }\end{array}$ & $\begin{array}{l}\text { Anastomotic } \\
\text { dehiscence } \\
\text { Peritonitis }\end{array}$ & Fistula \\
\hline $\begin{array}{l}\text { Abdomino-inters ph. } \\
\text { restection }\end{array}$ & $\begin{array}{l}\text { without } 2 \\
\text { with } 12\end{array}$ & 2 \\
$\begin{array}{l}\text { Segmental } \\
\text { resection }\end{array}$ & $\begin{array}{l}\text { without } 4 \\
\text { with } 5\end{array}$ & 1 & 3 \\
\hline Local resection & without 12 & 2 \\
\hline
\end{tabular}

Table 6.2. Complications after intersphincteric procedures.

All but one fistula healed while a colostomy was still present. One fistula developed after closure of the colostomy. A seton was encircled through the fistulous tract to permit adequate drainage of the accompanying perineal abscess and to induce perifismular fibrosis. After the infection had subsided, the fistulous tract (which ran outside the external sphincter complex) was layed open.

The fistulas closed after a mean of 6 months (range: 2 to 9 months). In 1 patient these complications led to a poor functional result which necessitated a secondary colostomy. Continence was usually present after the operation, or after collostomy closure. However, an increase in the degree of both urgency and frequency was commonly noted by the patients. This condition improved steadily in the ensuing months.

Functional results will be further discussed in the section: Physiological follow-up investigations.

One patient developed an urethral stricture which had to be treated by the urologist. None of the patients suffered from neurologic bladder dysfunc- 
tion the procedure except for two, who did temporarily. It subsided spontaneously without intervention.

\subsection{Oncological results.}

After short follow-up period, only preliminary data can be presented in table 6.3.

\begin{tabular}{llll}
\hline & $\begin{array}{l}\text { Abdomino-intersph. } \\
\text { procedures }\end{array}$ & $\begin{array}{l}\text { Legmental } \\
\text { resection }\end{array}$ & $\begin{array}{l}\text { Local } \\
\text { excision }\end{array}$ \\
\hline $\begin{array}{l}\text { Number patients } \\
\begin{array}{l}\text { Number patients } \\
\text { with malignancy }\end{array}\end{array}$ & 14 & 9 & 12 \\
\hline $\begin{array}{l}\text { Mean follow-up of } \\
\text { patients with } \\
\text { malignancy }\end{array}$ & 18 months & 21 months & 20 months \\
\hline $\begin{array}{l}\text { Local recurrence } \\
\begin{array}{l}\text { Development of } \\
\text { distal metastases }\end{array}\end{array}$ & 0 & 8 & 1 \\
\hline
\end{tabular}

Table 6.3. Oncological results.

\subsubsection{Abdomino-intersphincteric resections.}

Patients in this category were operated with curative intent or, at least, local curative intent. Basically, three steps had to be taken to achieve this: One: Confirmation had to be obtained during preoperative staging that the tumor was still confined to the inside of the rectal fascia. Two: At operation the complete mesorectum with its covering fascia had to be removed. Three: Adequate distal and lateral margins free of tumor had to be obtained.

The clinico-pathological staging predicting the radial borders of the tumors was correct in all patients. In none of the patients the tumor had crossed the perirectal fascia. In six cases the perirectal fat was tumor infiltrated. Lymphnodes were positive in three patients.

Removall of the complete mesorectal fat within its fascia was possible in all procedures. None of the patients had doubtful radial margins. Macroscopically, a distal margin of at least $10 \mathrm{~mm}$ could be obtained in all patients. Only four patients had distal margins of less than $20 \mathrm{~mm}$. The macroscopical margins were determined in the fresh, none stretched, specimen. Microscopically, distal margins were smaller due to shrinkage of the specimens after preparation in formaline. The distal margins were examined by opening the specimens and cutting them parallel to the bowel 
axis. In two patients, perpendicular cuts were used to evaluate the distal margin. In these specimens, the pathologist could not be certain whether the distal margins were free of tumor, which is why postoperative irradiation therapy was decided upon.

After a mean follow-up of 18 months (range 6-34 months), no patient has developed a local recurrence. Three patients developed distal metastases, respectively 9,10 and 12 months after the initial procedure. Another patient has progression of liver metastases which had been present at the time of operation. Three of these patients died of metastatic disease without signs of local recurrence.

\subsubsection{Segmental resections.}

One small Dukes'A tumor has been removed by segmental resection with curative intent. This patient is doing well, without any sign of recurrence 18 months after the resection.

Weighing the operative risk against the oncological benefit of a radical operation, seven patients were selected for segmental resection. Five had a T3 and two a T2 tumor without lymphnode involvement. Six patients were well over 70 years of age (mean of 79), one patient was 59 years old and suffered from severe emphysema. Segmental resection was performed as a palliative procedure with a albeit limited, chance of cure.

Three patients developed local recurrent disease. One patient also had multiple livermetastases when local recurrence was found six months later. This patient died 14 months after the initial operation.

One patient had received postoperative irradiation as adjuvant therapy after segmental resection of a $T 2$ tumor. This did not prevent the development of a local recurrence in the mesorectal fat eight months postoperatively. An abdomino-perineal resection could be performed, during which silicone tubes were left in the operation area. Through these tubes the patient received supplementary irradiation therapy by implant of iridium needles.

The third patient developed a small anastomotic recurrence nine months postoperatively, which could be treated by electrofulguration.

All three patients with recurrent disease had tumors located adjacent to the prostate which showed limited mobility on rectal palpation. Endorectal ultrasound suggested an intact fascia of Denonvilliers. During the resection, distal and radial margins were macroscopically free. Distal margins were microscopically free in all three patients. However, lateral margins, were microscopically doubtful in one and very small in the other two patients.

Mean follow-up was 21 months (range 15-26). 


\subsubsection{Interspbincteric local resection.}

Six malignant tumors were removed as a full thickness excisional biopsy. In three patients rectal carcinoma was diagnosed preoperatively. The first patient was a 56 year old woman who had a villous adenoma with focal malignant degeneration. An abdomino-perineal resection was advised. However, the patient refused any kind of procedure which might lead to a colostomy. A full thickness excisional biopsy was carried out. Thirty two months after the procedure she is still free of disease. Two patients whose condition was considered too high a risk for any major surgical procedure, had small rectall carcinomas, which met the criteria for local resection (chapter 7), removed by local excision.

Three other patients had villous adenomas with focal malignancies, which were not discovered prior to the operation. In a 52 year old man a frozen section of the specimen revealed malignancy, after which the procedure was continued as an abdomino-intersphincteric resection. This patient did not develop local recurrence, but was faced with liver metastases twelve months postoperatively. The remaining two patients, 75 and 80 year old women, had resections with adequate free margins. In the 75 year old female patient an indurated villous tumor was removed as a fulli-thickness biopsy. Pathologic examination revealed a villous adenoma with focal malignant infiltration into the perirectal fat. Postoperative irradiation therapy was advised, but the patient refused. Twelve months postoperatively recurrence at the site of the anastomosis occurred, which was treated by electrofulguration and, later, by abdomino-perineal resection.

The seventh patient was explored for a tumor in the bowel wall, which appeared to be a leiomyosarcoma of low malignancy grade. Frequent check-ups revealed no local recurrence.

Mean follow-up of patients treated for malignant tumors was 20 months.

\subsection{Functional results.}

\subsubsection{Introduction.}

Investigation of the physiological mechanisms which regulate continence after the intersphincteric approach has provided objective data. However, these data show a very wide range of values and their relation to impaired continence mechanism is difficult to interpret. The subjective interpretation of the activity of the continence mechanism is much easier to assess but far more difficult to quantify. Still, the subjective result of sphincter preserving procedures remains the golden standard for the assessment of the postoperative quality of life. 


\subsubsection{Subjective results.}

The functional results could be studied in 32 patients (see table 6.4.). Twelve patients were available for evaluation after combined procedures. Some soiling occurred in most patients during the first weeks/months after closure of the colostorny. This condition improved steadily and was compatible with normal live. Ten patients had a defaecation pattern comparable to preoperative habits, albeit with increased frequency. Two of these patients are regularly using an enema in the morning to empty their bowel, and to avoid small defaecations during the day. One of the patients takes 2 mg. loperamide per day in order to control frequency. One patient developed a "frozen pelwis" one year after postoperative irradiation therapy and became incontinent. He had an abdomine-perineal resection done (the specimen did not contain tumor cells).

\begin{tabular}{llll}
\hline & $\begin{array}{l}\text { Number patients } \\
\text { totalevaluable }\end{array}$ & Frequency & $\begin{array}{l}\text { Impaired } \\
\text { continence }\end{array}$ \\
\hline $\begin{array}{l}\text { Abdomino-intersph. } \\
\text { resection }\end{array}$ & $14 / 12^{*}$ & $2-5$ & $\begin{array}{l}\text { urge } \\
\text { frequency } 2\end{array}$ \\
\hline $\begin{array}{l}\text { Segmental } \\
\text { resection }\end{array}$ & $9 / 8^{* *}$ & $1-4$ & soiling 2 \\
incont $1^{+}$ \\
\hline \begin{tabular}{l} 
Local resection \\
\hline
\end{tabular}
\end{tabular}

Table 6.4. *One patient awaiting closure; One refused. "In One patient the colostomy was not closed due to an early local recurrence. +One patient received a permanent colostomy because of persisting incontinence.

Eight patients could be assessed after segmental resections. Two have an almost normal defaecation pattern. Two patients soil permanently but do not exhibit gross incontinence. One suffers from urge incontinence when afflicted by diarrhoea. One patient is incontinent, but was already so prior to the operation, when it was attributed to his low seated rectal cancer. "This was apparently a misassessment and a permanent colostomy had to be made. The majority of the patients continue to experience improvement more than 12 months after the initial procedure.

After local procedures two of the twelve patients have soiling problems, which necessitate use of pads. 
Some impairment in the fine tuning of defaecation is experienced by almost all of the 32 patients after resection with colo-anal anastomosis. Frequency is increased in 10 out of 32 patients. Some urge is felt by nine out of 32 . In terms of quality of life, 17 patients were able to compare a temporary colostomy with the situation after closure of the colostomy. Despite the more or less pronounced impairment of function in some patients, all patients stated that they preferred the inconvenience of urgency and/or occasional soiling to a life with a transverse colostomy.

Summarizing, colo-anal anastomoses are compatible with reasonable anal continence. After local procedures complete normal bowel function may even be expected. Improvement of the impaired function is a slow but gradual process which may take several years.

\subsubsection{Physiological follow up evaluation.}

\subsubsection{Introduction.}

Rectal sensation and the capability to interpret accurately the nature of rectal contents is dependent on the integrity of the levator ani muscles. Continence, the ability to retain faeces, depends on a functioning puborectal muscle. Apart from this, rectal capacity, also called reservoir continence, is also an integrated part of continence. After intersphincteric resection the rectal reservoir is removed and sometimes even the superior part of the internal sphincter. In these cases, postoperative continence solely depends on a distal segment of the internal sphincter as well as the pelvic floor muscles with the external sphincter extending down from the pelvic floor muscles. The remaining anal sphincter function has been studied by means of three dimensional pressure profilometry, which clearly detects variability due to radial pressure asymmetry. Pressure profilometry was performed with an eight-lumen polyvinyl manometric catheter with an outer diameter of $5.5 \mathrm{~mm}$. The eight side holes were circumferentially spaced at angles of 45 degree. Each channel was seperately perfused by a pneumohydrocapillary perfusion pump at a rate of $0.5 \mathrm{ml} / \mathrm{min}$. with destilled water and was connected to a waterfilled transducer. The catheter was introduced into the rectum and subsequently withdrawn with a linear pull back device at a speed of $7 \mathrm{~mm} / \mathrm{second}$. The sphincter pressure at rest and the maximal squeezing pressures were obtained via four measurements at rest and four at maximal squeezing. The functional anal length was determined as well.

$A$ waterfilled balloon was used to elicit the recto-anal inhibitory reflex and to estimate rectal (i.e.colonic) capacity. A simple condome was attached to the tip of a microtip sensor catheter. The sensor was mounted $5 \mathrm{~cm}$ proximal to the tip of the catheter, to enable simultaneous filling of the 
condome and registration of the pressure in the anal canall. Table 6.5. gives a review of the results of these measurements.

\subsubsection{Manometric maximum resting pressure and maximum squeezing pressure and anal length.}

The average maximal resting pressure that was measured with this 8channel catheter in 15 healthy young volunteers was $108 \pm 27 \mathrm{mmHg}$ (vd. Hulst, unpublished data). The maximal squeezing pressure was $201 \pm 58$ mmHg.

\begin{tabular}{lll}
\hline & $\begin{array}{l}\text { Mean pressure } \\
\text { resting/squeeze }\end{array}$ & $\begin{array}{l}\text { Mean length } \\
\text { anal canal } \\
\text { resting/squeeze }\end{array}$ \\
\hline Controls & $108 / 201 \mathrm{mmHg}$ & $3.6 / 5.0 \mathrm{~cm}$ \\
\hline Abdomino-intersph. & $65 / 130 \mathrm{mmHg}$ & $4.6 / 5.3 \mathrm{~cm}$ \\
\hline Segment & $30 / 80 \mathrm{mmHg}$ & $3.9 / 5.3 \mathrm{~cm}$ \\
\hline Local & $75 / 120 \mathrm{mmHg}$ & $4.3 / 5.2 \mathrm{~cm}$ \\
\hline Very low anterior & $70 / 125 \mathrm{mmHg}$ & $4.2 / 4.6 \mathrm{~cm}$ \\
\hline
\end{tabular}

Table 6.5. Results anal manometry.

Mean resting pressures after combined procedures was $65 \mathrm{mmHg}$, ranging from 40 to $80 \mathrm{mmHg}$. Mean squeezing pressures were $130 \mathrm{mmHg}$, ranging from 80 to $250 \mathrm{mmHg}$. (increases of 25 to $210 \%$ ). After segmental resection, resting pressures were lower: mean $30 \mathrm{mmHg}$, ranging from 20 to 60 $\mathrm{mmHg}$, and squeezing pressures were also lower with a mean of $78 \mathrm{mmHg}$, ranging from 40 to $150 \mathrm{mmHg}$ (increases of 60 to $300 \%$ ). After local procedures, mean resting and squeezing pressures were respectively $75 \mathrm{mmHg}$, ranging from 35 to $150 \mathrm{mmHg}$ and 120 , ranging from 70 to 250 mmHg (increases of 30 to $150 \%$ ). Additional measurements were taken in 5 patients with very low anterior resections. In these patients, a mean resting pressure of $68 \mathrm{mmHg}$, ranging from 30 to $100 \mathrm{mmHg}$, and squeezing pressure of $124 \mathrm{mmHg}$, ranging from 100 to $>180 \mathrm{mmHg}$ (increases of 30 to 300\%) were found.

The most important conclusion to be drawn from these measurements is, that an individual value is not capable of predicting the degree of impaired function... 
This finding is demonstrated in table 6.5 .

\begin{tabular}{lcc}
\hline & continent & continence problem \\
\hline mean & 10 & 4 \\
\hline mean & 6 & 5 \\
\hline
\end{tabular}

Table 6.5. Comparison of the patients of all categories having $>$ mean resting pressure in their category and those having resting pressures $<$ mean.

(chi square test: $\mathrm{p}>0.25$ n.s.).

After segmental resection, pressures were clearly lower than after combined, local or transabdominal procedures. The most serious impairment of continence was seen in the group of segmental resections, yet, some of these patients experienced no ill effects but were showing values in the same range as patients who were impaired.

One factor that may be partly responsible for the measured differences is age. The mean age of patients in the group of segmental resections was 20 years higher than the one of those who had combined procedures.

Functional length of the anal canal did not differ considerably among the groups of patients. In the control group, resting length was $3.6 \mathrm{~cm}$ and squeezing length $5.0 \mathrm{~cm}$. Mean resting functional length for combined, segmental, local and abdominal resections was $4.6 \mathrm{~cm}, 3.9 \mathrm{~cm}, 4.3 \mathrm{~cm}, 4.1$ $\mathrm{cm}$ respectively. After squeezing an increase in length was seen to $5.3,5.2$, 5.3 and $4.6 \mathrm{~cm}$, respectively.

\subsubsection{Measurement of rectal capactty.}

The exact volumes that could be retained by the patients were of interest. This is why waterfilled balloons, instead of airfilled ones were used. Condomes with very low compliance were used. Pressure in the balloon was recorded, so that presence and magnitude of peristaltic waves could be detected. With waterfilled balloons most controls feel an unpleasant urge to defecate with volumes above $180 \mathrm{cc}$. Ability to retaining $180 \mathrm{cc}$ would result in a defaecation frequency of less than three times per day. After combined procedures, we measured a range of $120 \mathrm{cc}$ to $>180 \mathrm{cc}$. After segmental resections $100 \mathrm{cc}$ to $>180 \mathrm{cc}$; after local procedures $100 \mathrm{cc}$ to $>$ $180 \mathrm{cc}$ and, finally, after transabdominal procedures also $100 \mathrm{cc}$ to $>180 \mathrm{cc}$. Patients in the lower range (less than $130 \mathrm{cc}$ ) usually suffered from urge (five out of six patients). If rectal capacity exceeded $130 \mathrm{cc}$ urge problems 
were not encountered. This finding was significant (chi square test $p<$ $0.001)$

\subsubsection{Recto-anal inbibitory reflex.}

This reflex is believed to play an important role in the mechanism of normal defaecation. Not clear though is, whether it also plays a role in the continence mechanism. After rectal resections (combined segmental, transabdominal), the reflex was present in 11 out of 16 patients. After local procedures in 8 out of 9 . Its presence or absence did not correlate with continence disturbances (Chi square test $p>0.10 \mathrm{n} . \mathrm{s}$ ).

\begin{tabular}{|c|c|c|}
\hline & continent & continence problem \\
\hline positive reflex & 12 & 7 \\
\hline negative neflex & 4 & 2 \\
\hline
\end{tabular}

Table 6.6. Presence of recto-anal reflex.

All patients were able to sense filling of the rectum and to differentiate the contents. Three patients were occasionally unable to discriminate between flatus and liquid contents, which naturally led to inadvertent soiling. The impaired sensory function in these patients probably contributes to their overall continence problem. 


\section{Chapter 7.}

\section{Intersphincteric procedures. - Discussion and conclusion -}

\subsection{Complications of colo-anal anastomoses, following intersphincteric procedures.}

Anastomotic dehiscence is one of the most prominent complications after anastomosis of the retro-peritoneal rectum to the anal canal. Insight in the pathogenesis of anastomotic failure is incomplete. However, some knowledge has been derived from clinical and experimental observations. Many separations of the sutureline do not lead to clinical symptoms. Goligher (1970) recorded $49 \%$ breakdowns after careful radiological assessment, of which $16 \%$ were of a major kind. He also noted that the anastomotic insufficiency was nearly always located in the posterior part of the bowel circumference. De Ruiter (1973) confirmed these findings; $46.2 \%$ of the extra-peritoneal anastomoses were insufficient. The integrity of the anastomosis is dependent on a wide variety of factors.

Everett (1975) reported the results of a well controlled trial of one and two layer methods of suture for anterior resection. Results were in favour of the one layer technique. Goligher (1977) had opposite results in a controlled trial which favoured a two layer suture. Fielding (1980) noted no difference: Beart (1981) concluded that the use of the stapler did not decrease morbidity. Goligher (1980) concluded that each surgeon should adopt his own suture technique. No one method of joining the colon to the rectum has proved superior to others in eliminating anastomotic failures.

In this study , the stapler was used in the first patients, but because of discongruence of thickness of the anal stump and the distal colon, a two layer technique for secure approximation was adopted. The outer layer consists of four to six approximation sutures, while the inner one is made of fine internupted stitches, or a running suture. Monofilament absorbable 4.0 suture material is used. In theory, ischemia may be due to severe trauma, lack of arterial bloodsupply, or tension on the proximal colon. It seems unlikely however that experienced surgeons who report on breakdowns failed to eliminate these factors. In three patients of this series, who developed an anastomotic dehiscence, the surgeon was convinced that the arterial bloodsupply was sufficient judging the freely bleeding cut edges of the bowel. Furthermore, the anastomoses were without tension.

Several authors have reported that faecal loading correlates with pelvic sepsis (Goligher 1970, Irvin 1973). A thorough bowel cleansing, in combi- 
nation with a protective colostomy eliminates this problem. Anastomic failures may occur in spite of the presence of a colostomy, but septic complications are considerably reduced by a faecal diversion. All patients in this series received thorough bowel cleansing, preferably by wash out. None of the patients with a colostomy suffered septic complications, but five developed a faecal fistula to the perineal wound.

Cronin (1968) has advanced the concept of the collagenous equilibrium to explain the failure of apparently adequate anastomosis. In the vicinity of the sutureline $50 \%$ of collagen is lost in the first four to six days. This is followed by a rapid rise in collagen content so that, in 10 to 12 days, the sutureline is stronger than normal colon tissue. Extensive tissue trauma and infection cause the release of collagenase from the inflammatory process, common to some extent in any wound. This collagenase activity reduces bursting strength (Hawley 1970). Irvin (1974) proved in an animal model, that impairment of collagen accumulation and the development of bursting strength associated with infection, appears to be due to both increased lysis and decreased synthesis of collagen.

Peranal colo-anal anastomoses are even more liable to failure. A special feature of the colo-anal anastomosis is, that an atonic bowel muscle coat is joined to the tonic internal sphincter. It has been well established, that after transsection in the recto-anal segment, the recto-anal inhibitory sphincter reflex is absent. After several months this reflex usually reappears, but in the critical postoperative days it is absent. (Lane 1977, Kuijpers 1983). Thus, the anal stump may act as a functional stenosis for flatulation and defaecation.

In this series an absent recto-anal reflex was seen in some patients even longer than a year postoperatively.

Beckers (1972) advocated internal sphincterotomy. Many surgeons consider dilation of the anus after low anterior resection essential. In handbooks however (Goligher 1980, Maingot 1980, Corman 1989), this procedure is not mentioned. If considered, the dilation should be performed preoperatively, and insertion of four fingers should suffice. Postoperative dilation may endanger the anastomosis. Most authors advocate a diverting colostomy (Rudd 1979, Parks 1982, Enker 1985) after peranal anastomosis.

Localio (1983) saw a leakage rate of $12 \%$ after abdomino-sacral resection. In his opinion, leakage occurred predominantly in males younger than 65 .

In combined procedures, as well as in segmental resections, the perineal wound is located in the vicinity of the anastomosis. De Leu (1980), who reviewed results of York Mason's patients, reported eight local complications in twelve patients, of whom two died postoperatively (three segmental resections, nine abdomino-transsphincteric procedures). Huber (1983) reported wound complications in 8 out of 36 patients treated with 
transsphincteric approach. After intersphincteric approaches with colo-anal anastomoses, 8 out of 23 developed a fistula (three of which were iatrogeneous, for the perineal wound was opened by the surgeon as an extra drainage of a peritonitis).

The advantage of an easy anastomosis under direct vision in the perineal area, turns into a disadvantage in case of an anastomotic leakage. As leakage is most common on the posterior side of the anastomosis, the perineal wound will be contaminated and a wound fistula is likely to develop. After intersphincteric approaches, the tract of the fistula will also run intersphincterically and will not disturb the external continence mechanism. If necessary, as it was in one patient, the fistula may be layed open without risk of severance of the external sphincter. The fistulas did not constitute a major problem as they healed spontaneously (or, as in one case, after division of the tract), but they did delay closure of the colostomy for an average of six months. If a diverting colostomy was not present, it was not necessary to create on account of this complication.

In general, septic complications due to separation of the sutureline can be dealt with by drainage and a diverting colostomy. Occasionally it may be necessary to complete the separation of the anastomosis and to bring the colon out as a terminal colostomy, in the manner of a Hartman's operation (Goligher 1980). This was never necessary in this series.

Summarizing: Information on some intrinsic factors such as the collagen equilibrium, which threatens the anastomotic integrity up to six days postoperatively already exists. Prophylactic measures such as, preoperative bowel cleansing, the use of antibiotics, and a meticulous surgical technique were unable to prevent anastomotic dehiscence in all patients. A protective colostomy was not routinely created, but when faced with severe complications the protocol was modified. After this modification, no further serious adverse effects were seen.

\subsection{Oncological principles applying to intersphincteric approaches.}

\subsubsection{Introduction.}

So far, the results of only a short term follow-up can be presented. Since the number of patients is limited, convincing statistical evidence cannot be produced. This would have been possible only after prospective randomization of approximately 100 patients into two groups ( $O^{\prime}$ Connell 1988). However, the indication range for intersphincteric approaches is relatively small, and would necessitate a multicentre trial to obtain sufficient patient numbers. Moreover, the ethical aspect of randomizing patients into two 
groups, -restorative resection and abdomino-perineal resection-, would present an unsurmoutable problem. For any of the restorative techniques such a study has not yet been conducted. However, the techniques used in rectal resections are based on sound oncological principles and fulfil the demands of adequate cancer surgery. The particular properties of the specimens, from combined or segmental intersphincteric procedures, will be the basis for a review of the above mentioned oncological principles.

\subsubsection{Surgtcal anatomy.}

A short posterior mesorectum suspends the upper third of the rectum. Descending into the pelvis, the rectum is suspended by the peritoneum which sweeps off more laterally. Finally, the peritoneum reflects forward at the bottom of the recto-vesical or recto-uterine pouch, leaving the lower part without peritoneal suspension. In the frontal plane, the lateral ligaments suspend the extraperitoneal rectum to the pelvic wall. In the sagittal plane the urethro-rectal muscle or ligament anteriorly and the rectosacral ligament posteriorly, anchor the rectum. Beneath the level of the pelvic diafragm the longitudinal muscle layer of the bowel wall fuses with the external sphincter. If not covered by peritoneum, the rectum is completely enveloped in a perirectal fascia which shuts off the mesorectum from the surrounding structures. The difference between a palliative and curative resection depends on, whether or not, there is tumor penetration into the fascia visceralis interna or fascia recti propria. Adequacy of local tumor clearance is a fundamental principle to the prevention of local recurrent disease. Previously, the emphasis has always been on adequate distal clearance. However, there is now substantial evidence that a $5 \mathrm{~cm}$ distal

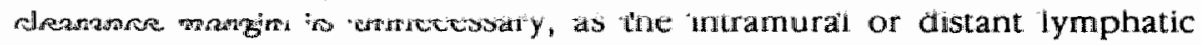
spread is rarely present more than $2 \mathrm{~cm}$ from the macroscopic edge of the growth and even then, only in advanced stages of the disease (Williams 1983, 1985). Clinical studies have confirmed that restorative resection with small distal margins is not accompanied by a high rate of local recurrence (Gillen 1986, Williams 1984, Phillips 1984, McDermott 1985) when compared to abdomino-perineal resection. Still, local recurrence constitutes a major problem. Exact figures on local recurrences are difficult to evaluate as they show a wide range: Localio reports $14.6 \%$ after abdomino-sacral resection, Parks $15 \%$ after abdomino-transanal resection, Williams $11 \%$ after very low stapled anastomosis. Much higher local recurrence rates have also been reported. Adequate excision of the mesorectum is probably very important. Heald (1982) obtained a $2.6 \%$ local recurrence rate with wide excision of the mesorectum. Quirke (1987), extensively analyzed resected specimens for micrometastases in the mesorectum. He found that many 


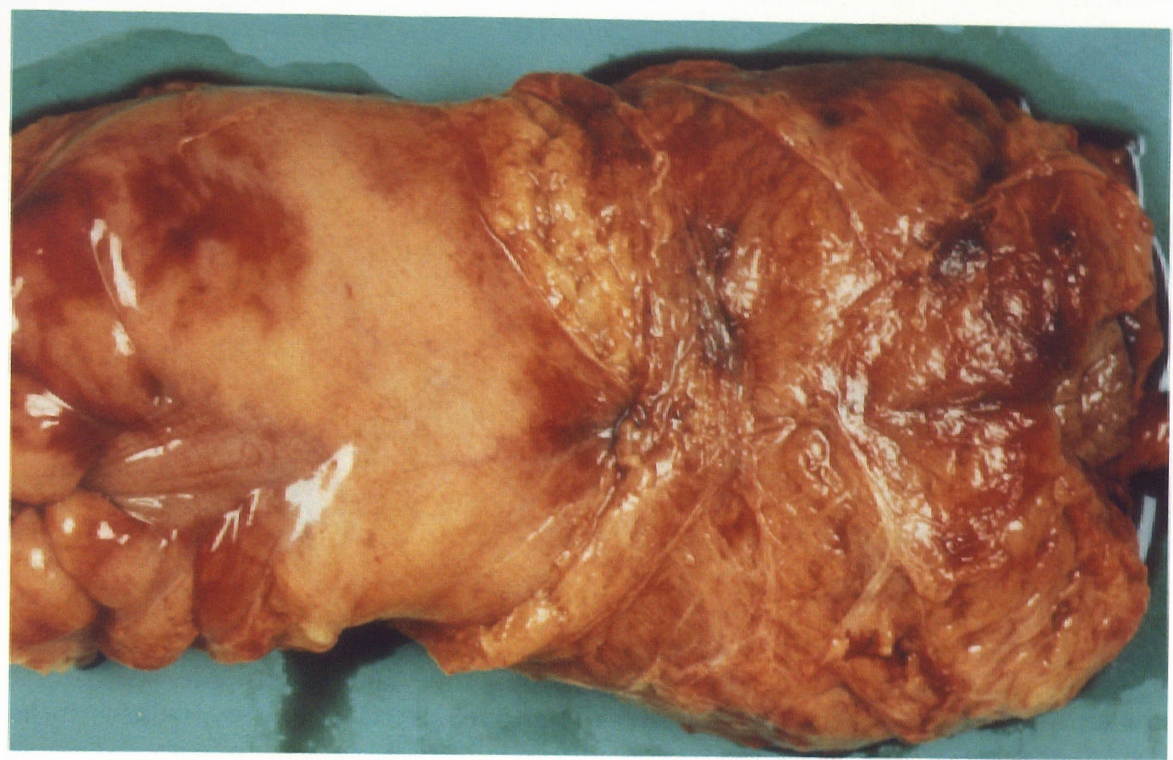

Fig. 7.1. Close-up of the ventral side of a specimen, removed by abdominointersphincteric approach. The covering of the mesorectum by the fascia visceralis recti, can be seen.

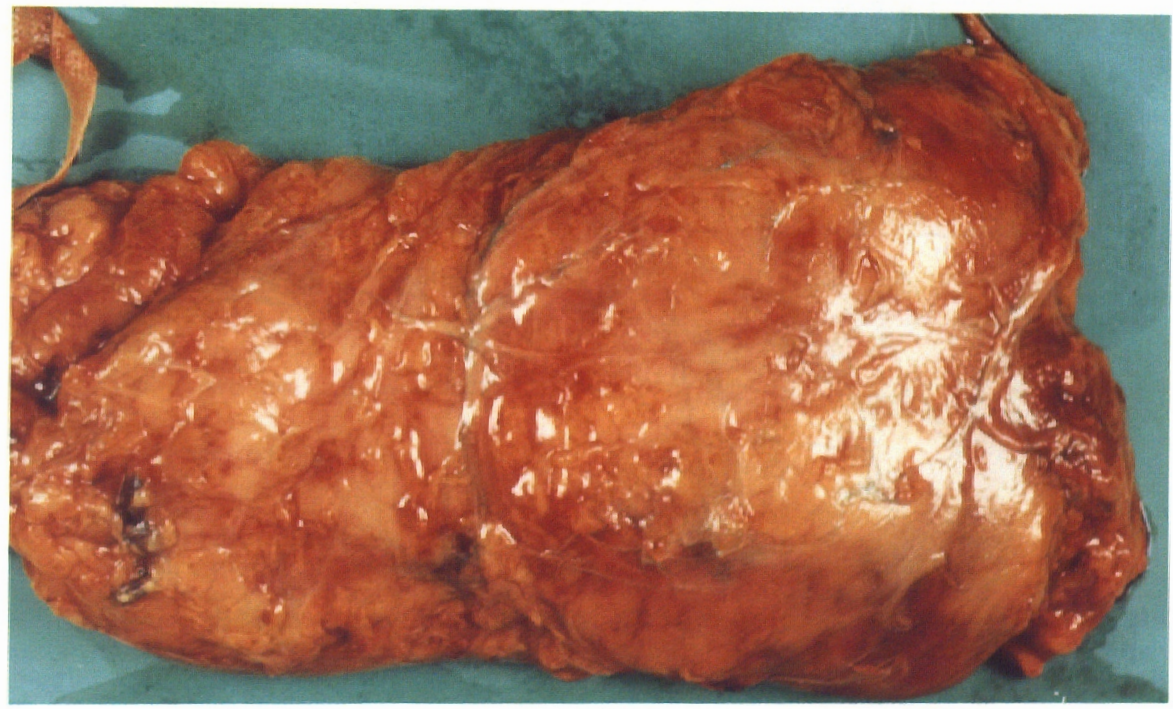

Fig. 7.2. Close-up of the dorsal side of a specimen removed by abdominointersphincteric approach. The shining fascia visceralis recti covers the dorsal part of the mesorectum. Fig. 7.1. and 7.2. demonstrate that the complete mesorectum, enveloped in its fascia, can be removed, thus securing an optimal local radical resection. 


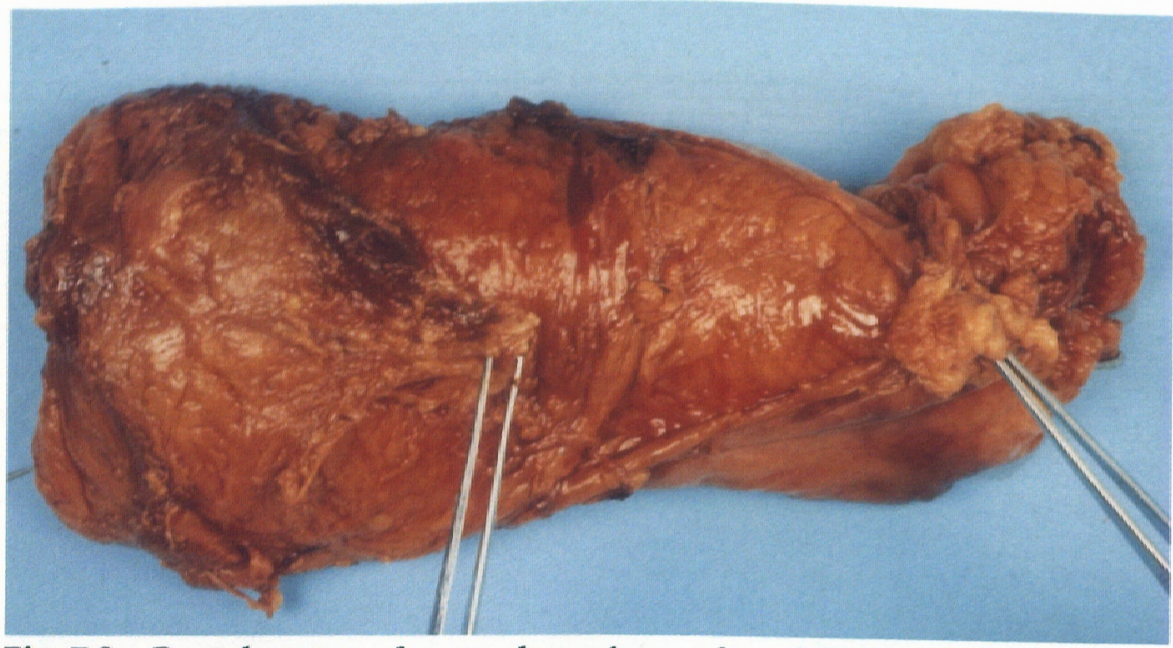

Fig. 7.3a. Dorsal aspect of a rectal specimen after abdomino-intersphinteric resection. "The right pair of tweezers holds the transsected lympho-vascular piedicle; the left one holds Waldeyer's fascia.

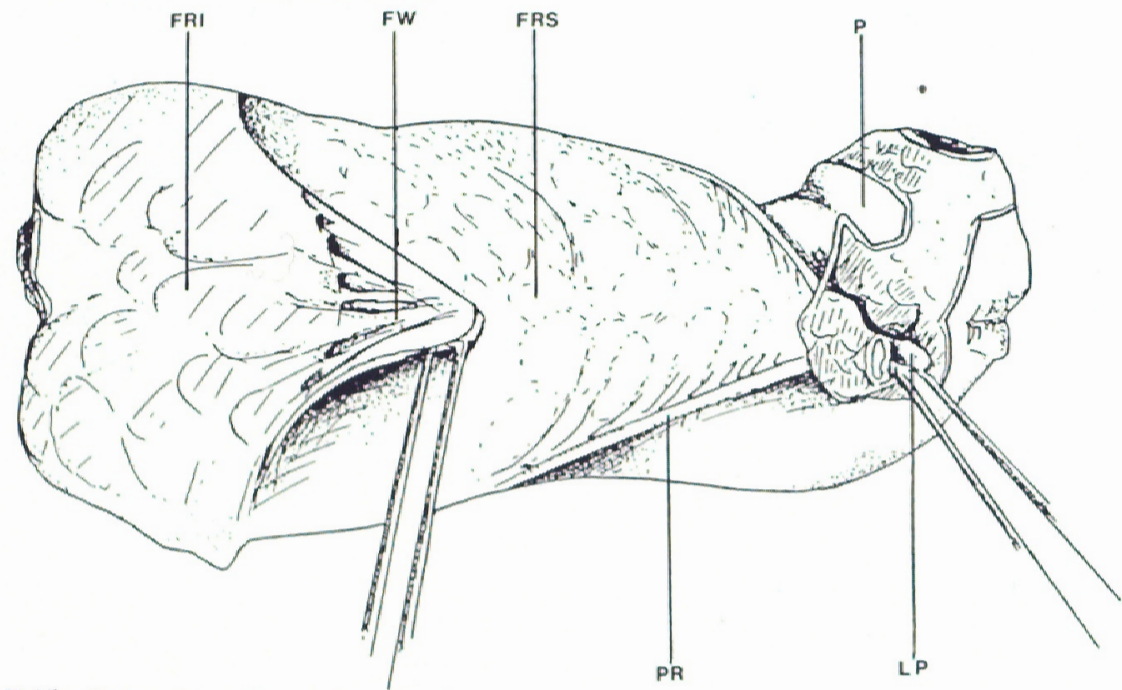

Fig. 7.3b. Drawing of specimen of fig. 7.1a. The different faces of the specimen are demonstrated. The upper third of the rectum is suspended by a small mesorectum. More distally, the peritoneum sweeps off more laterally. Finally, the peritoneum reflects forward, leaving the lower part without peritoneal covering. The dorsal fascia visceralis recti is divided into two parts by Waldeyer's fascia. A considerable quantity of the mesorectal fat is covered by the inferior part of the fascia visceralis recti.

FRI=fascia recti (lining spatium retrorectale, pars inferior), FW=fascia Waldeyer, FRS=fascia recti (lining spatium retrorectale, pars superior), $P R=$ perineal reflection, $\mathrm{P}=$ peritoneum, $\mathrm{LP}=1 \mathrm{ym}$ phovascular pedicle. 
Fig. 7.4a. In sagittal direction divided specimen of

fig. 7.3a. Waldeyer's fascia, which has been removed completely in this specimen and not divided as usual in abdomino-intersphincteric resections, is clearly visible.

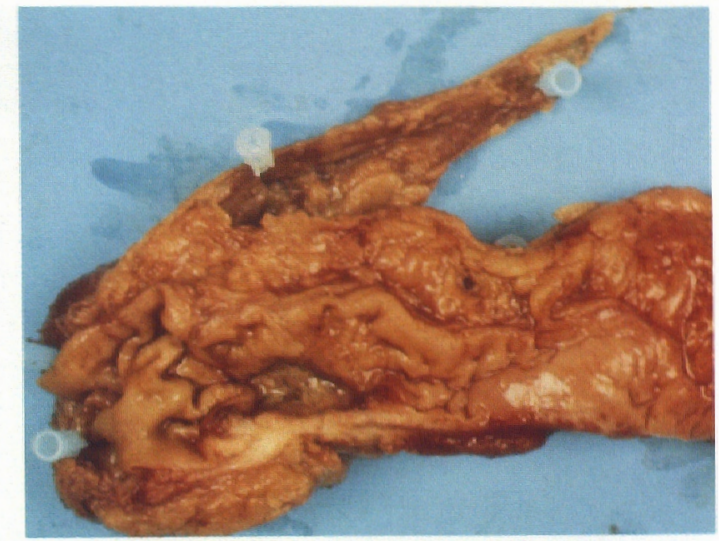

Fig.7.4b.

Demonstration of former topographical relations of the resected specimen. The retrorectal space is divided in a superior and inferior part by Waldeyer's fascia. This fascia prevents complete transabdominal mobilization of the rectum.

\begin{tabular}{|c|c|c|}
\hline 1 & $=$ & m.sphincter ani \\
\hline 2 & $=$ & ligamentum anococcygeum \\
\hline 3 & $=$ & m.levator ani \\
\hline 4 & $=$ & $\begin{array}{l}\text { fascia pelvis visceralis } \\
\text { fascia recti }\end{array}$ \\
\hline 5 & $=$ & $\operatorname{os} \operatorname{cocc} y x$ \\
\hline 6 & $=$ & $\begin{array}{l}\text { spatium retrorectale } \\
\text { pars inferior }\end{array}$ \\
\hline 7 & $=$ & $\begin{array}{l}\text { corpus adiposum recti } \\
\text { mesorectum }\end{array}$ \\
\hline 8 & $=$ & $\begin{array}{l}\text { fascia pelvis parietalis } \\
\text { fascia sacralis }\end{array}$ \\
\hline
\end{tabular}

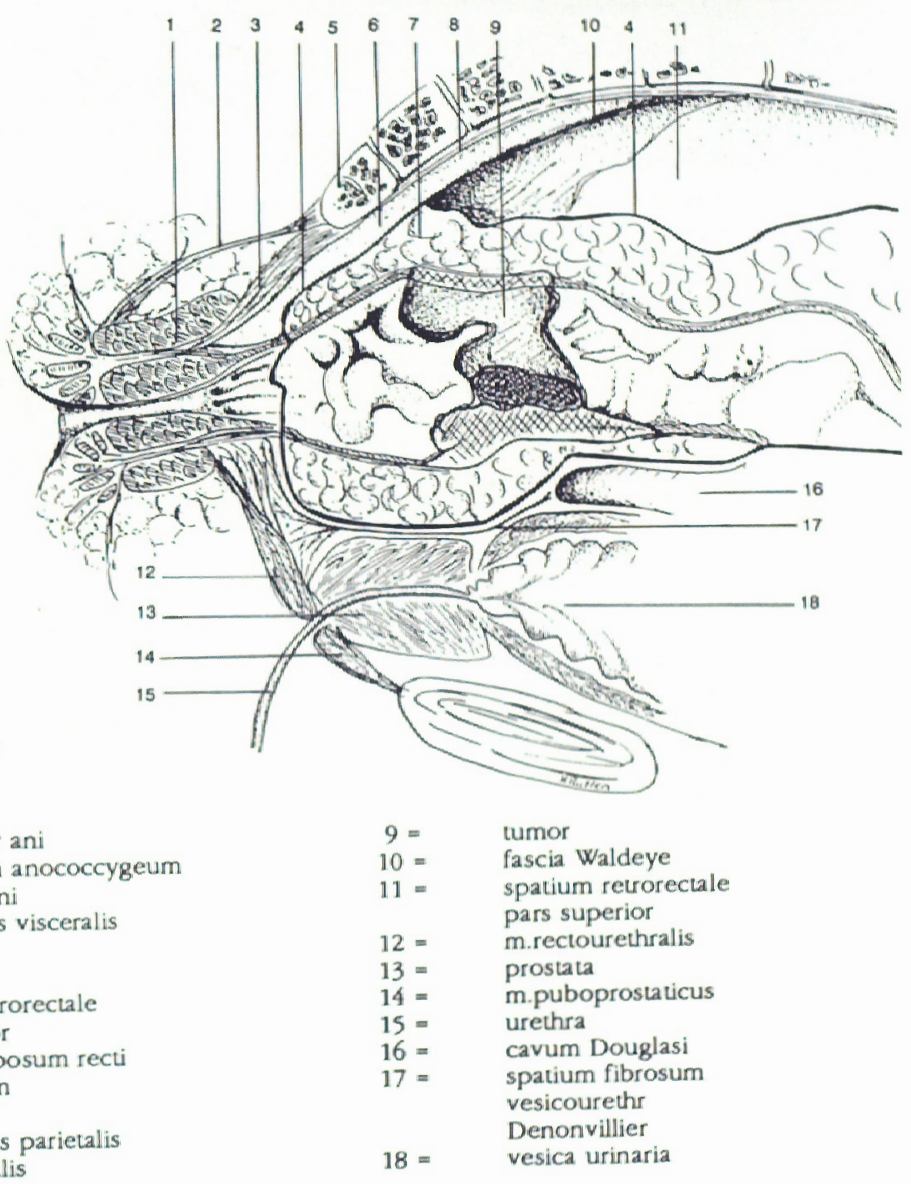




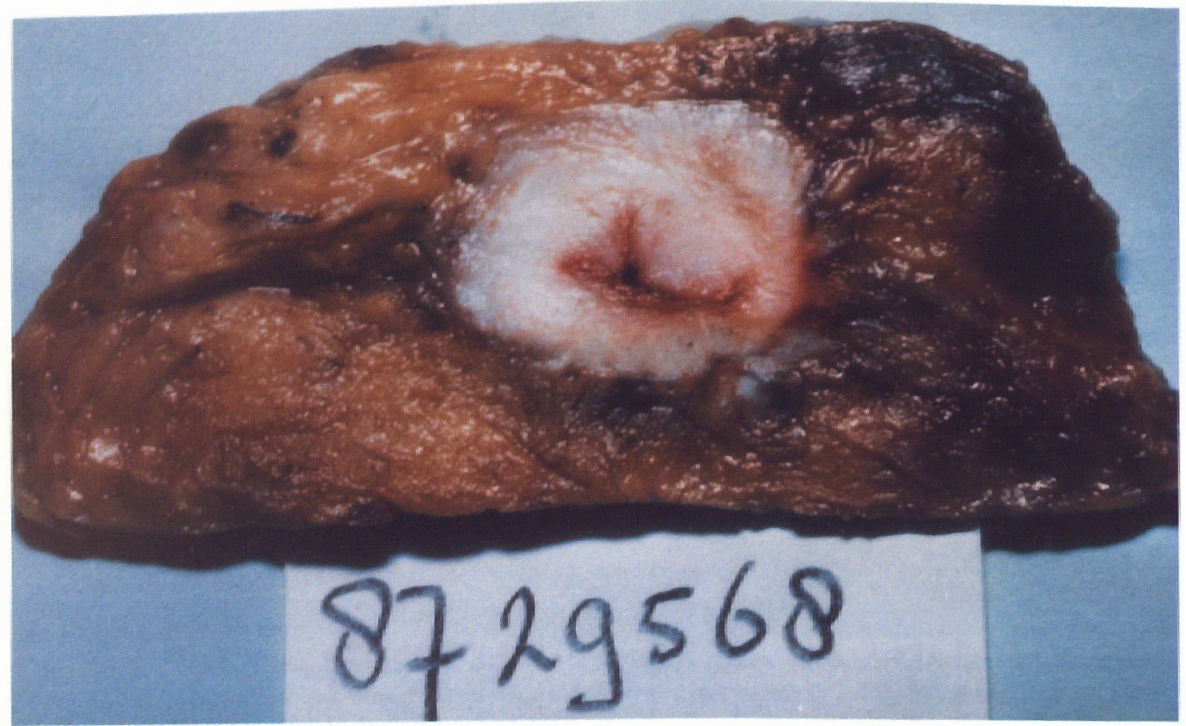

Fig. 7.5a. Macroscopical, transversal slice of a rectal specimen. The tumor, appearing as a white mass in the centre of the specimen, obstructs almost completely the rectal lumen. Macroscopically, the turnor seems fairly well delineated from the surrounding mesorectum.

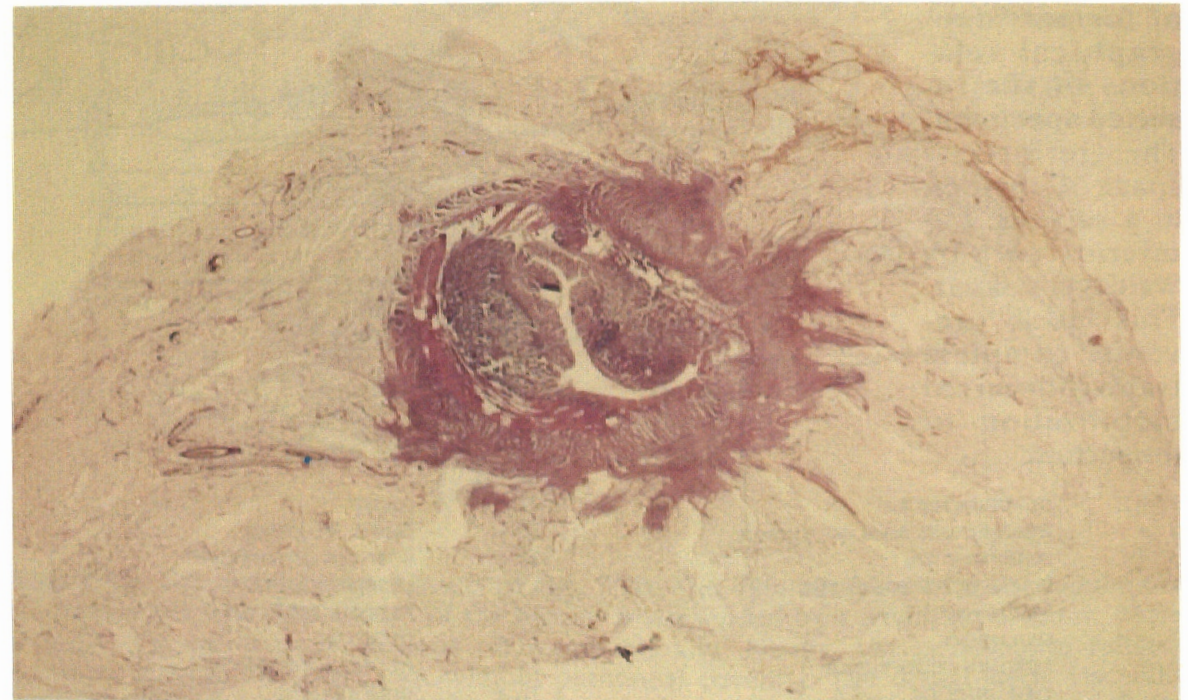

Fig. 7.5b. Same specimen as $7.5 a_{\text {., }}$ thin transversal specimen. The circumerentially growing tumor is seen irregularly infiltrating into the perirectal fat. The chance of a local recurrence, due to residual microscopic deposits of tumor cells, if the mesorectum had not been removed within its fascia, is conceivable. 
previously undiscovered micrometastases were present, which correlated strongly with local pelvic recurrence. The distance between tumor deposits in the mesorectal fat and the radial resection margin is of much more prognostic significance. Keighley (1987) has found that cytologic smears of the tumor bed are reliable indicators of inadequate lateral/radial tumorclearance. Removal of the mesorectum with its potential for micrometastases seems a keystone in the prevention of local recurrences (Williams 1989).

\subsubsection{Oncological consideration in abdomino-interspbincteric procedures.}

In transabdominal mobilization of the rectum the posterior pelvic dissection is realized as far as the retro-rectal space allows. Goligher (1980) describes: "Into the space thus created (proximal opening of the retro-rectal space) the fingers, and then the whole hand are gradually introduced lifting the rectum out of the sacral concavity. In this way the rectum is mobilized posteriorly as far as the tip of the coccyx."

Similar descriptions of the posterior pelvic dissection are found in Localio's (1987), Corman's (1989), Maingot's (1980) handbooks on rectal surgery. This manoeuvre will not free the entire posterior mesorectum from the sacrum as the retro-rectal space does not extend as far as the tip of the coccyx or the ano-rectal junction as was learned from performing intersphincteric approaches. The posterior sagittal suspensory ligament is the inferior border of the retro-rectal space. This ligament is described by Crapp (1974) as recto-sacral fascia and runs transwersally forward from the fourth sacral segment to blend with the posterior rectal fascia 3 to $5 \mathrm{~cm}$ proximal to the ano-rectal junction. It is a tight ligament which is erroneously called Waldeyer's fascia, since Waldeyer never described it. Waldeyer believed that the retromrectal space extended downward as far as the ano-coccygeal ligament. This fascia is of surgical importance:

1. In intersphincteric approaches (as for rectal mobilization in the described techniques, or in postanal repair (Henry 1985, 1988), it has to be divided to mobilize the rectum from the sacrum.

2. In transabdominal approaches it prevents full mobilization of the rectum, unless the perirectal fascia is opened which, from an oncologic point of view, is a break in local radical surgery.

In the intersphincteric approach the mesorectum covered by its fascia is mobilized from the ano-rectal junction to the investment of the recto-sacral fascia, permitting optimal radical posterior dissection.

The anatomy of the perirectal fascia can be studied on a CT-scan. Grabbe (1983), studied the anatomy of the perirectal fascia in more than $2000 \mathrm{Cr}$ examinations of the lower pelvis. He suggests that the perirectal fascia 
completely encloses the corpus adiposum recti within the extraperitoneal space. The laterall ligaments blend antero-laterally in the frontal plane with the perirectal fascia. The lateral ligaments may contain the middle haemorrhoidal anteries Eighty eight percent of the middle haemornoidal arteries do not participate in the bloodsupply of the rectum (Von Lanz Wachsmuth 1984). Boxall (1963) could not find one major middle haemorrhoidal artery in 32 postmortem or surgical specimens. In abdominal moblization, division of the lateral ligaments without entering the perirectal fascia is impossible. As the transsection is carried down in the pelvis, exposure is limited and much of the dissection must be done blind. In combined abdomino-intersphincteric mobilization, the superior border of the ligaments is visualized transabdominally and the inferior border intersphincterically. The ligament can be grasped between two fingers, the free hand can accurately place a clamp guided by the position of the fingers of the other hand. On the rectal side the ligament may then be divided. This technique prevents inadvertent opening into the mesorectal fat. Bleeding is unlikely to occur as the ligament itself does not contain major vessels, and the major vessels in the mesorectum are nor severed. Because no major vessels cross the lateral ligaments, the transsection may also be carried out without clamps.

What applies to dissection of the lateral ligaments applies also to the anterior dissection of the prerectal space. Under direct vision this may be done from below after encircling the distall rectum with a rubber seton. After luxation of the rectum through the perineal wound the exact transsection site can be chosen. The combined abdomino-intersphincteric rectal excision enables the performance of an optimal local radical resection. The complete mesorectum with its intact perirectal fascia is then removed.

\subsubsection{Oncological considerations in segmental resections.}

In segmental resections a radical resection equal to a combined procedures can be realized for the extraperitoneal part of the rectum. A limitation of segmental resection is the transsection of the superior haemorrhoidal lympho-vascular pedicle at a level 3 to $5 \mathrm{~cm}$ more distal than in combined procedures. Ipse facto, much less bowel with an equally less part of the mesorectal fat, can be removed proximal to the tumor. The outcome of segmental resections of the rectum is not clear. York Mason (1976) suggested that this procedure if carried out via a transsphincteric approach may be adequate for tumors confined to the bowel wall. De Leu (1980) studied York Mason's patients but he found only three segmental resections. One patient died postoperatively; one was treated with an open tube resection for a locally advanced tumor but died later on of extensive 
local and general recurrence; the last patient treated for a benign lesion did well. Huber reported results of 36 transsphincteric open tube segmental resections. Eight out of 36 patients suffered a local recurrence that could be treated either by abdomino-perineal resection or by local measures. Eight patients developed a woundinfection with fistula, which healed spontaneously in four and after diverting colostomy, in the rest.

Segmental resections have one great advantage; they obviate the need of a laparotomy and thus reduce morbidity considerably (Häring 1978, Huber 1984). After major procedures mortality may be as high as $15 \%$ in the elder age group (Hughes 1980). From 1971 to 1985, 13 out of 94 patients older than 70 years died in the Catharina Hospital as a result of postoperative complications after major surgery for rectal cancer (unpublished data). A complicated postoperative course was seen in a substantial portion of this age group. Intrinsically, segmental resections do also carry a risk of postoperative complications, but, since no laparotomy is performed, this will be lower than after major procedures. In this series morbidity was due to local complications and no serious cardio-pulmonary morbidity was encountered.

It is difficult to assess the oncological risk after a segmental resection. In segmental resection the proximal and distal margins are equally small. Black (1948) studied longitudinal spread of tumor occurring beyond the raised edge of the carcinoma. No appreciable difference of spread above or below the lesion was noted. Neither the grade of carcinoma nor the depth of penetration through the bowel wall was related to the distance of longitudinal spread. He concluded that only $2 \mathrm{~cm}$ of normal bowel wall needed to be resected above and below the lesion to be able to remove the primary cancer. Bacon (1958) compared a series of patients who had undergone extensive retroperitoneal dissection and radical hemicolectomy with patients who had undergone segmental resection only. He found a five percent increase in the five-year survival rate in the group that underwent radical resection, which was not statistically significant. Most large bowel tumors spread progressively along the lymphnodes, immediately draining the tumor. Skip metastasis occurs in less than five percent of patients (Gabriel 1935, Wood 1933). Many clinical trials have been performed in order to find out whether a removal of more positive lymphnodes resulted in an increased survival rate. Extended retroperitoneal dissections found more positive lymphnodes (Deddish 1950, Sauer 1952, Enker 1979). However, when the survival statistics associated with radical pelvic and retroperitoneal dissections are examined, enthousiasm for this procedure tends to disappear (Bacon 1958, Stearns 1959, Rosi 1962, Grinell 1965, Dwight 1969, Enker 1979, Pezim 1984). The results of some local procedures such as electrocoagulation (Madden 1983) or endocavitary 
irradiation (Papillon 1987) indirectly support the use of segmental resection in patients with increased general risk factors.

Summarizing: Segmental resections may be regarded locally as radical. From previous clinical investigations it is difficult to assess the relation between regional lymphatic clearance and survival rate. Segmental resections may have a place in cancer surgery for high risk patients where the morbidity, associated with a laparotomy, outweighs the possible benefits of a more radical regional resection.

\subsubsection{Oncological considerations in local procedures.}

Cancer of the rectum generally follows a predictable pattern of growth and spread. A cancer starts life as a surface epithelial growth, which can be recognized as a polyp. For obvious reasons it is not possible to observe focal malignant degeneration, subsequent infiltration into the bowel wall and further spread in patients. However, statistical evidence is available to support the adenoma-carcinoma etiology (Morson 1979).

Grinell and Lane (1958) found contiguous benign neoplasms in $7 \%$ of the tumors that extended into the perirectal fat, in $20 \%$ of those limited to the bowel wall and in $60 \%$ of those restricted to the submucosa. Their conclusion was, that if an adenocarcinoma enlarges it increasingly replaces its benign ancestor. Muto (1975) studied 2500 adenomas at the St.Mark's hospital. Seventy five percent were tubular adenomas, in which in $5 \%$ of the cases an adenocarcinoma was found. Fifteen percent were tubulovillous adenomas, in which in $22 \%$ an adenocarcinoma was found. Ten percent were villous adenomas in which in $40 \%$ a focal adenocarcinoma was detected.

There is also a definite relationship between the degree of epithelial dysplasia, polyp size and the incidence of adenocarcinoma:

\begin{tabular}{lccc}
\hline & $<1 \mathrm{~cm}$ & $1.2 \mathrm{~cm}$ & $>2 \mathrm{~cm}$ \\
\hline mild dysplasia & $0.3 \%$ & $3 \%$ & $42.3 \%$ \\
\hline moderate dysplasia & $2.0 \%$ & $14.4 \%$ & $50 \%$ \\
\hline severe dysplasia & $27 \%$ & $24.1 \%$ & $48 \%$ \\
\hline
\end{tabular}

Muto (1975) 
A simillar effect was seen by Muto when comparing histologic type, polyp size and incidence of adenocarcinoma:

\begin{tabular}{llll}
\hline & $<1 \mathrm{~cm}$ & $1-2 \mathrm{~cm}$ & $>2 \mathrm{~cm}$ \\
\hline tubular adenoma & $1 \%$ & $10 \%$ & $34 \%$ \\
\hline tubulo-villous ad. & $3.9 \%$ & $7.4 \%$ & $45.8 \%$ \\
\hline villous adenoma & $9.5 \%$ & $10.3 \%$ & $52.9 \%$ \\
\hline
\end{tabular}

Muto (1975)

Different authors have confirmed the progressive chance of adenocarcinoma with increasing size (Stulc 1988).

Indirect evidence for the adenoma-carcinoma sequence is, that small adenocarcinoma $<0.5 \mathrm{~cm}$ are seldom encountered, suggesting that de novo origin is rare (Fenoglio 1973, Muto 1975).

Gilbertson (1967) proved that removal of polyps did decrease the incidence of adenocarcinoma dramatically in a population of 12.000 patients screened for polyps. This strongly suggests a polyp phase in the etiology.

Regardless of the morphology or history of the original epithelial growth, it is considered malignant if invasion of the muscularis mucosa has occurred. In the muscularis mucosa, lymphatic vessels are present and from this point lymphogenic spread may occur. Further progress is a spearhead invasion straight across the submucosal plane which continues into the circular muscle coat and from there into the longitudinal layer. Williams (1983) concluded after an extensive literature review of results reported over 3000 investigated specimens and a study of his own patient material, that intramural spread is extremely rare and only appears in advanced growth or in anaplastic tumors. Morson (1966) calculated the incidence of lymphatic metastases according to the degree of local continuous spread for a consecutive series of 2084 tumors treated by rectal resection. He found a $10.9 \%$ incidence for growth limited to the mucosa, an $12.1 \%$ incidence of lymphatic spread for growth spreading into the bowel wall, but not beyond. An extra depending factor for lymphatic metastasis was histologic grading. Lymphwessel and bloodvessel invasion occurs in every stage of the disease. Minsky (1988) demonstrated that this was not an independent factor with regard to prognosis. Infiltration of the larger extramural veins correlated with poor prognosis, however, this applied only to advanced stages of the disease (Tallbot 1988).

An understanding of these pathologic features in the natural history of rectal cancer constitutes the basis for local treatment of early rectal cancer. 
In weighing the risk of a major radical surgical therapy versus a local procedure, the surgeon should realize that there is no way of telling which early rectal cancers already have lymphatic or bloodborne metastases. In the event of lymphatic metastases, radical resection may lead to cure in approximately $50 \%$ of all cases. For bloodborne metastases, cure is out of reach of surgical therapy and the patient would benefit from a lesser procedure.

Localio (1987) presents an appealing calculation. Assuming an original cohort of 1000 patients with early rectal cancer, $12 \%$ would be Dukes' C lymphnode positive. Of these lymphnode positive patients, $50 \%$ might survive after radical surgery, thus $6 \%$ of the original cohort might have been saved by radical surgery if all 1000 patients had radical surgery, instead of a locall procedure. However if we estimate the operative mortality of $3.5 \%$ up to $14 \%$ in the older high risk age group, it becomes obvious that a fair price must be paid to save a few patients and surely in case of early rectal cancers high risk patients are better off with local procedures.

Histologic grading may help in the selection, as anaplastic early cancers are relatively more associated with lymphnode metastasis. Morphology may also help in the decision, as polypoid small lesions are also less often associated with lymphnode metastasis (Morson 1966, 1985). Morson (1977) has defined histological criteria for local excision. Several authors from different centres have adopted these criteria (Stearns 1984, Hager 1983, Killingback 1985). The local procedure should be carried out as a total biopsy to enable the pathologist to estimate depth of penetration into the wall and to judge whether the peripheral margins are clear of tumor. Furthermore, it is necessary to define the histologic grade. After mapping these tumor characteristics, a decision can be made whether the resection can be considered curative, or whether further major surgery or adjuvant therapy should be necessary. Local procedures have a definite indication in the treatment of rectal cancer. Assignment of patients to a true Dukes stage of disease is impossible because it requires the pathologic assessment of the radical rectal excision specimen. Clearly, knowledge of true nodal status would be desirable since it precludes undertreating all node positive patients by inadequate local approaches. In selecting patients for local procedures, a guess on clinical grounds has to be made at the true stage of the disease. From pathologic studies it can be concluded, that given a suitable lesion, patients suitability can be met for any of several reasons. Patients with disseminated disease have a limited life expectancy. Therefore, it seems reasonable to subject these patients, if possible, to a small palliative local procedure rather than a major procedure. High risk patients with small, polypoid, mobile, less than $1 / 4$ of the circumference of bowel involved and well or moderately well differentiated tumors have an 
acceptable chance of cure after weighing the chances of operative morbidity and mortality. Patients who refuse to consent to a permanent colostomy may also be candidates if the lesions meet the criteria for suitability. Several techniques have been developed for the local treatment of rectal cancer. The intersphincteric approach offers some distinct advantages: 1. A full thickness specimen can be obtained, which enables thorough pathologic assessment.

2. The dorsal mesorectum may be palpated, and if desired, biopsies can be taken.

3. The anatomy of the continence mechanism is disturbed as little as possible. Even in the case of woundinfection the integrity of the puborectal and levator ani muscles is not in danger.

4. It is a simple technical procedure.

\subsection{Physiological follow up evaluation.}

\subsubsection{Introduction.}

The mechanism of continence is composed of many factors: pelvic floor muscles, puborectalis muscle, external, internal sphincter, rectal ampulla, rectal and anal sensibility. Damage to one of these factors may result in a certain degree of incontinence. Undisturbed factors may adjust for the loss of another factor. Not all structures are equally important to the physiological mechanisms that maintain continence. Damage to the puborectal muscle will lead to gross incontinence. The internal sphincter can be considered important for the fine tuning of continence (Henry 1985).

After very low rectal resections the reservoir function and sensory function of the rectum are lost. It has been assumed by most surgeons in the past, that at least 6 to $8 \mathrm{~cm}$ of intact rectum was necessary to preserve rectal sensation (Golligher 1951). Lane (1977) showed that after complete excision of the rectum with anastomosis of the colon to the top of the anal canal, virtually normal continence could be achieved, also with regard to sensation and recto-anal reflexes. Since then, several authors have confirmed that discrimination of the quality of rectal contents and initiation of physiological reflex mechanisms are a function of the pelvic floor muscles rather than of the rectal ampulla (Rudd 1979, Williams 1980, Kuijpers 1983, Enker 1985, Henry 1985). 


\subsubsection{Sensory function.}

The recto-anal reflex was present in the majority of our patients, also indicating that the stretch receptors in the levator ani and external sphincter as demonstrated by Winckler (1958) and Walls (1959) provide the possible mechanisms whereby sensation is mediated.

All patients were able to discriminate between the different contents of the rectum to at lleast some degree. The level of the colo-anal anastomosis is not critical with regard to the sensory function. Stephens and Smith (1971) observed that children, who had supra-levator and intermediate rectal deformities and were operated by drawing the upper rectum or colon through the pubo-rectal sling and anastomosing it to perineal skin, were capable of interpreting accurately the nature of rectal contents. In these children neither the true anal canal with its transitional zone nor the external sphincter were present. "They concluded that the levator and puborectal muscles conserve discriminatory function. Johnston (1987) and also Keighley (1987) observed that discrimination is not impaired by excision of the anal transition zone after restorative proctocolectomy for ulcerative colitis.

After intersphincteric resection, the discriminatory function was retained. Some patients suffered transient loss in the first postoperative days/weeks.

\subsubsection{Reservoir function.}

Loss of the rectal reservoir, which is specialized in adapting to changing volumes, leads to impairment of continence. Small volumes of faeces, evoking only unconscious transient pressure rises in patients with a normal rectum, cause an irresistible sense of evacuation in a person with a much reduced rectal capacity. Lane and Parks noted an increase in bowel movements from four to eight times per day (1977). They also noted that, as the colon above the anastomosis gradually assumes the function of a new rectum, the frequency of defaecation decreases to two or three actions daily. Suzuki described a decrease of volume which urges the patient to defecate after low anterior resection from $192 \pm 99.6 \mathrm{ml}$ to $73 \pm 23 \mathrm{ml}$ (Suzuki 1980). Williams (1980) reported an increase in frequency, but no dramatic decrease in maximum tolerable neorectal volume after low anterior resection. Keighley (1980) recorded a significant fourfold reduction in the mean rectal capacity in six patients six months after an endo-anal
anastomosis. Drake (1987), Lazorthes (1987) and Nicholls (1988) advocate the construction of a colonic pouch in order to increase the capacity and subsequently decrease the frequency of defaecation after colo-anal anastomosis. Their
functional results are good, however, their studies were not randomized. 
Surprisingly, after rectal resection with intersphincteric anastomosis the patients generally (did not show a very significant) decrease in rectal capacity during the follow-up study. These findings are comparable with the findings of Williams (1980). Moreover, frequency of defaecation spontaneously decreased during the first postoperative year and only one patient had to rely temporarily on antidiarrhoeal medication to maintain an acceptable defaecation pattern. Importantly, only one patient was incapacitated by poor bowel function and required for this reason a permanent diverting colostomy. Employment of a colonic pouch does not seem indicated after intersphincteric colo-anal anastomosis, as rectal capacity remains within an acceptable range and the natural course of adaptation is favourable.

After postoperative irradiation ( $5500 \mathrm{rad}$ ), one patient became incontinent due to the development of a rigid, stenotic neorectum.

\subsubsection{Spbincter function.}

Numerous manometric studies have been performed. Anal manometry can provide information on the resting and squeeze pressure as a result of internal and external sphincter function. With pull-through catheters the functional lengths of the anal canal can be estimated. The internal sphincter is thought to maintain a closed anal canal and this probably prevents inadvertant passage of flatus and liquid stool. Dysfunction would result in soiling. Stelzner (1965) suggested an additional mechanism to prevent soiling, namely, the corpus cavernosum recti. The venous haemorrhoidal plexus would act as a corpus cavernosum and be able to occlude the anal canal watertight as a result of venous backflow obstruction caused by internal sphincter tone. By vigorous contraction the external sphincter may preserve continence in situations in which normal mechanisms would be severely challenged like in case of profuse liquid stool or urge from decreased rectal capacity and compliance (Henry 1985).

Interpretation of manomatric studies is difficult. Values depend on a wide variety of factors. Krogh Pederson (1989) recently studied the intraindividual variation in anal manometry. The maximum intra-individual variation in the length of the anal canal, resting pressure and squeeze pressure were: $10 \mathrm{~mm}, 26 \mathrm{mmHg}$ and $68 \mathrm{mmHg}$, respectively. He found a mean length of $25 \mathrm{~mm}$, a mean resting pressure in male of $66 \mathrm{mmHg}$, a mean resting pressure in female of $46 \mathrm{mmHg}$, and a mean maximum squeeze pressure of $163 \mathrm{mmHg}$ in male and $103 \mathrm{mmHg}$ in female. The value range was approximately $50 \%$ of the mean value. Significant sex differences but no effect of age was found. Krogh Pederson used an open tip perfused catheter. Catheters with water filled balloons, multiple side 
Chapter 7

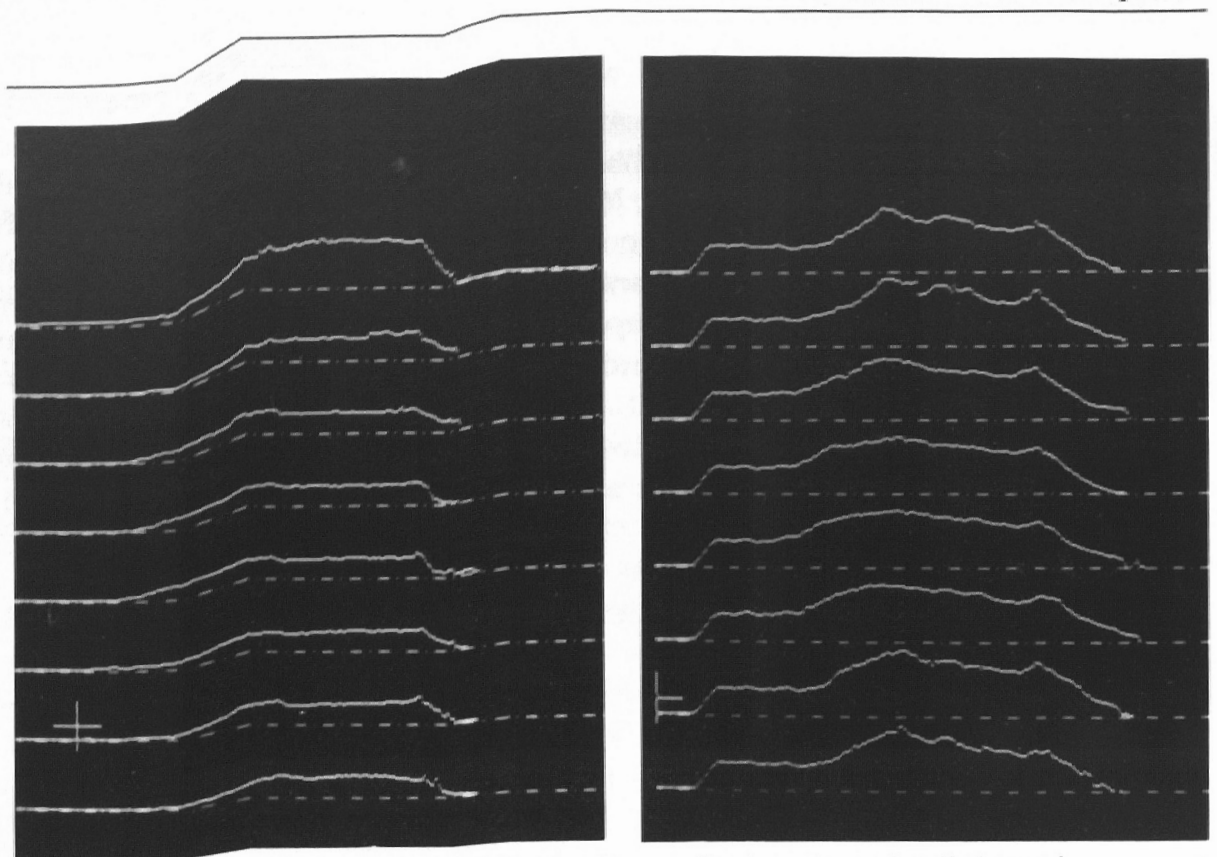

Fig. 7.6a-b. Eight channel anal manometry. Registration of pull-through curves at rest and at maximal squeezing.
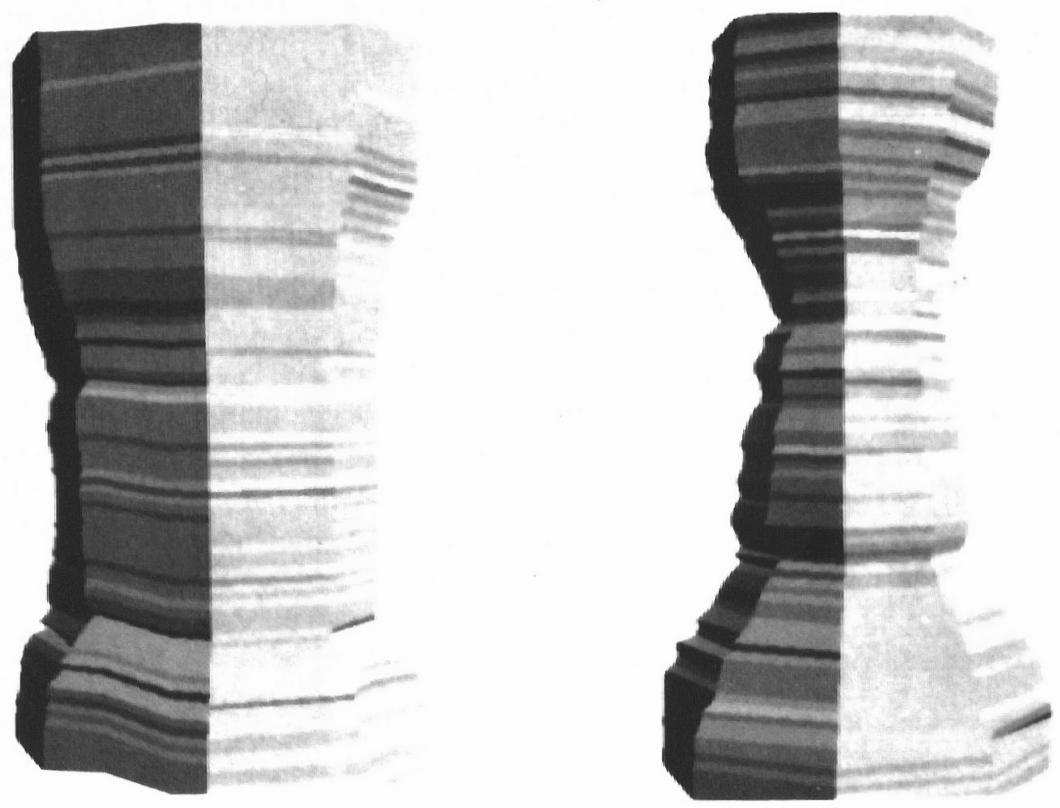

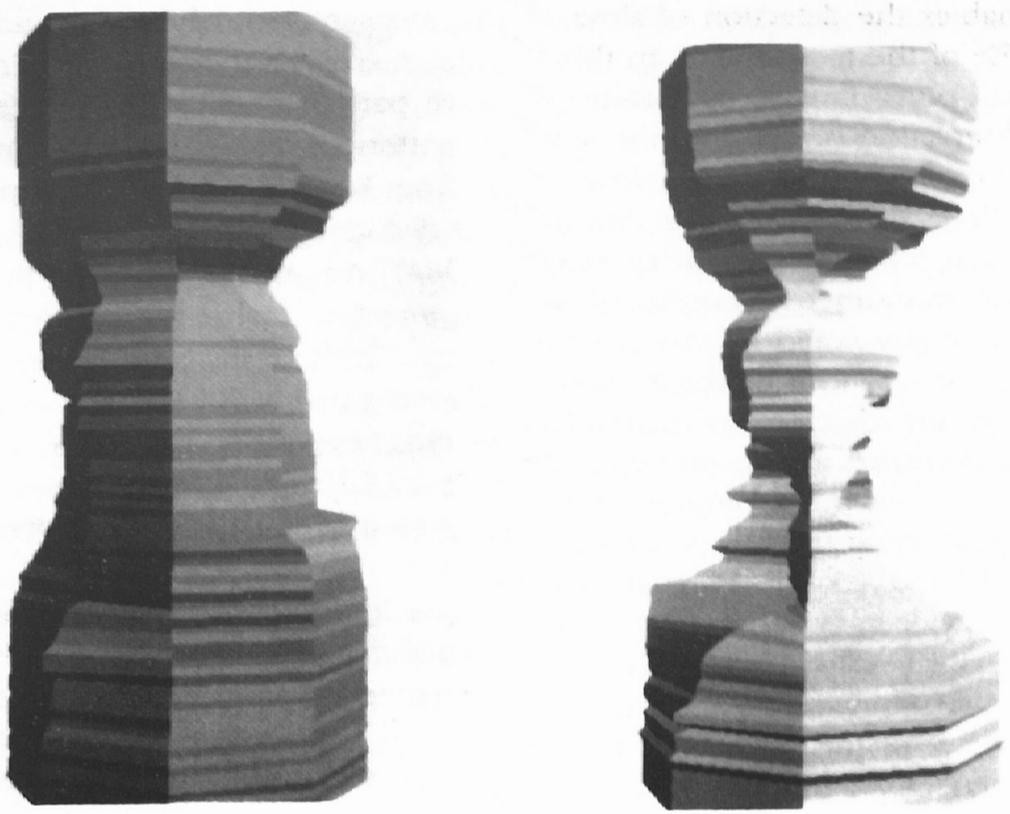

Fig. 7.8a-b. Three dimensional graphic reconstruction of another pressure profile. Scale $0-60 \mathrm{mmHg}$. It is obvious in both examples, that the pressure changes are the result of a dynamic sphincter function.

\section{$\leftarrow$}

Fig. 7.7a-b. Three dimensional graphic reconstruction of the curves in fig 7.6. Distance from the outside to the core of the cilinder represents anal pressure. The cilinder has eight faces, corresponding with the pressure data from the sideholes of the eight channel manometry catheter. The deeper the indentation the higher the pressure. The scale from outside to the core of the cilinder may differ. In fig. 7.7. the scale is $0-300 \mathrm{mmHg}$.

holles, microsensors and air filled balloons have been used (Duthie 1971, Nivatvong 1981, Varma 1984, Taylor 1984, Hancke 1988, Miller 1989). Superimposed on the intra-individual differences in measured values, are the differences caused by the measuring device. Guitierrez (1975) demonstrated the relationship between intraluminal pressure and diameter of the recording assembly. Using static devices instead of pull-through devices 
enables the detection of slow amplitude waves, which may be as high as $75 \%$ of the mean value. In this study, measurement of the recto-anal reflex was performed with a static double microsensor catheter which made observation of this intrinsic slow wave pattern possible. After intersphincteric procedures these slow wave patterns were seen in 13 out of 20 patients, with amplitudes that ranged from 5 to $75 \%$ of the resting pressure. Radial pressure asymmetry is another disturbing factor in the evaluation of anal manometric studies (Taylor 1984). An explanation for this radial asymmetry could be the fact that the emptied anal canal is flattened from side to side in a slitlike manner (Phillips 1965). In this way, forces working from the outside on this slitlike closed canal will produce asymmetry. Multichannel anal manometry allows exact evaluation of this asymmetry. A special computer program developed by Dijkhuis (1988) permits graphic spatial reconstruction of the pressure profile which gives greater insight into radial and axial pressure asymmetry.

The wide range of normal values limits the predicting impact of an individual measurement. However, if normal values for the specific device are known, some statements can be made comparing groups of patients.

Twenty of the patients in this study who had undergone intersphincteric approach for low rectal pathology underwent eight-channel manometry. Use of this technique was made possible through the help of the department for experimental surgery of the Academic Medical Centre of Amsterdam (head of the department: Prof.Dr. P.J.Klopper). Five other patients who had a very low anterior resection (anastomosis at 6 or less than $6 \mathrm{~cm}$ from the anal verge) were likewise examined.

In all three groups of patients who were operated intersphincterically as well as in the group of patients with a very low anterior resection, resting pressures and squeeze pressures were lower than normal. Soiling, a symptom indicating a functional defect of the anal sphincter, occurred to some degree in the majority of patients after segmental resection. This finding is in agreement with the fact that after segmental resection the resting pressure is lowest. Obviously, greater damage is inflicted on the sphincter when the rectal resection is done completely via an intersphincteric approach, as in segmental resections. Mean age of patients that underwent segmental resection was considerably higher than of those in the other groups. Some decrease in resting pressure and squeeze pressure was noted after combined, local and transabdominal procedures, but anal continence was not affected by this. Williams (1980) had similar results after very low anastomosis. Other authors did not find any difference in resting and squeeze pressure (Keighley 1980, Nicholls 1988).

Due to organizational problems we did not have enough measurements at our disposal to allow comparison between the pre and post operative 
manometric values. Conclusions were drawn from comparising the postoperative values of the different groups of patients.

The most important findling of the manometric investigations is that sphincter function is actually retained. The quality of the anal sphincter could be demonstrated graphically by computerization of the eight-channel manometry. This evidenced that a dynamic sphincter function is retained. Closure of the anus is not achieved via scar formation but by a dynamic sphincter activity. After an intersphincteric approach of his low rectal pathology a patient is left with a functioning sphincter capable of preventing inadvertent escape of gas or mucous and is also able to forcefully close his anus by conscious vigorous contraction. Patients who underwent segmental resection were continent, albeit with a deficit in their fine tuning, because of an impaired internal anal sphincter.

Baeten (1985) demonstrated that individual measurements are of no importance as predictive parameters for continence problems after treatment for haemorrhoids. In this study, individual measurements also appeared to be of little value. Any continent patient is eligible for an intersphincteric procedure. Preoperative functional evaluation is not necessary.

\subsection{Conclusion.}

\subsubsection{Introduction.}

Undoubtedly the spectrum of rectal surgery is changing. Today, restorative resections are considered just as safe as abdomino-perineal resections. However, as the level of transsection of the rectum gets lower, technical problems are increasing proportionally. New techniques have been developed to try to overcome these problems. The principles of all these methods have been described by our surgical forefathers over one century ago. Despite technical advances, the natural course of the disease has remained unaffected. One of the major problems which still has to be solved, is local recurrence. Microscopic tumor deposits in remaining mesorectal tissue are considered responsible for local recurrent disease after an apparently succesful curative resection. Future developments in modern operative surgery will have to focus on this residual disease, either by perfecting standard methods, thereby aiming at limiting intersurgeon variation in the extent of local tissue removal, or by developing of new techniques, which can remove the entire mesorectum in its fascia. Evidence, that irradiation therapy could be a potent adjuvant modality in the control of local recurrent disease, is increasing. Combining surgery with irradiation therapy seems a logical step toward better local control of rectal cancer. 
As therapeutic strategies are becoming more complex, proper selection of patients becomes possible only after accurate preoperative clinicopathological assessment. The orientation and integrity of possible surgical cleavage planes have to be known in advance. High risk patients have to be selected for adjuvant trials. Incurable patients will have to be treated by optimal minor procedures instead of major surgery.

As resections are proceding more distally, functional results will have to be evaluated more critically. Understanding the factors which are responsible for the action of preserving continence is of the utmost importance, since more extensive resection is damaging to the continence mechanism. Integrity of the somatic pelvic floor muscles, especially the puborectal muscle, seems to be the key to an acceptable functional end result.

\subsubsection{Place of the interspbincteric approacb in rectal cancer surgery.}

Basically, the concept of the intersphincteric approach of rectal pathology is based on two theoretical principles.

1. Removal of the complete mesorectum with its covering fascia, thus securing optimal radical resection.

2. Preserving the integrity of pelvic floor and puborectal muscles, thus optimizing functional results.

The intersphincteric approach offers some distinct advantages to the other approaches for low rectal pathology.

The double stapling technique for a low resection has solved the technical problem of a difficult anastomosis, since much of the anastomosis can now be carried out blind. An anastomosis can be performed at the level of the pelvic floor at the top of the anal canal. The procedure of mobilization and resection is completely transabdominal and limited by the accessibility to the lower pelvis. With the endo-anal technique for anastomosing the proximal colon, an anastomosis at the level of the dentate line is possible; but this technique is difficult however and requires special instruments. Transsacral and transsphincteric techniques are developed to gain additional access from below in order to facilitate deep mobilization and anastomosis. With these techniques a limited exposure from below is obtained at the cost of either the removal of the os coccygis or transsection of the sphincters, resulting in a disturbance of the normal anatomical relations of the important components of the continence mechanism. In case of wound infection, permanent disturbance of the pelvic floor will result.

The abdomino-intersphincteric approach for low rectal pathology fulfils the criteria for radical surgery, specifically by the removal of the complete 
mesorectum with its covering fascia. Maximal exposure from below facilitates mobilization, transsection and anastomosis at any level of the anorectum. The external sphincter, puborectal muscle and levator muscles are not transsected, theoretically ensuring optimal functional result.

The new approach has been performed in 35 patients and the first results are presented and evaluated in this study. From a clinical, functional, as well as an oncological point of view the intersphincteric approach seems promising at the end of a short follow-up.

One of the main draw-backs of intersphincteric procedures is the high percentage of anastomotic dehiscence $(31 \%)$, which inevitably leads to perineal woundinfections with resulting fistulas since the anastomosis is adjacent to the perineum. This impending complication forced the primary use of a diverting colostomy in case of a colo-anal anastomosis, such as in abdomino-intersphincteric and segmental resections. All fistulas healed spontaneously and none of them affected the functional end result, because the fistulous tracts did not pass through the external sphincter or the puborectal muscle. Nevertheless, it considerably prolonged recovery.

No golden standard for physiological testing of continence is available. All tests look at only one factor of a mechanism which depends on the cooperation of multiple factors, some of which are not clearly understood yet. From a functional point of view, little objection can be made to the intersphincteric approach of the rectum. Subjectively, patients experience impairment of their continence to such a small degree that it remains compatible with normal life. Objectively, the remaining neorectal capacity and the sphincter function is acceptable. Functionally, these patients are comparable with patients who underwent a traditional resection and low anastomosis.

This new approach may have a place in the surgical armament for the treatment of low seated rectal cancers. The procedure proved to be of value for local procedures, such as, segmental resections, but especially, for local resections. In the author's opinion, there is no longer a place for the transsphincteric approach to the lower rectum. 


\section{References chapter 6 and 7t}

Bacon HE, Dirbas F, Myers TB.,Ponce de Leon F.: Extensive lymphadenectomy and high ligation of the inferior mesenteric artery for carcinoma of the left colon and rectum.

Dis Colon Recturn 1;457-467, 1958 .

Baeten CGMI.: Haemorrhoids, evaluation of methods of treatment.

Thesis, 1985.

Beart RW. Kelly KA.: Randomized prospective evaluation of the EEA stapler for collorectal anastomoses.

Ann.Surg. 141;143-147, 1981.

Beckers J, Kerremans R: De sphinctersparende operaties voor rectumcarcinoom.

Tijdschr.Geneesk. 1;44 1972.

Black WA. Waugh JM.: The intramural extension of carcinoma of the descending colon sigmoid and rectosigmoid.

Surg.Gynecol.Obstet. 84;457-464, 1948.

Boxall TA., Smart PJG., Griffiths JD.: The blood-supply of the rectum in anterior resection.

Br.J.Surg. 50;399, 1963.

Corman ML.: Collon and rectal surgery.

J.B. Lippincott Company, Philadelphia, 1984.

Crapp AR., Cuthbertson AM.: William Waldeyer and the recto-sacral fascia.

Surg.Gynecol. Obstet. $138 ; 252,1974$.

Cronin K., Jackson DS., Dunphy JE.: Changing bursting strength and collagen content of the healing colon.

Surg.Gynecol.Obstet. $126,747-753,1968$.

Deddish MR., Stearns MW: Anterior resection for carcinoma of the rectum and recto-singmoid area.

Ann. Surg. 154;961-966, 1961.

Deleu HWO.: Het villeus adenoom van het recnum. Een transsphincterische benadering.

Thesis, 1980 .

Dijkhuis Th., vd.Hulst VPM., Bemelman WA.: Een impressionistische kijk op de werking van de sluitspieren

Klinische Fysica 68-71, 1988.

Drake DB., Pemberton Jh, Beart RW., Dozois RR., Wolff BG.: Coloanal anastomosis in the management of benign and malignant rectal disease.

Ann.Surg. 206,600-605, 1987. 
Duthie $\mathrm{HL}_{\text {: }}$ Progress report: anal uncontinence.

Gut $12 ; 844-852,1971$.

Dwight RW., Higgins GA., Keehn RJ: Factors influencing survival after resection in cancer of the colon and rectum.

Am.J.Surg. 117;512-522, 1969.

Enker WE., Laffer UT., Block GE: Enhanced survival of patients with colon and rectal cancer is based on wide anatomic resection.

Ann.Surg. 190;350-360, 1979.

Enker ME., Stearns MW., Janow AL.: Peranal coloanal anastomosis following low anterior resection for recial carcinoma.

Dis.Collon Rectum 28;575-581, 1985.

Fenoglio CM., Kaye GI., Lane N.; Distribution of human colonic lymphatics in normal, hyperplastic and adenomatous tissue.

Gastroenterology 64;51-66, 1973.

Flelding LP., Stewart-Brown S., Blesovsky L., Kearney G.: Anastomotic integrity after operations for large bowel cancer a multicenter study.

Br.Med.J. 9:411-414, 1980.

Gabriel W/B., Dukes C., Bussey HJ.: Lymphatic spread in cancer of the rectum.

Br.J.Surg. 23;395-413, 1935.

Gilbertsen VA., Knatterud GL., Lober PH., Wangensteen PH.: Invasive carcinoma of the large intestine: a preventable disease.

Surgery 57;363-365, 1967.

Gillen P., Peel ALG.: Comparison of the mortality, morbidity and incidence of local recurrence in patients with rectall cancer treated either by stapled anterior resection or abdominoperineal resection.

Br.J.Surg. 73,339-341, 1986.

Goligher JC., Hughes ESR.: Sensibility of the rectum and colon: its role in the mechanism of anal continence.

Lancet 1;543-548, 1951.

Goligher JC., Graham NG. Dombal FT.: Anastomotic dehiscence after anterior resection of rectum and sigmoid.

BrJ.Surg. 57;9, 1970.

Goligher JC, Lee PWR., Simpkins KC., Lintott DJ.: A controlled comparison of oneand two-layer techniques of suture for high and low colorectal anastomoses.

Br.J.Surg. 64;609, 1977.

Goligher JC. Surgery of the anus rectum and colon.

Ed.4, Bailliere Tindall, London, 1980. 
Grabbe $E_{*}$, Lierse W, Winkler $\mathrm{R}$ : The perirectal fascia: morphology and use in staging of rectal carcinoma.

Radiology 149;241-246, 1983 .

Grinell RS. Lane $N_{:}$: Benign and malignant adenomatous polyps and papillary adenomas of the colon and rectum. An analysis of 1856 tumors in 1335 patients.

Int.Abs. Surg. 106,519-538, 1958.

Grinell RS: Results of ligation of inferior mesenteric artery at the aorta in resections of carcinoma of the descending and sigmoid colon and rectum.

Surg. Gynecol. Obstet. 120;1031-1036, 1965.

Gutierrez JG., Oliai A., Chey WY.: Manometric profile of the internal sphincter in man.

Gastroenterology $68,907,1975$.

Hager $T_{*}$ Gall FP., Hermanek P.: Local excision of cancer of the rectum.

Dis.Colon Rectum 26;149-151, 1983.

Hancke E: Anorectale Manometrie mit Mikro-Transducer.

Chirurg 59;119-122, 1988.

Häring $R_{\text {, }}$ Karavias $T_{\text {, }}$ Konradt J.: Die posteriore Proktorectotomie

Chirurg 49;265, 1978.

Hawley PR., Faulk WP., Hunt IK., Dunphy JE.: Collagenase activity in the gastrointestinal tract.

Br.J.Surg. 57;896-900, 1970.

Heald RJ., Husband EM., Ryall RDH.: The mesorectum in rectall cancer surgery- the clue to pelvic recurrence?

Br.J.Surg. 69;613-616, 1982 .

Heald RJ., Ryall RDH:: Recurrence and survival after total mesorectal excision for rectall cancer.

Lancet $19861 ; 1479-1482,1986$.

Henry MM, Swash M: In: Coloproctology and the pelvic floor.

Buttersworths, London, 1985.

Henry MM., Porter NH.: A colour atlas of faecal incontinence and complete rectal prolapse.

Wolfe Medical Publications Ltd., London, 1988.

Holdsworth PJ., Johnston D.: Anal sensation after restorative proctocolectomy for ulcerative colitis

Br.J.Surg. 75,993-996, 1988

Huber A., Hochstetter v. AHC., Allgöwer M.: Transsphinktere Rektumchinurgie.

Springer-Verlag, Berlin, 1983. 
Irvin TT. Goligher JC.: Aetiology of disruption of intestinal anastomoses.

Brit.J.Surg. $60 ; 461=464,1973$.

Irvin TT., Hunt TK.: Pathogenesis and prevention of disruption of colonic anastomoses in traumatized rats.

Br.J.Surg. 61;437-439, 1974.

Johnston D., Holdsworth PJ., Nasmyth DG $_{.,}$Neal DE., Primurose JN., Womack N., Axon ATR.: Presevation of the entire anal canal in conservative proctocolectomy for ulcerative colitis: a pilot study comparing end-to-end ileo-anal a mucosal proctectomy and endo-anal anastomosis.

Br.J.Surg. 74;940-944, 1987.

Keighley MRB., Matheson D.: Functional results of rectal excision and endo-anal anastomosis.

Br.J.Surg. 67;757-761, 1980.

Keighley MRB., Hall C.: Anastomotic recurrence of colorectal cancer - a biological phenomenon or an avoidable callamity?

Gut $28 ; 786-791,1987$.

Keighley MRB., Winslet MC., Yoshioka K., Lightwood R.: Discrimination is not impaired by excision of the anal transition zone after restorative proctocolectomy.

Br.J.Surg. 74;1118-1121, 1987.

Killingback MJ.: Indications for local excision of rectal cancer.

Br.J.Surg. 72suppl;54-56, 1985.

Krogh Pedersen I., Christiansen J.: A study of the physiological variation in anal manometry.

Br.J.Surg. 76;69-71, 1989.

Kuijpers JHC: Fecal continence after subtotal to total excision of the rectum.

Neth.J.Surg. 35;73-76, 1983.

Lane RHS , Parks AG.: Function of the anal sphincters following colo-anal anasto mosis.

Br.J Surg. 64,596-599, 1976.

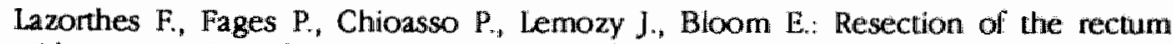
with construction of a colonic reservoir and colo-anal anastomosis for carcinoma of the rectum.

Br.J.Surg. 73;136-138, 1986.

Localio SA, Eng $\mathrm{K}_{\text {: }}$ Abdominosacral resection for midrectall cancer.

Ann.Surg. 198;320-324, 1983.

Localio SA., Eng K., Coppa GF.: Anorectal presacral and sacral tumors.

W.B.Saunders Company, Philadelphia, 1987. 
Madden JL., Kandalaft. SI.: Electrocoagulation as a primary curative method in the treatment of carcinoma of the rectum.

Surg Gynecol. Obstet. $157,164-179,1983$.

Maingot Abdominall operations.

Ed. 7th, Appleton Century Crofts, New York, 1980.

MdDermott FT, Hughes ESR, Pihl E.: Local recurrence after potentially curative resection for rectal cancer in a series of 1008 patients.

Br.J.Surg, $72 ; 3437,1985$.

Miller R, Bartolo DCC., James D., McMortensen NJ.: Air-filled microballoon. manometry for use in anorectal physiology.

Br. J Surg. 76,72,75, 1989.

Minsky BD., Mies C., Recht A., Rich TA., Chaffey JT.: Resectable adenocarcinoma of the rectosigmoid and rectum. 1 . Patterns of failure and survival.

Cancer $61 ; 1408-1416,1988$.

Morson $\mathrm{BC}$ : Factors influencing the prognosis of early cancer of the rectum.

Proc.R.Soc.Med. 59;607-608, 1966.

Morson BC., Bussey HJR., Samoorian S: Policy of local excision for early cancer of the colorectum.

Gut 18 ; $1045-1050$, 1977 .

Morson BC. Dawson IM.: Gastrointestinal pathology.

Blackell, Oxford, 1979.

Morson BC: Histological criteria for local excision.

$\mathrm{Br}_{\mathrm{r}}$.Surg. 72suppl;53-54, 1985.

Muto T., Bussey HJR., Morson BC.: The evolution of cancer of the colon and rectum.

Cancer $36,2251-2270,1975$.

Nicholls RJ., Lubowski DZ., Donaldson. DR. Comparison of colonic reservoir and straight colo-anal reconstruction after rectal excision.

Br.J Surg. $75,318-320,1988$.

Nivatvongs S., Stern HS., Fryd DS.: The length of the anal canal.

Dis. Colon Rectum 24;600-601, 1981.

OConnell MJ. Gunderson LL., Fleming TR. Surgical adjuvant therapy of rectal cancer.

Semin. Oncol. $15 ; 138-145,1988$.

Papillon $J_{\text {.: }}$ The future of external beam irradiation as initial treatment of rectal
cancer. Br.J.Surg. 74;449-454, 1987 . 
Parks AG., Stuart AE: The management of villous tumours of the large bowel. Br.J.Surg. $60 ; 688,1973$.

Parks $A G$, Percy JP: Resection and sutured colo-anal anastomosis for rectal carcinoma.

Br.J.Surg. 69;301-304, 1982.

Pezim ME., Nicholls RJ.: Survival after high or low ligation of the inferior mesenteric artery during curative surgery for rectal cancer.

Ann.Surg. 200;729-733, 1984 .

Phillips RKS., Hittinger R., Blesovsky L: Local recurrence following 'curative" surgery' for large bowel cancer: the overall picture.

Br.J.Surg. 71;12-16, 1984.

Phillips SF., Edwards DAW.: Some aspects of anal continence and defaecation.

Gut 6,396-405, 1965.

Quirke $P_{n, 1}$ Durdey P., Dixon MF., Williams NS. Local recurrence of rectal adenocarcinoma due to inadequate surgical resection.

Lancet II:996-999, 1986.

Rosi PA., Cahill WJ., Carey J.: A ten year study of hemicolectomy in the treatment of carcinoma of the left half of the colon.

Surg.Gynecol.Obstet. 114;15-24, 1962.

Rudd WWH: The transanal anastomosis: A sphincter-saving operation with improved continence.

Dis.Colon Rectum 22;102-105, 1979.

Sauer $\mathbf{I}_{\text {, }}$ Bacon HE. A new approach for excision of carcinoma of the lower portion of the rectum and anal canal.

Surg. Gynecol. Obstret. 95;229-249, 1952.

Stearns MW., Sternberg S., Decoss JJ.: Treatment alternatives. Localized rectal cancer. Cancer $54 ; 2691-2694,1984$

Stearns MW., Deddish MR.: Five-year results of abdominopelvic lymph node disection for carcinoma of the rectum.

Dis.Colon Rectum 2;169-172, 1959.

Stephens FD., Smith ED: Anorectal malformations in children.

Chicago, Year Book Medical Publishers, 1971.

Stulc JP., Petrelli NJ., Herrera L. Mittelman A.: Colorectal villous and tubulovillous adenomas equal to or greater than four centimeters.

Ann.Surg. 207;65-71, 1988.

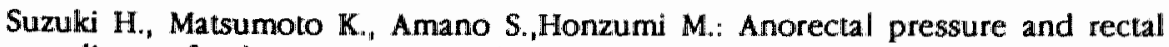
compliance after low anterior resection.

Br.J.Surg. 67;655-657, 1980. 
Talbot IC., Ritchie S., Leighton MH.: The clinical significance of invasion of veins by rectal cancer.

Br.J.Surg. 67;439-442, 1980.

Taylor BM., Beart RW., Phillips SF.. Longitudinal and radial variations of pressure in the human anal sphincter.

Gastroenterology 86;693-697, 1984 .

V.Lanz Wachsmuth: Praktische Anatomie-Becken-

Zweiter Band. Teil 8a, Springer Verläg, Heidelberg, 1984.

Varma JS., Smith AN.: Anorectal profilometry with the microtransducer.

Br.J.Surg. $71 ; 867-869,1984$.

Walls EW: Recent observations on the anatomy of the anal canal.

Proc.Roy.Soc.Med. 52, Suppl 85-87, 1959.

Williams NS., Price R., Johnston D.: The long term effect of sphincter preserving operations for rectal carcinoma on function of the anal sphincter in man.

Br.J.Surg. 67;203-208, 1980.

Williams NS., Dixon MF, Johnston D.: Reappraisal of the 5 centimetre rule of distal excision for carcinoma of the rectum: a study of distal intramural spread and of patient's survival.

BrJ.Surg. 70;150-154, 1983.

Williams NS.: The rationale for preservation of the anal sphincter in patients with low rectal cancer.

Br.J.Surg. 71;575-581. 1984.

Williams NS., Durdey P., Johnston D.: The outcome following sphincter saving resection and abdomino-perineal resection for low rectal cancer.

Br.J.Surg. 72;595-598, 1985.

Williams NS.: Changing patterns in the treatment of rectal cancer.

Br.J.Surg. 76;5-6, 1989.

Winckler $G_{\text {.: }}$ Remarques sur la morphologie et l'innervation du muscle releveur de I'anus.

Arch.Anat.Histol.Embryol. 41;77-95, 1958.

Wood WQ., Wilkie DP.: Carcinoma of the rectum : an anatomicopathological study.

Edinburgh Med.J. 40;321-343, 1933.

York Mason A: The spectrum of selective surgery.

Proc.Roy.Soc.Med 69;237-244, 1976. 


\section{Chapter 8.}

\section{Recommendations for the selection of patients for inter- sphincteric procedures.}

The abdomino-intersphincteric resection may be considered a radical procedure for low seated rectal tumors which are confined to the perirectal fascia.

The surgeon should be informed about the level and infiltration depth of the tumor.

Level: A free margin of at least two $\mathrm{cm}$ between the dentate line and the inferior border of the tumor is necessary.

Infiltration depth: On digital palpation the tumor should be mobile or just slightly tethered, indicative of clinical stage 1 or 2 . In case of clinical stage 3 , the surgical cleavage planes should be assessed carefully. If doubtful, a computed tomogram of the lesion should be obtained in order to verify that the perirectal fascia has not been invaded by tumor.

A history of impaired continence is a contraindication for this procedure, as it challenges the continence mechanism to some extent. However, if continence has been reasonably good, an acceptable functional result may be expected. Further preoperative evaluation of the continence mechanism is not necessary.

The procedure should start as an exploratory laparotomy. If a low anterior resection can be carried out safely it should be done. If mobilization is limited by insufficient exposure and access, the procedure may be continued intersphincterically. If the patient has not been placed in right lateral position, he should be turned and redraped to allow simultaneous abdominal and perineal access.

A diverting colostomy is strongly recommended. After abdomino-intersphincteric resection, non-clinical leaks, which are very common after coloanal anastomoses, will often turn into clinical ones, as the anastomosis is adjacent the perineal wound. A diverting colostomy will prevent serious sequelae of anastomotic complications.

Woundinfections commonly result in perineal fistulas. These fistulas have an uncomplicated course, as they do not run through the external sphincter apparatus. If the infection does not subside, a seton through the fistulous tract is an adequate means of drainage. The fistula will be filled by granulation tissue and should close spontaneously. Fistulas may persist for months. 
The patient will have to be informed about the expected change in his continence habits. The sphincter will be weakened to some degree, leading to inadvertent soiling in the postoperative period. This condition will very likely improve in the ensuing months. The reservoir and compliance function of the rectum are lost. This results in frequent defaecations and feeling of urge. Again, some adaptation will occur. Some patients will need an enema in the morning, as a remedy against problems during the rest of the day. Temporarily, antidiarrhoeal medication, such as loperamide, may be necessary in order to control an unacceptable increase in frequency.

Patients who are at high risk for local recurrence may benefit from adjuvant irradiation therapy. High risk patients are those patients with small distal or radial resection margins or those in whom tumor spill has occurred.

At present, local procedures cannot be regarded as curative as radical resections and should therefore be reserved for patients at high risk for general complications or be used in palliative procedures.

For the treatment of benign rectal lesions, i.e. giant villous adenoma, intersphincteric local procedures are eminently suitable and, in the opinion of the author, could well replace the former transsphincteric approach.

A flow-chart for the choice of therapy in patients with rectal cancer is presented in figure 8.1. 


\section{level flxation Inflitration operabllity therapeutlc procedure}

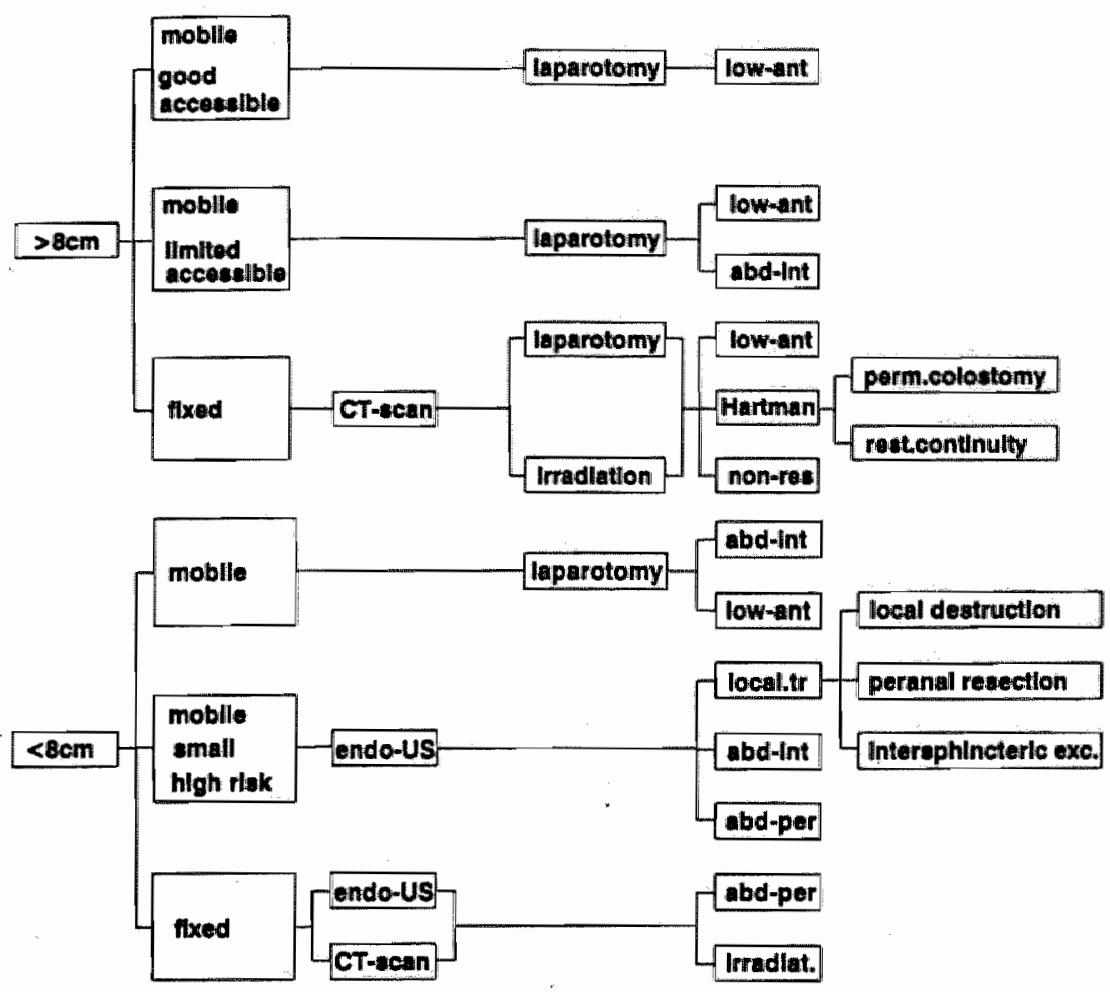

Fig. 8.1. Flow-chart for the cholce of therapy in patients with rectal cancer. (endo-US-endorectal ultrasonography, low-ant-low anterior resection, abdint-abdomino-intersphincteric resection, non-res-non-resective treatment, perm.colostomy-permanent colostomy, rest.continuity-restoration of bowel continuity, local tr-local treatment, abd-per-abdomino-perineal resection, irradiat-irradiation therapy) 


\section{Chapter 9.}

\subsection{Summary.}

This study is a clinical pilot study exploring the fundamentals for a new concept for the treatment of rectal cancer. The thesis consists of three parts. Part one includes four chapters in which, based on a literature survey, the principles of the intersphincteric approach are discussed. Part two consists of one chapter which deals with surgical techniques. The last part is made up of two chapters in which clinical results are presented and discussed. Finally, a chapter is added with some practical recommendations.

In chapter one, the discussion centres on whether or not there is room for still another alternative surgical modality in the treatment of rectal pathology. In the last few decades survival rates have not improved and up to the present the problem of local recurrences has still not been resolved. Microscopic tumor deposits, left inside the patient after an apparently curative resection are thought to be responsible for local recurrences. Theoretically, two approaches for the eradication of residual disease may be considered. The first is, to search for improved adjuvant therapy to the standard surgical procedures; the second is, to develop new surgical techniques which enable a more radical eradication of cancer.

In current techniques, limited transabdominal exposure with uncertain lateral and distal resection margins and subsequent incomplete removal of the mesorectum is a problem in low resections. The intersphincteric approach is intended as a new surgical technique in order to solve some of the existing problems and to accomplish a more radical resection. The combination of a transabdominal approach and an approach from below offers the possibility of performing the most difficult part of the resection under direct vision. By doing so, the complete mesorectum, enveloped in its perirectal fascia, can be removed. The fact that a colo-anal anastomosis can be easily performed at any level of the anal canal adds to the advantages of this procedure.

In chapter two, the history of the dorsal approach to rectal pathology is discussed. In 1826, Lisfranc was the first to remove a cancerous rectum via a perineal approach. Various procedures were since developed to remove rectal cancers by local posterior procedures. In an effort to remove the rectum as high up as possible, Kraske removed parts of the sacral bone. Around 1900 , laparatomies became technically possible. The combined abdomino-perineal resection was developed by Miles and showed much 
better results than the earlier perineal procedures. Lockhart Mummery is the last to advocate a perineal procedure in selected patients. Worldwide, the abdomino-perineal resection is now accepted as the treatment of choice for rectal cancer.

An improved understanding of the metastasizing pattern of rectal cancer has enabled the development of sphincter saving anterior resection. Contrary to the accepted opinion of three zones of lymfogenic spread, this spread is primarily directed cranially.

Insufficient exposure and access to the narrow pelvis limits to anterior resection. To overcome this problem various surgeons have developed new techniques. In the early seventies, interest was renewed in the perineal approach in order to gain additional access to the pelvis.

The anatomical and physiological principles which apply to restorative surgery for low seated rectal cancer are discussed in chapter three.

Understanding the organisation of the pelvic connective tissue is the clue to the development of the appropriate surgical cleavage planes. The connective tissue is, in part, tightly organized in the form of ligaments which support the pelvic organs and which contain smooth muscle fibres and the neurovascular system, and partly, loosely organized as spaces which surround the pelvic organs. These spaces are bordered by the fascia pelvis visceralis on the organ side and by the fascia pelvis parietalis on the opposite side. These interfascial spaces are not crossed by neurovascular or supportive structures and form ideal cleavage planes. The anatomical topography, necessary for the approach of the rectum through the interfascial spaces is discussed.

The intersphincteric plane at the level of the anal canal is seen as a surgical cleavage plane for the approach of the perineal part of the rectum. The surgical importance of Waldeyer's fascia, which runs in a ligament-like fashion from the sacrum to the perirectal fascia, is pointed out as well. The influence of restorative surgery on the mechanisms of continence is investigated in several clinical studies. Continence is dependent on the interaction of several factors. It is known from experience that compensatory mechanisms are capable of replacing loss of function of any factor, with the exception of the musculus puborectalis, which plays a crucial role in the preservation of continence.

In intersphincteric approaches the importance of the integrity of the pelvic floor muscles and especially the puborectal muscle is emphasized.

In chapter four the preoperative preparation of patients with rectal cancer is discussed. Tumor staging is the first step in the choice of therapy. The surgeon has to be informed about the level, extent and infiltration depth of 
a tumor. Apart from digital palpation and endoscopy, special imaging techniques may be necessary. Computed tomography is capable of discerning pathologic changes after infiltration into the perirectal fascia, indicating an advanced stage of disease. The author has carried out a study to investigate if endosonography is a reliable technique in evaluating depth of infiltration. Even for tumors which are out of reach for the investigator's finger, the endosonogram produced useful information. Both techniques are complementary in tumor staging.

The literature was reviewed to identify risk factors and to study measures for the prevention of complications. Adequate bowel preparation and antimicrobial prophylaxis seem to be keystones in the prevention of infectious complications. Antimicrobial prophylaxis should find a balance between reduction of possible pathogens and preservation of the mechanism of colonisation resistance. It is concluded that short parenteral use of antibiotics is effective in reducing infectious complications.

A place for irradiation therapy in the control of local recurrence in high risk patients is suggested.

The standard techniques that have been developed for restorative rectal surgery are discussed in the first part of chapter five.

Sphincter saving rectal surgery has evolved along two lines. The first approach attempts to resect the tumor and its lymphatic field and to restore intestinal continuity without sacrificing the sphincter. The second is to identify patients with early rectal cancer and then to ablate the tumor locally before lymphatic spread has occurred.

The different techniques for radical restorative resection are discussed: anterior resection, stapler techniques, abdomino-sacral, abdomino-anal, abdomino-transsphincteric and abdomino-intersphincteric resections. The different techniques for local procedures are discussed as well: electrocoagulation laser therapy, endocavitary irradiation and excisional techniques.

The second part of chapter five describes the different intersphincteric procedures in detail. The abdomino-intersphincteric resection is presented as a radical resection which enables the removal of the rectum with its complete mesorectum enveloped in the perirectal fascia. Restoration of the continuity is possible at any level of the anal canal. Segmental resections are considered extended local resections of a rectal segment via the intersphincteric approach without the need of a laparotomy. Local excisions via an intersphincteric proctotomy offer some distinct advantages when compared to the transsphincteric technique. 
The clinical results in 35 patients who underwent a rectal procedure by an intersphincteric approach are discussed in chapter six.

Three kinds of intersphincteric procedures were performed in three quite different categories of patients. Fourteen patients had abdomino-intersphincteric resections, meant as radical procedures in the treatment of rectal cancer. These patients had mobile or just slightly tethered tumors with a free margin of at least two centimetres between the lower border of the tumor and the dentate line. A mixed group of nine patients underwent segmental resection. One procedure was concerned the removal of a giant villous adenoma; another a curative extended local resection and seven were more or less palliative procedures in patients who were considered to be too high a risk for major surgery. Local procedures were performed in twelve patients. Six of these were for malignancies.

More or less serious complications were encountered in one third of the patients. Three had a anastomotic dehiscence leading to peritonitis, which necessitated the creation of a diverting colostomy. Eight developed perineal fistulas, which healed spontaneously.

Preliminary data, after a short-term follow-up, show that after combined procedures none of the patients has developed a local recurrence, but that three out of eight patients, after segmental resection, and one of the patients who underwent a local excision, did develop local recurrences.

The functional results are reasonably good. Most patients experience an acceptable defaecation pattern, albeit with an increased frequency and in some cases with less than perfect control leading to inadvertent soiling. Only one patient remained incontinent after a segmental resection. After local resections, continence was generally comparable to the situation before the operation. The physiological follow-up examinations showed some reduction in sphincter tone and rectal capacity.

In chapter seven the clinical results are discussed and some conclusions are drawn.

Anastomotic dehiscence is a grave but, alas, common complication after colo-anal anastomoses. A literature review revealed non-clinical leaks in over $50 \%$ of all low anastomoses. Diverting colostomies will not prevent anastomotic failure but will alleviate its sequelae. In this series the routine use of diverting collostomies in major procedures prevented the recurrence of peritonitis. Perineal woundinfections with resulting fistulas occurred in eight patients. The perineal wound becomes easily infected as it is adjacent to the anastomosis. Some speculative remarks are made about the role of the temporary absence of the recto-anal reflex in the etiology of anastomotic insufficience.

Basically, two oncological principles are applied to abdomino-intersphinc- 
teric resections. The first is that distal spread rarely occurs and that therefore distal margins may be small. The second is that radial clearance should include the complete mesorectal fat covered with its fascia.

From an oncological point of view, segmental resections should be regarded as extended local resections, and may have a place in cancer surgery in high risk patients where the morbidity associated with a laparotomy outweighs the possible benefits of a more radical resection.

Local procedures can easily be performed by the intersphincteric approach. Indications for local procedures are discussed.

Physiological follow-up examinations were conducted in most of the patientsd. The results seemed to be of little practical value to the individual patient, but, three dimensional profilometry did prove that a truely functioning sphincter is retained.

It is concluded that intersphincteric procedures definitely offer a new concept in the treatment of rectal pathology.

In chapter 8 some practical recommendations are given. Furthermore, a flow-chart for the therapy choice in rectal cancer patients is suggested. 


\subsection{Samenvatting.}

Een nieuw concept voor de behandeling van het rectumcarcinoom wordt in dit proefschrift beschreven. het proefschrift is in drie onderdelen opgesplitst. In de eerste vier hoofdstukken wordt na literatuurondezoek de theoretische basis gelegd voor de intersphincterische toegang. In hoofdstuk viff wordt de chirurgische techniek uitvoerig beschreven. De klinische resultaten worden in hoofdstuk zes en zeven gepresenteerd. In hoofdstuk acht tenslotte worden enkele aanbevelingen gedaan met betrekking tot selectie van patienten voor, en uitvoering van de intersphincterische technieken.

De vraag of behoefte bestaat aan nog een nieuwe techniek voor de behandeling van het rectumcarcinoom staat centraal in hoofdstuk een. In de laatste decennia is weinig vooruitgang geboekt met betrekking tot de prognose en het ontstaan van locale recidieven. Het achterblijven van microscopisch kleine tumorhaarden na een ogenschijnlijk radicale resectie wordt verantwoordelijk geacht voor het locale recidief. Een verbeterde aanpak zou theoretisch langs twee wegen bewerkstelligd kunnen worden. Ten eerste kan naar een adekwate adjuvante therapie gezocht worden, ten tweede kan de chirurgische techniek verbeterd worden, gericht op het voorkomen van achterblijven van potentieel tumorbevattend weefsel.

Een beperkte abdominale toegang maakt in de huidige technieken de dissectie moeilijk, zodat de laterale en distale marges onzeker zijn met de kans op achterblijven van een deel van het mesorectum. De intersphincterische toegang is bedoeld om enkele van de bestaande technische problemen op te lossen en zodoende een meer radicale resectie te bewerkstelligen.

De combinatie van een transabdominale en perineale benadering is bedoeld ter vereenvoudiging van de lastige diepe dissectie. Hierdoor kan, namelijk a vue, het complete mesorectum, bedekt met de fascia recti, verwijderd worden. Een bijkomend voordeel is, dat een colo-anale anastomose op eenvoudige wijze vervaardigd kan worden.

De geschiedenis van de dorsale toegang tot rectumpathologie wordt in hoofdstuk twee besproken. Lisfranc was in 1826 de eerste, die een rectumcarcinoom langs perineale weg verwijderde. Verschillende chirurgische procedures werden ontwikkeld om rectumcarcinomen, zo hoog als mogelijk, langs dorsale weg te verwijderen. Kraske verwijderde delen van het sacrum om een adekwate toegang te verkrijgen. Pas nadat, rond de eeuwwisseling, laparotomieen veilig uitgevoerd konden worden, was het voor Miles mogelijk om de gecombineerde abdomino-perineale rectumamputatie te ontwikkelen. Hij boekte hiermee veel betere resultaten. Lackhart Mummery 
was de laatste die, op indicatie, de excusief perineale benadering adviseerde. Wereldwijd werd de rectumamputatie volgens Miles als de standaardbehandeling voor het rectumcarcinoom geaccepteerd.

Een beter begrip van het metastaseringspatroon maakte de ontwikkeling van sphinctersparende behandelingen, namelijk de anterior resectie, mogelijk. In tegenstelling tot wat voorheen gedacht werd, trad lymfogene metastasering niet primair in drie richtingen op, maar voornamelijk craneaalwaarts.

Onvoldoende toegankelijkheid van het kleine bekken beperkte de mogelijkheden voor de anterior resectie. Daarorn werden verschillende technieken omtwikkeld om dit probleem op te lossen. In de zeventiger jaren kwam de perineale benadering, als een additionele toegang, opnieuw in de aandacht te staan.

De anatomische en fysiologische grondslagen voor sphinctersparende chirurgie worden in hoofdstuk drie besproken.

Inzicht in de architectuur van het bindweefsel in het kleine bekken vormt de sleutel van de kennis over de juiste chirurgische klievingsvlakken. Als ligamenten, die ook neurovasculaire structuren bevatten, steunt het bindweefsel de bekkenorganen. Rondom de bekkenorganen vormen de fascia pelvis parietalis en fascia pelvis visceral is ruimten, die niet doorkruist worden door neurovasculaire of lymfogene structuren. Deze interfasciale spatia vormen de ideale chirurgische klievingsvlakken. De topografische anatomie ervan wordt gedetailleerd gepresenteerd. De intersphincterische toegang tot het perineale gedeelte van het rectum wordt besproken. Het chirurgische belang van de fascie van W/aldeyer wordt eveneens aangegeven.

De invloed van sphinctersparende therapieèn op het continentie apparaat wordt aan de hand van diverse klinische studies onderzocht. Continentie blijkt afhankelijk van de interactie van verschillende factoren. Uitval van een gedeelte van het continentiemechanisme kan gecompenseerd worden door andere delen, met uitzondering van de musculus puborectalis, die onvervangbaar is. Het belang van de integriteit van de bekkenbodemmusculatuur wordt speciaal bij de intersphincterische toegang onderkend en gewaarborgd.

De preoperatieve voorbereiding wordt in hoofdstuk vier besproken. Pas na een adekwate stagering van niveau, uitgebreidheid en infiltratiediepte kan een therapeutisch plan opgesteld worden. Hoofdpunten in de stagering worden gevormd door het rectaal toucher en de scopie. Hiernaast kan aanvullend onderzoek middels CT-scan of endorectale echografie nodig zijn. De CT-scan geeft vooral informatie over de relatie van de tumor tot de perirectale fascie en de omgevende bekkenstructuren. Endosonografie is 
uiternate geschikt om de infiltratiediepte ten opzichte van de muscularis propria te onderzoeken. Zelfs bij tumoren, die klinisch niet goed gestageerd kunnen worden, omdat ze te hoog zitten. De CT-scan en endosonografie vullen elkaar aan.

Risicofactoren en profylactische maatregelen ter preventie van complicaties werden in de literatuur bestudeerd. Met name adekwate darmvoorbereiding en antibiotische prophylaxe ter preventie van infectieuze complicaties krijgen uitvoerig de aandacht. Het belang van een juist evenwicht tussen de antibiotische prophylaxe ter reductie van potentiële pathogenen en het behoud van de kolonisatieresistentie werd onderstreept. Geconcludeerd werd, dat een kortdurende parenterale toediening van antibiotica gecombineerd met een goede darmvoorbereiding het effectiefst is ter preventie van infectieuze complicaties.

De plaats van radiotherapie als adjuvante therapie bij patiènten, die een verhoogdle kans op een locaal recidief hebben, werd aangeduid.

De verschillende chirurgische mogelijkheden om laagzittende rectumtumoren sphinctersparend te opereren worden in hoofdstuk viff beschreven. Het behoud van de continentie kan in principe op twee manieren gerealiseerd worden. Op de eerste plaats kan een radicale resectie uitgevoerd worden met herstel van de darmcontinuäteit en behoud van een voldoende deel van het sphincterapparaat om continent te blijven. Op de tweede plaats zouden die patienten geselecteerd kunnen worden, waarbij een localle procedure curatief uitgevoerd kan worden.

De bestaande technieken voor radicale resecties, zoals anterior resectie, stapler technieken, abdomino-sacrale, abdomino-transsphinctere en de, in deze studie gepresenteerde, abdomino-intersphinctere resecties worden met elkaar vergeleken. De diverse locale behandelingsmogelijkheden komen ook aan bod: electrofulgeratie, laser therapie, endorectale radiotherapie en de diverse locale excisie technieken.

In het tweede deel van hoofdstuk vijf volgt een gedetailleerde beschrijving gegeven van de diverse ingrepen waarbij de intersphinctere toegang gebruikt wordt. De abdomino-intersphinctere resectie wordt gepresenteerd als een radicale resectie, die complete verwijdering van het mesorectum mogelijk maakt met herstel van de darmcontinuïteit. Segment resecties worden beschouwd als een uitgebreide vorm van een locale excisie. Tot slot komen de locale excisies in stricte zin aan bod, waarbij via een intersphinctere proctotomie hetzij mucosectomieèn of wigexcisies uitgevoerd worden. De intersphinctere toegang voor locale behandelingen is technisch veel eenvoudiger dan de transsphinctere benadering.

De klinische resultaten bij 35 patiënten, die allen een vorm van intersphinctere benadering ondergingen voor rectale tumoren, worden in hoofdstuk zes gepresenteerd. 
Op verschillende indicaties werden drie types van operaties uitgevoerd. Veertien patiènten kregen een abdomino-intersphinctere resectie als radicale behandeling van een rectumcarcinoom. Al deze patiènten hadden tumoren die nog binnen de perirectale fascie groeiden. Een heterogene groep van negen patiënten onderging segment resecties: eén patiënt had een zeer groot villeus adenoom, eén patiënt had een "early rectal cancer" en zeven patiënten hadden verder voortgeschreden grotere tumoren, maar werden in verband met een te hoog operatierisico ongeschikt geacht voor grote abdominale chirurgie. Locale procedures werden uitgevoerd bij twaalf patiënten, waarvan zes een maligniteit hadden.

Het postoperatieve beloop werd bij één derde van de patiènten in mindere of meerdere mate verstoord door complicaties. Drie maal trad een naaddehiscentie op, die resulteerde in een gegeneraliseerde peritonitis, waarvoor het verrichten van een laparotomie en het aanleggen van een ontlastend stoma noodzakelijk was. Acht patiënten ontwikkelden perineale wondfistels.

Over het oncologisch resultaat kan alleen maar een eerste indruk gegeven worden, omdat de follow-up nog te kort is. $\mathrm{Na}$ gecombineerde procedures werd nog geen enkel, na segment resectie drie en na locale excisies éen locaal recidief gezien.

De functionele resultaten zijn zeer acceptabel. De meeste patiénten ontwikkelden een redelijk normaal defaecatiepatroon, al is de frequentie toegenomen en hadden enkele patiënten in de eerste tijd postoperatief wat last van "soiling". Eên patiënt had een onacceptabel resultaat, hetgeen resulteerde in een permanent stoma.

Het fysiologisch follow-up onderzoek liet een vermindering van sphinctertonus en rectumcapaciteit zien.

Aan de hand van literatuurgegevens worden de klinische resultaten in hoofdstuk zeven besproken.

Met betrekking tot de naaddehiscenties werd opgemerkt, dat dit een zeer vaak voorkomende complicatie is na zeer lage naden. In de literatuur wordt een getal van $50 \%$ genoemd. Ontlastende stoma's kunnen naadlekkages niet voorkomen, maar kunnen wel de klinische gevolgen verminderen. Nadat in deze serie routinematig ontlastende stoma's vervaardigd werden is geen peritonitis meer opgetreden. Wondinfecties, met als gevolg perineale fistels, werden bij acht patiënten gezien. De perineale wond, die in direct contact staat met de anastomose, zal in gewall van een naadlekkage zeer gemakkelijk infecteren en tot fistelvorming aanleiding geven. Het postoperatief tijdelijk ontbreken van de recto-anale reflex speelt mogelijk een rol in de etiologie van anastomose insufficièntie, omdat daardoor de anus als functionele stenose zou kunnen fungeren. 
De abdomino-intersphinctere resecties zijn op twee oncologische principes gebaseerd: ten eerste, het feit dat intramurale distale tumoruitbreiding zelden voorkomt, waardoor de distale marge niet groter dan twee centimeter hoeft te zijn, ten tweede, het feit dat radiale tumoruitbreiding wel voorkomt, met als gevolg, dat het belangrijk is, dat het perirectale vet compleet met bedekkende fascie verwijderd wordt. Segment resecties en locale excisies kunnen alleen maar in geval van zeer kleine tumoren als afdoende beschouwd worden en dienen eerder alls palliatief gezien te worden. De locale procedures zijn uitstekend geschikt voor benigne aandoeningen.

Het fysiologisch follow-up onderzoek bleek van weinig waarde voor de evaluatie van de individuele patiènt. De driedimensionale profilometrie demonstreerde wel duidelijk; dat een feitelijk functionerende sphincter ani behouden bleef:

De auteur concludeert, dat de intersphinctere toegang zeker een nieuw concept biedt bij de behandeling van rectale pathologie.

In hoofdstuk acht worden enkele praktische aanbevelingen gegeven naast een flow-chart voor de therapiekeuze bij patiënten met rectale maligniteiten. 


\section{Dankwoord.}

ledereen die aan de realisatie van dit proefschrif heeft bijgedragen wil ik hartelijk danken. Allen met name noemen is niet mogelijk. Zonder iemand tekort te willen doen wil ik enkelen naar voren halen.

Het onderzoek zelf hebben wij met zijn tweeèn gedaan. Zonder het vertrouwen van dr JJakimowicz in de methode, zou het niet mogelijk zijn geweest om de technieken te ontwikkelen. De overige chirurgen van de maatschap algemene heelkunde stonden ons voortdurend met raad en daad terzijde.

Professor G.Kootstra, mijn promotor, en dr C.Baeten van de afdeling heelkunde van de universiteit Maastricht hebben belangrijke adviezen gegeven over hoe de resultaten tot een proefschrift verwerkt konden worden, en de tot stand koming daarna zeer intensief begeleid. Bovendien heeft $\mathrm{dr}$ C.Baeten de uitvoerbaarheid van de technieken aangetoond door zelf al een aantal patiënten in Maastricht te opereren.

De vakgroep experimentele chirurgie onder leiding van professor P.J. Klopper in het academisch medisch centrum Amsterdam en met name Theo Dijkhuis en Casper Verhoeven mogen niet ongenoemd blijven. De resultaten van het fysiologisch follow-up ondezoek zijn met hun hulp verzameld.

De foto's zijn door Wil en Guy van Dael, senior en junior van de audiovisuele dienst van het Catharina Ziekenhuis, gemaakt. Zij waren altijd bereid om op de meest ongelegen ogenblikken toch tijd vrij te maken om naar de OK te komen.

Ria Palme was bereid om het manuscript uit te typen, dat vervolgens door dhr Melman gecorrigeerd werd met betrekking tot het engels taalgebruik.

Mijn collegae will ik bedanken voor hun hulp en constructieve kanttekeningen, en die bovendien mijn afwezigheid, zo nu en dan, onopvallend camoufleerden.

Last but not least wil ik Yvonne bedanken, wiens vertrouwen het mijne weleens overtrof.

Met dank voor de financiële ondersteuning bij hel onderzoek en de tot standkoming van het proefschrift aan:

Het Catharina Ziekenhuis Eindhoven

Hoffmann Laroche 


\section{Curriculum vitae}

Harm Rutten werd op 9 juli 1956 geboren in Kerkrade. Na voltooiing van de gymnasium opleiding aan het Bernardinus College te Heerlen in 1974 werd een begin gemaakt met de medicijnen studie aan de KU Nijmegen. Tijdens de studie werkzaam geweest als student assistent op de afdeling ademhalingsfysiologie van de medische faculteit.

Vanaf het artsexamen op 16 oktober 1981 tot 17 oktober 1983 als assistent werkzaam geweest bij de maatschap heelkunde van het Carolus Ziekenhuis Den Bosch.

Als overbrugging van de tijd tot het begin van mijn opleiding in de algemene heelkunde als intensivist in het Catharina Ziekenhuis in dienst geweest.

Vanaf 1 februari 1984 in opleiding tot algemeen chirurg (opleider dr J.Prins) in het Catharina Ziekenhuis Eindhoven. 